\title{
The probabilistic seismic hazard assessment of Germany-version 2016, considering the range of epistemic uncertainties and aleatory variability
}

\author{
Gottfried Grünthal $^{1}$ (D) Dietrich Stromeyer ${ }^{1} \cdot$ Christian Bosse $^{1} \cdot$ \\ Fabrice Cotton ${ }^{1,2} \cdot$ Dino Bindi $^{1}$
}

Received: 18 August 2017/Accepted: 18 January 2018/Published online: 6 February 2018

(C) The Author(s) 2018. This article is an open access publication

\begin{abstract}
The basic seismic load parameters for the upcoming national design regulation for DIN EN 1998-1/NA result from the reassessment of the seismic hazard supported by the German Institution for Civil Engineering (DIBt). This 2016 version of the national seismic hazard assessment for Germany is based on a comprehensive involvement of all accessible uncertainties in models and parameters and includes the provision of a rational framework for integrating ranges of epistemic uncertainties and aleatory variabilities in a comprehensive and transparent way. The developed seismic hazard model incorporates significant improvements over previous versions. It is based on updated and extended databases, it includes robust methods to evolve sets of models representing epistemic uncertainties, and a selection of the latest generation of ground motion prediction equations. The new earthquake model is presented here, which consists of a logic tree with 4040 end branches and essential innovations employed for a realistic approach. The output specifications were designed according to the user oriented needs as suggested by two review teams supervising the entire project. Seismic load parameters, for rock conditions of $v_{S 30}=800 \mathrm{~m} / \mathrm{s}$, are calculated for three hazard levels $(10,5$ and $2 \%$ probability of occurrence or exceedance within 50 years) and delivered in the form of uniform hazard spectra, within the spectral period range $0.02-3 \mathrm{~s}$, and seismic hazard maps for peak
\end{abstract}

Gottfried Grünthal

ggrue@gfz-potsdam.de

Dietrich Stromeyer

stro@gfz-potsdam.de

Christian Bosse

bosse@gfz-potsdam.de

Fabrice Cotton

fcotton@gfz-potsdam.de

Dino Bindi

bindi@gfz-potsdam.de

1 Helmholtz Centre Potsdam, GFZ German Research Centre for Geosciences, Potsdam, Germany

2 Institute for Earth and Environmental Sciences, University of Potsdam, Potsdam, Germany 
ground acceleration, spectral response accelerations and for macroseismic intensities. Results are supplied as the mean, the median and the 84 th percentile. A broad analysis of resulting uncertainties of calculated seismic load parameters is included. The stability of the hazard maps with respect to previous versions and the cross-border comparison is emphasized.

Keywords Seismic hazard · Germany · DIN EN 1998-1/NA · Seismic load parameters

\section{Introduction}

Probabilistic seismic hazard assessments (PSHA) represent the most resilient means to calculate seismic load parameters for seismic building codes or other anti-seismic design provisions, presupposing that the input models are carefully chosen and related parameters accurately derived. Still challenging with respect to modern PSHA in general is the comprehensive incorporation of all uncertainties in the models and their corresponding parameters into a probabilistic approach, one which has the advantage of providing a rational framework for integrating uncertainties in a transparent way.

The seismicity of Germany, the target area of the study, and the related seismic hazard is elevated in certain regions of the country, when compared to other parts of central Europe, particularly along the course of the river Rhine. In general, the seismicity is indeed low in relation to the plate-boundary regions of the Mediterranean; however, it is not so low that earthquake resistant design provisions are negligible. Extremely low geodetic movements near their own confidence limits, in conjunction with the low seismic activity make it in particularly difficult to assess where strong ground shaking might occur in future. Quite simply, low seismicity regions do not necessarily make seismic hazard assessments any easier, and such complexity requires adequate treatment of uncertainties.

A significant portion of Germany's industry, infrastructure and regions of high residual density are located in areas of elevated seismicity and, hence, exposed to a certain degree of seismic risk (Grünthal et al. 2006; Tyagunov et al. 2006). Although earthquakes with moment magnitudes $M_{w}>6$ are not known to have occurred within Germany in the historical past, they have struck the immediate surroundings (cf. Sect. 3) and could be expected within the country as well. Though the probability of the occurrence of $M_{w}>6$ earthquakes within Germany is comparatively low, the impacts of such events could be dramatic if critical regions like conurbations or specific industrial plants were to be affected.

The first building-code related seismic zonations of Germany were based on maps of generalized maximum observed intensities (DIN ${ }^{1} 4149$ 1955a, b; DIN 4149 1957; DIN 4149 1981), which was subsequently updated for the DIN 4149 (1992) with the extension to the new federal states of Germany by the first author. The first country wide seismic zonation by means of a probabilistic approach was provided by Grünthal and Bosse (1996) and is used as national seismic zoning map since the introduction of the DIN 4149:2005-04 (Grünthal 2005). A corresponding web portal has been in operation since 2005 (http://gfzpotsdam.de/DIN4149_Erdbebenzonenabfrage). Here one can find the assignment of each German settlement to one of the three seismic zones of the DIN 4149, with the corresponding geological underground class (rock R, soil S, transitional T) and related design spectra, which still has some 100 hits daily. A much more advanced PSHA was

\footnotetext{
${ }^{1}$ DIN—Deutsches Institut für Normung, German Institute for Standardisation.
} 
accomplished for the needs of the safety regulation of hydraulic structures DIN 19700 (Grünthal 2008; Grünthal et al. 2009a), where uniform hazard spectra (UHS) on rock or soil conditions for four different hazard levels for any site in Germany are provided via a web-service (http://gfz-potsdam.de/DIN19700), which has been operational since 2007. These web-based seismic hazard results are used intensively for a wide variety of applications, not only for safety assessments of dams or other hydraulic structures. The latter approach included epistemic uncertainties and aleatory variabilities of input parameters and models already to a considerable extent.

Other probabilistic seismic hazard maps cover at least parts of Germany but were not prepared for national standardization purposes. These include, e.g. those by Ahorner and Rosenhauer (1978) for SW Germany, who apply the generalized Gumbel distribution of magnitudes on the basis of Monte-Carlo simulations (Ahorner and Rosenhauer 1975), which was later updated with the focus on western Germany (Ahorner and Rosenhauer 1986) and modified for the Lower Rhine embayment (Rosenhauer and Ahorner 1994). For the latter area, Grünthal et al. (2004, 2006) calculated PSHA with an advanced consideration of uncertainties by applying logic trees and distributions of aleatory variability as our standard approach since Grünthal and Wahlström (2001) and Wahlström and Grünthal (2000, 2001).

In addition to the aforementioned national PSHA by the authors, their activities have been integrated into pan-European models by achieving cross-border harmonization in all steps of their procedures. The first of those projects was the Global Seismic Hazard Assessment Program GSHAP (Giardini et al. 1999), where the map from Grünthal and Bosse (1996) was updated and extended to Switzerland and Austria, i.e. the D-A-CH countries, (Grünthal et al. 1998a) which served as test case for the European part of the GSHAP map north of $44^{\circ} \mathrm{N}$ (Grünthal et al. 1996; Grünthal and GSHAP Region 3 Working Group 1999). While the hazard map according to the project SESAME (Jiménez et al. 2003) north of $44^{\circ} \mathrm{N}$ coincides with the GSHAP map, an innovative hybrid zoneless approach was applied for the European-wide seismic hazard map of the EU project NERIES (Chan and Grünthal 2010). Another harmonized Euro-Mediterranean seismic hazard map was calculated on behalf of the Global Earthquake Modeling Project GEM1 (Grünthal et al. 2010). The most recent and most elaborated harmonized European seismic hazard map is the one produced in the framework of the EU-FP7 project SHARE (Seismic hazard harmonization in Europe) (Woessner et al. 2015).

After the SHARE project as a milestone, further updated PSHA projects have recently been finished in Europe, e.g. for Switzerland the model SUIhaz2015 (Wiemer et al. 2016), Spain (IGN-UPM Working Group 2013; Gaspar-Escribano et al. 2015), Portugal (Carvalho and Albarello 2016), Iceland (D’Amico et al. 2016), Turkey (Sesetyan et al. 2016) or are just under preparation, e.g. in Italy (Meletti et al. 2016), Belgium (indicated in Vanneste et al. 2014), in Norway (C. Lindholm, pers. comm.), or in France (P. Labbé, pers. comm.). Such new projects provide opportunities for harmonization and at least comparisons of achieved results at state boundaries, as it will be discussed at the end of the paper.

It is commonly understood that PSHA requires updates from time to time when novel data, better constrained models and improved approaches become available (Frankel 1995). Amongst the innovations motivating the new seismic hazard analysis for Germany are: (1) updated and extended seismicity data, (2) the adoption of a range of seismic source zone concepts (areal based, fault based and zoneless), (3) a comprehensive treatment of uncertainties of seismicity rates in relation to probability density functions of maximum magnitudes, (4) consideration of varying fitting rules for seismicity rate estimations, (5) improved implementation of parameters like focal depths and tectonic regimes in 
superzones, and (6) use of the latest generation of ground motion prediction equations (GMPEs) suitable for the target area.

The PSHA project described herein was accomplished on behalf of the Deutsches Institut für Bautechnik (DIBt; German Institute for Civil Engineering) and was launched by the respective national committee on standardization of the DIN. Two review panels have been established to provide critical review of all steps of the work in the frame of this project. The panellists for one of these control groups were selected by the DIBt, while the second reviewing group represents the task force for performance based design of the respective committee of standardization. The panellists are composed of representatives of ministries, other authorities, universities, research institutions, technical control boards and consulting engineers.

The paper describes the approach for deriving the new version of the national PSHA, including uniform hazard spectra (UHS) for any site within Germany for the hazard levels of 10,5 and $2 \%$ exceedance probability within 50 years, hazard maps for spectral response accelerations, peak ground accelerations, and deaggregations for selected sites. As agreed upon by the project partners, all hazard calculations have been performed for rock site conditions in terms of a shear wave velocity of $v_{S 30}=800 \mathrm{~m} / \mathrm{s}$; i.e. the average shear-wave velocity of the upper $30 \mathrm{~m}$. The shear wave velocity of $800 \mathrm{~m} / \mathrm{s}$ defines the transition from subsoil class A (unweathered rock with high strength, $v_{S}>800 \mathrm{~m} / \mathrm{s}$ ) to class B (moderately weathered rock with lower strength, $350 \mathrm{~m} / \mathrm{s}<v_{S}<800 \mathrm{~m} / \mathrm{s}$ ) of the DIN 4149:2005-04 or later in the NA to the EC8 (DIN EN 1998-1/NA:2011-1), respectively. Moreover, the approach is based on natural tectonic earthquakes. Additionally, the UHS were fitted according to the control parameters of the design spectra of the Eurocode 8 (CEN 2004). All results, including the maps and, in particular, the UHS with the corresponding Eurocode 8 related control parameters, are accessible for the three hazard levels via a web-portal for any site within the target area Germany.

Although the PSHA was performed for $v_{S 30}=800 \mathrm{~m} / \mathrm{s}$, different underground conditions are prevalent in most parts of Germany. A corresponding research project aiming at modifications of the here derived $v_{S 30}$ rock UHS has been conducted in parallel at the Bauhaus University Weimar (Schwarz et al. 2017) for the combination of classes of subsoil and geological underground conditions defined in the national building code and in the NA to the EC 8, respectively.

The study is based on the assumption of stationarity of seismicity and is therefore restricted to the time-independent seismic hazard approach, which considers a constant average occurrence frequency of earthquakes in their source regions and does not include the hazard due to aftershocks or foreshocks. Cases of foreshocks or aftershocks of economic concern in the target area are extremely rare. Applications of time-dependent approaches to PSHA in the study area are strongly limited due to the short observation time of earthquakes with respect to the low level of seismicity. Similarly, induced seismic events in the target area (Grünthal 2014) are not considered here, since they are related to human activities in the underground and follow other principles than the natural tectonic earthquakes.

We use here the probabilistic approach based on Cornell (1968), subsequently extended by Esteva $(1969,1970)$ to incorporate the aleatory variability of ground motion relationships. Quantitative analysis of epistemic uncertainty, in the form of logic trees (LT), was first introduced into to PSHA by Kulkarni et al. (1984). Concerning the probabilistic methodology of PSHA in its current understanding we are referring McGuire (2004).

A specific goal of our regional study is to consider epistemic uncertainties in a comprehensive way; to a degree that is usually applied rather to site specific analyses. The 
employment of LTs requires that their branches must be mutually exclusive and collectively exhaustive. Pitfalls in applying LTs are discussed in Bommer and Scherbaum (2008). Epistemic uncertainties are accounted for here in several components of the model: (1) in form of five models of seismic source zones (SSZ) and two models to handle the zoneless approach in one logic tree, and (2) via the variability of all parameters qualifying the SSZs. These topics are the subjects of the following sections: the models of seismic sources (including the zoneless models), in Sect. 4 and the parameters characterizing the source zones of all models, in Sect. 5. The strategy to consider the epistemic uncertainties of ground motion models in form of a selection of a set of suitable GMPEs is described in Sect. 6. A comprehensive presentation of the logic tree to define the epistemic uncertainties of our models with the parameters of their elements is presented in Sect. 7. The parameters characterized by aleatory uncertainties are derived as respective density functions and are subject to the integration procedure. This part of the seismic hazard model is described in Sect. 8. The presentation of the results is subject of Sect. 9.

The comprehensive incorporation of epistemic uncertainties into the approach enables the calculation of mean and any required quantile, typically given in the form of the median and the 84th percentile. As a check on plausibility, the input model is also used to calculate an intensity based hazard map.

The results of the PSHA are discussed and compared with former national PSHA data and those of neighbouring countries (Sect. 10). Whilst it is our intention to make available the entire range of input parameters and results, this would go far beyond the scope of this paper. Therefore, reference is made to accompanying material summarized in a related technical report (Grünthal et al. 2017), which is publicly available in a direct way from the web portal of the library of the GFZ Potsdam. The results of the hazard calculations are accessible to the public via an interactive web portal (http://www.gfz-potsdam.de/EqHaz D2016).

\section{Seismicity}

Well established seismicity data on natural, tectonic earthquakes are the prerequisite for reliable determination of seismicity rates of SSZ and hence for trustworthy PSHA. In low seismicity areas especially, the record of available sufficiently complete data should be as long as possible. The data source for this study is primarily the European-Mediterranean Earthquake Catalogue (EMEC) (Grünthal and Wahlström 2012), which is available from http://www.gfz-potsdam.de/EMEC. Compilation and harmonisation of the catalogue is described very detailed in the preceding catalogue version; i.e. the CEntral, Northern and northwestern European earthquake Catalogue (CENEC) (Grünthal et al. 2009b). These catalogues use harmonized moment magnitudes $M_{w}$ throughout. The catalogue EMEC (Grünthal and Wahlström 2012) represents the southern expansion of CENEC (south of the study area of this paper) and the temporal extension by 2 years up to 2006 . The generally high degree of harmonization achieved in CENEC, which holds for the de facto identical data of EMEC as well, is analysed in Grünthal et al. (2009c). The specificity and transparency of descriptions in Grünthal et al. (2009a), how these catalogues for the study area were created, enable users to produce further temporal extensions as well as those with respect to lower magnitude thresholds where local sources provide such data. We employ here the temporal extension up to 2014 and the lower threshold of $M_{w}=2.0$ as already applied and described in Grünthal (2014) and Stromeyer and Grünthal (2015). 
The seismicity of the study area is shown in the epicentre map of Fig. 1. The study area itself encompasses all seismic source regions that can generate earthquakes with macroseismic shaking effects in Germany. This requires the usage of corresponding SSZ (cf. Sect. 5.1) up to a distance of $250 \mathrm{~km}$ for the hazard calculations. The SSZ themselves can extend well above the given range, particularly in regions of very low seismicity. Since the entire area of such SSZ has to be involved, an even larger area to gather sufficient seismicity data for the calculation of credible parameters of such SSZs, we get an extent of our study area as shown in Fig. 1. In the NW, it is the seismicity of the western Dogger bank, east of England, which needs to be included as SSZ. This, however, necessitates the consideration of most parts of Great Britain to include sufficient seismicity data for deriving solid rate parameters for the SSZ Doggerbank (cf. SSZ A08 in Sect. 5). In the east it is the area of the Tornquist-Theisseyre zone (TTZ), and the area of northwest Poland east of the TTZ, which requires an appropriate enlargement of the study area to include a significant portion of the East European craton (EEC) up to the Baltic region to gather sufficient seismicity data.

To estimate the completeness times of bins of larger magnitudes with few data, the statistical method by Hakimhashemi and Grünthal (2012) was employed, as well as an assessment from a historical perspective in combination with the cumulative number of events with time. The former is based on statistical interpretation of temporal changes in variances of inter-event times. The results of both approaches are very similar. In case of differences, standard deviations of maximum likelihood estimates of Gutenberg-Richter $b$ values decide which datum to use. For the west and southwest of our target area, i.e. in the regions of elevated seismicity of Germany, the completeness time of $M_{w}$ of 3.5-4.5 is

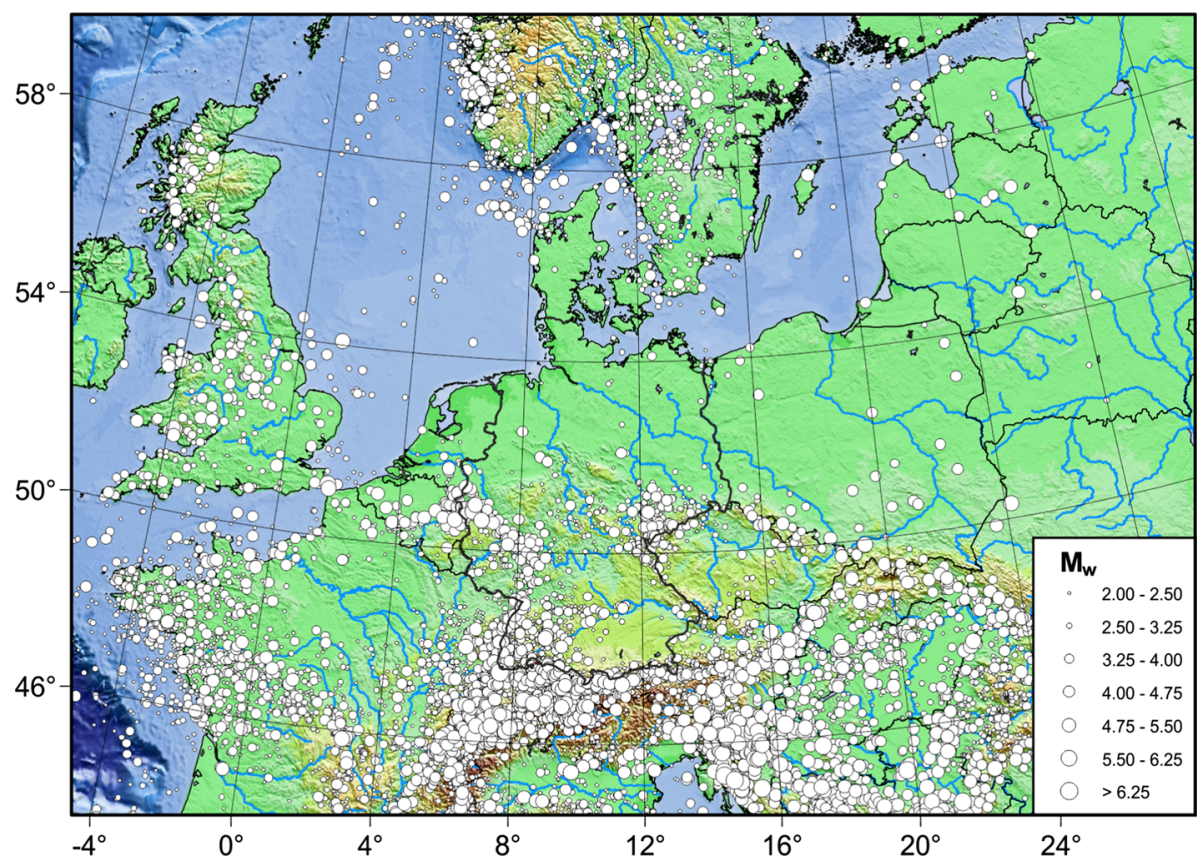

Fig. 1 The natural tectonic seismicity of the study area according to an updated database of Grünthal and Wahlström (2012); Germany, as target area of the PSHA is highlighted. Foreshocks and aftershocks are not shown to establish clarity 
about 1870, of $M_{w} 4.5-51800, M_{w}$ 5-5.5 1650, $M_{w}$ 5.5-6 1450 and $M_{w}$ 6-6.5 1250 (cf. Grünthal et al. (2017)).

Figure 2 displays the seismicity of Germany and surroundings in greater detail. Of particular note is the $1911 M_{w} 5.7$ Hohenzollernalb earthquake. With this event, the seismicity of this most pronounced activity spot commenced in historically well studied times. There, the seismicity started with this, for German conditions, huge shock in a region otherwise lacking significant activity in the historical past before 1911, within the completeness window. In the Lower Rhine Graben (LRG), superior earthquakes were those of $1756 M_{w} 5.9$ Düren, $1878 M_{w} 5.7$ Tollhausen and1992 $M_{w} 5.3$ Roermond, whilst further southwest the northeastern parts of the Ardennes bordering to the LRG were host to the $1692 M_{w} 6.1$ Verviers earthquake. South of the Upper Rhine Graben (URG) occurred the

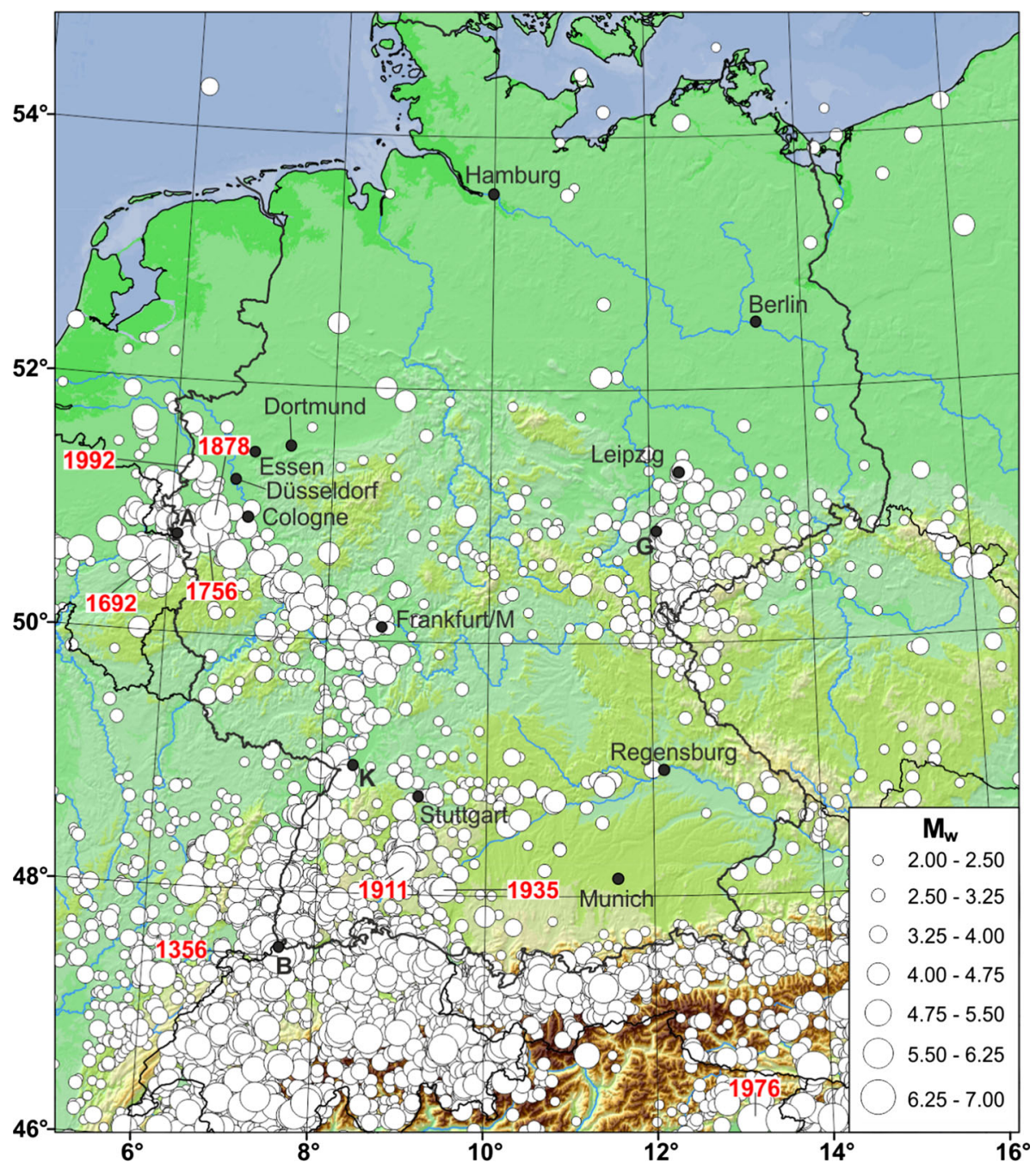

Fig. 2 Natural tectonic seismicity of Germany and surroundings in detail. Main shocks only. Years of key earthquakes are given. $A$ Aachen, $B$ Basel, $G$ Gera, $K$ Karlsruhe 
$1356 M_{w} 6.6 \mathrm{Basel}$ earthquake, and in the northeastern most part of Italy the $1976 M_{w} 6.3$ Friuli earthquake, which was felt northwards up to the Baltic Sea.

\section{Regional tectonic setting and seismicity}

The general characterization of the target area as stable continental region would be a too strong simplification. Therefore, same basics of the tectonic and structural geological rationale behind the development of essential input models are provided in form of a tectonic sketch map of Germany sensu lato (Fig. 3). These input models, which are strongly related to the principal tectonic architecture, are our large scale seismic source

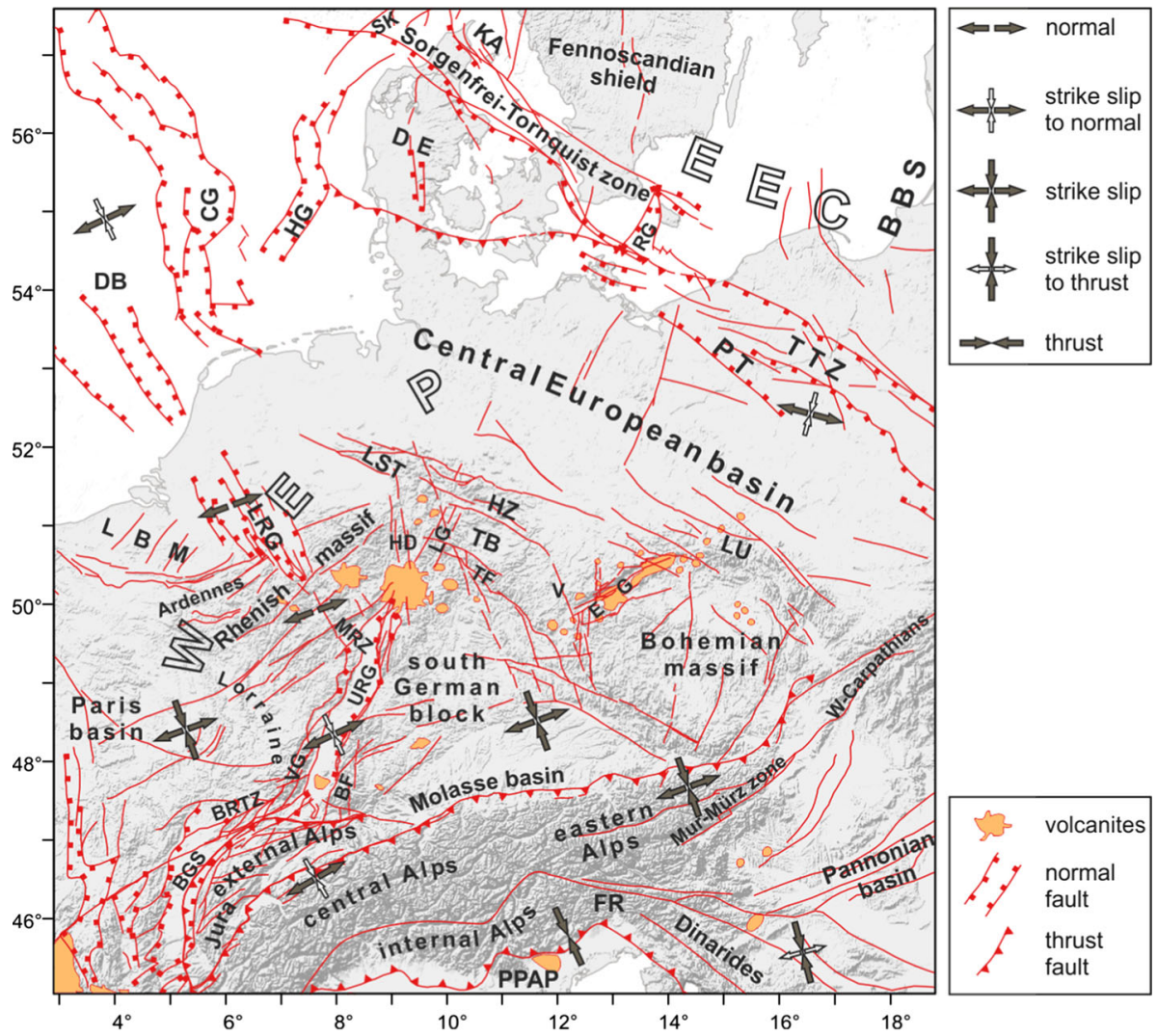

Fig. 3 Tectonic sketch map of Germany sensu lato with the recent tectonic regime in principal structural units. Modified after Cloetingh et al. (2005), Decker et al. (2005), Gautier (2003), Geluk et al. (1994), Thybo (1997), Wetzel and Franzke (2001, 2003), Ziegler and Dèzes (2006). Data concerning the tectonic regime derived from the World Stress Map Database (Heidbach et al. 2016). BBS-Baltic Belarus syneclise, BFBlack Forest, BG-Bresse Graben, BRTZ-Bresse-Rhine transitional zone, CG-Central Graben, DBDoggerbank, DE_-Danish embayment, EEC_East European craton, EG_Eger Graben, Fr_Friuli, HD— Hessian depression, HG-Horn Graben, HZ-Harz mountains, KA-Kattegat, LBM-London-Brabant massif, LG-Leine Graben, LRG_-Lower Rhine Graben, LST_-Lower Saxonian tectogene, LU_Lugicum, MRZ-Middle Rhine zone, PL_Pfahl line, PPAP_Po plain and Apulian promontory, PT_Polish trough, RG, Rønne Graben, SK-Skagerrak, TB-Thuringian basin, TF-Thuringian Forest, TTZ-TornquistTeisseyre zone, URG_-Upper Rhine Graben, V_-Vogtland, VG_-Vosges, WEP_-West European plate 
zone models, the different superzones used for the study, the derivation of maximum magnitudes within specific terranes, and the choice of appropriate GMPEs according to the tectonic environment.

However, the most active seismicity spots within the target area cannot be explained by classical tectonic features but especially by fault indications according to satellite remote sensing information, especially radar data. A respective compilation is shown in Fig. 4.

\subsection{Principal tectonic architecture}

The crustal basement of Germany, in the range of the focal depths of most of the observed seismicity, is built mainly by the central European Variscides, and only in the northwest and most northern parts by the central European Caledonides. Both form the West European Platform (WEP). It is embedded between the Alpidic-Carpathian orogen in the south and the Fennoscandian shield in the north, as well as the EEC in the northeast and the Bohemian massif in the east. The latter is acting as a rigid indenter into the WEP, as it was modelled by Grünthal and Stromeyer (1992).

Figure 3 shows a tectonic sketch map illustrating the major tectonic features. Since the present day seismicity occurs in the clear majority of cases along pre-existing faults and fractures, the sketch map includes tectonic elements that originate in different geological eras. Also depicted is the current tectonic regime within larger areas (cf. Sect. 8.5), which allows for the identification of the most likely orientations under which faults might be active for each style of faulting. Additional information represents lineaments interpreted according to Earth and Space Research (ERS) radar mosaics of large parts of the target area and surroundings (Fig. 4).

The WEP was heavily affected by the Apulian continent-continent collision from the mid-Cretaceous onset of Alpine orogeny onwards (Sissingh 2006; Schmid and Kissling 2000). This continent-continent collision is still ongoing as active uplift of external Alpine basement massifs and is connected with remarkable seismicity. It coincides to a large extent with increased uplift gradients (Ustaszewski and Pfiffner 2008).

The Apulian indentation into the relatively ductile WEP, in conjunction with the rigid lithospheric shields that bound the WEP from north to east, created a system of Cenozoic rifts (Ratschbacher et al. 1991; Cloetingh et al. 2005). They appear as grabens and subgrabens (e.g. Lower Rhine, Upper Rhine, Eger, Bresse), activated during the late Eocene with more pronounced rifting starting in late Oligocene and filled with Cenozoic sediments (Ziegler 1994; Geluk et al. 1994; Ziegler and Dèzes 2006, 2007; Bourgeois et al. 2007). Additionally, a system of horsts, blocks and tilted blocks was formed under a still present NW-directed compressional stress field, emerging in the early Miocene and accelerated in the Pliocene (Ziegler and Dèzes 2006, 2007). These processes lead to a considerable level of neotectonic activation of the WEP, manifest in the geomorphologic features, and is still ongoing, as demonstrated in the current observed seismicity (Cloetingh and Cornu 2005).

Volcanism accompanied this fragmentation of the upper crust of the WEP at different spots (Bourgeois et al. 2007). The last volcanic eruptions occurred in the Eifel (mid-west of Germany) about 11,000 years ago at the Maar of Ulmen and 12,900 years ago at the Lake of Laach volcano (Schmincke 2010). Volcanic and magmatic activities are still present in different areas, but to a substantially diminished extent. This holds also for intraplatefaulting and block movements. Accordingly, Scholz et al. (1986) classify not only the Alpidic region but also the Rhine Graben structure as a plate-boundary related area; however, the Alpine foreland, west of the URG, are classed as an intraplate related area. 


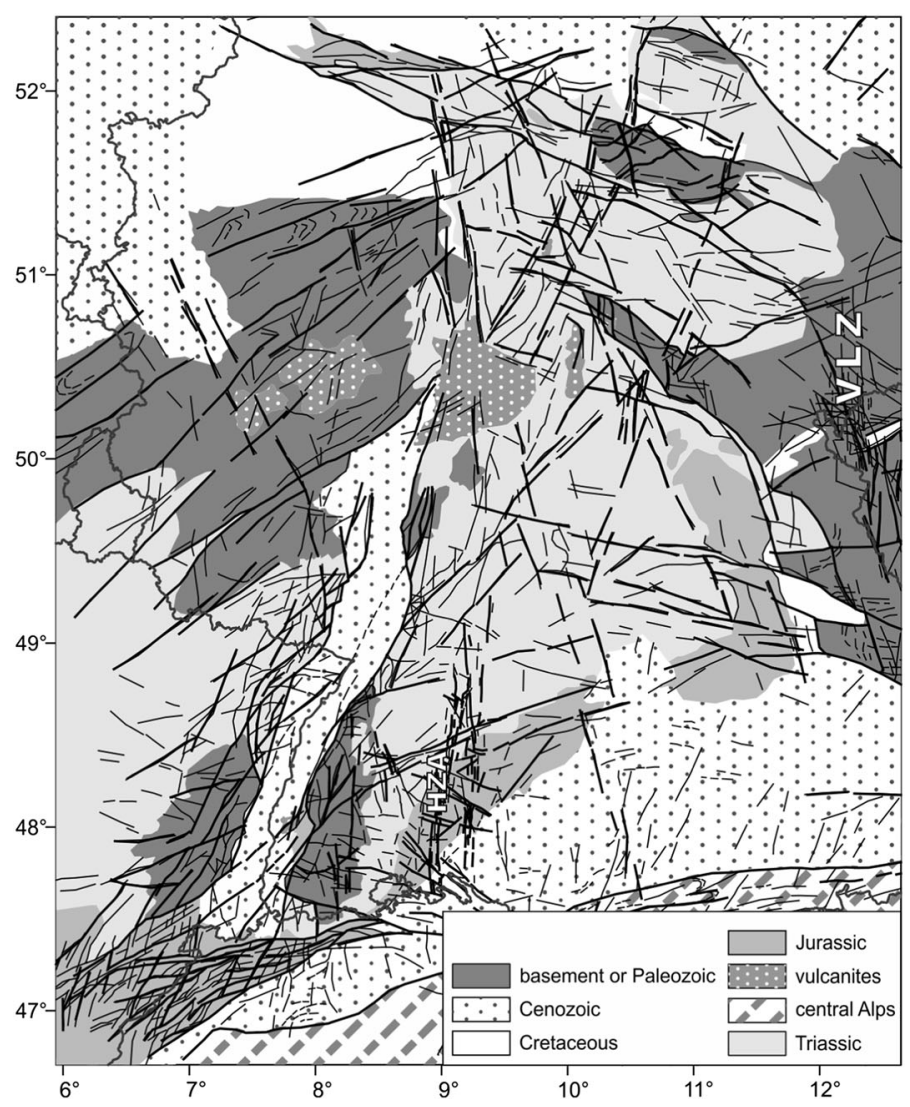

Fig. 4 Fracture lineaments of the seismically most active parts of Germany and surrounding parts of France, Switzerland and Austria, supplemented and redrawn as combination of data from Wetzel and Franzke (2001, 2003), Bankwitz et al. (2003) and Pohl et al. (2006). The fracture lineaments were derived from high resolution data from ERS-1/2 radar mosaics, Landsat-TM, Aster-DEM, and X-SAR-SRTM. Fractures associated with the seismicity of the Hohenzollernalb (HZA) and of the Vogtland-Leipzig zone (VLZ) are basically manifested as photo lineations

The present-day crustal stress field governs the tectonic regime of an area, which reveals the proportion of strike slip faulting, normal faulting and thrust faulting (Fig. 3). The maximum horizontal stress $\left(S_{H \max }\right)$ orientation is, according to more than 750 data points for Germany (Reiter et al. 2015; Heidbach et al. 2016), predominantly in NW-SE direction in the seismically most active parts of Germany. Since the tectonic regime parameters are a direct input in PSHA, its derivation on the basis of observed stress data is subject of the respective Sect. 8.5 of the elaboration of the earthquake model. Vertical and horizontal displacement data exist only according to a few sub-regional areas of Germany. These data do not yet provide a coherent picture on strain accumulation or strain release.

Much of the seismicity of Germany is connected with distinct elements of the fragmented character of the upper crust in the area, which proves that the tectonic processes within the WEP connected with the Alpidic collision did not at all come to a standstill. Although the WEP can in general be seen as "stable continental region" (e.g. Johnston 
1994; Kanter 1994), it clearly presents features of ongoing crustal activities, even though they are comparatively weak.

\subsection{Areal distribution of seismicity and its relation to tectonic elements}

The seismicity of the study area (Fig. 1) can be related to tectonic elements as they are compiled in Fig. 3. The seismicity shows highest activity along the Alpine belt, spanning parts of northern Italy, the western and eastern Alps through to the transition to the Dinarides. The Alpine belt continues further northeast in form of the Mur-Mürz zone in eastern Austria continuing as seismicity chain along the Carpathians, which encircles the Pannonian basin.

North of the Alpine belt, the seismicity is remarkably elevated along the course of the river Rhine up to The Netherlands and into the adjoining parts of Belgium. Outside Germany, diffuse seismicity occurs in several different regions: western and southeast France along the Bresse Graben, in the London-Brabant massif, in western and central Great Britain (extending to the westernmost part of the Doggerbank with the remarkable $1931 M_{w} 5.8$ earthquake), in the central Graben of the North Sea, in the southern Fennoscandian Shield (i.e. western Norway and southwest Sweden) flanked by the Kattegat and Skagerrak, representing lowered southern margins of the Fennoscandian Shield, as well as in the northeastern rim of the Bohemian massif, the Lugicum.

The pronounced seismicity zone along the river Rhine north of the epicentre of the Basel earthquake consists of, from south to north, the URG, the Middle Rhine area and the LRG. The latter shows well defined NW-SE striking normal faults, which can be well associated with most of the seismicity there. They are used here as a composite fault model for the hazard calculation. The border faults of the URG are seismically not noticeable, as the seismicity occurs mainly along north-south striking fault elements (cf. related material in Grünthal et al. 2017). Likewise, the seismicity is also relatively elevated both west and east of the southern part of the URG; towards the west in the French Vosges region and towards the east in the Black Forest. It is also elevated further east in the local seismicity spot of the Hohenzollernalb (HZA) with the 1911 quake as the historically strongest event. Here, the seismicity is connected with sub-parallel lamellar north-south striking sinistral en echelon segments (Reinecker and Schneider 2002), which manifest in form of fissures with at least Pleistocene openings (Illies 1982). These fault information is represented as lineaments according to Earth and Space Research (ERS) radar mosaics in Fig. 4.

A singular area of elevated activity ranges basically $\mathrm{E}$ of $12^{\circ} \mathrm{E}$ and $\mathrm{N}$ of $50^{\circ} \mathrm{N}$ in the middle east part of Germany, covering western Saxony, eastern Thuringia, and extending southeastward to the mostwestern part of the Czech Republic and further to Bavaria. This area of seismic activity was so far not generating earthquakes with $M_{w}>5$ in historical times. Tectonically, it is connected with a system of almost north-south directed faults, which are most pronounced from the Vogtland swarm quake area in the south up to the area of Leipzig, where the seismicity fades out. These north-south striking tectonic features of the Vogtland-Leipzig zone (VLZ) (Fig. 4) are clearly traceable as photo lineations of satellite imasges (Grünthal et al. 1985; Bankwitz et al. 2003; Pohl et al. 2006). At the southern edge, in the Vogtland region and immediate surroundings, seismicity occurs mainly in form of intensive earthquake swarms with events no larger than $M_{w} 4.7$ within each individual swarm. There and directly south, a remarkable amount of mantle-derived gas exhalations are interpreted as indications of ongoing magmatic activities (Bräuer et al. 2011). The immediate surroundings of the swarm quake region and the easterly adjacent Eger Graben have experienced remarkable Cenocoic volcanism (cf. Fig. 3). 
A diffuse seismicity arises, besides of the described seismicity zones within Germany, de facto in all parts. This means, no part can be regarded as aseismic; i.e. economically significant seismic events can be expected, in principle, everywhere. This issue, which is typical for many, if not most small-to-moderate seismicity regions, we are considering in our PSHA approach, as it is described below.

\section{Models of seismic sources}

The modelling of the areal distribution of seismicity, including the likelihood of its future occurrence, can be connected with considerable epistemic uncertainties. To account for the uncertainties, the areal distribution of seismicity is treated with a range of altogether seven models. They follow three general approaches:

1. two large scale areal seismic source zone models (LASZ) based solely on the principal geological structure and tectonic regime and architecture as basically outlined in Fig. 3. Such a model predicts that large earthquakes may occur in areas where no earthquakes have been observed yet and far from known faults or past seismic events,

2. three seismicity data driven small scale areal seismic source zone models (SASZ) considering numerous photo lineations of small scale tectonic features (cf. Fig. 4) and including composite seismic fault zones,

3. two versions of a zoneless approach. These are taking into account the fact that earthquakes may be clustered in stable continental interiors (Calais et al. 2016). Higher probability is then given to earthquake occurrences close to earthquakes that have been observed (smoothed seismicity models) or known fault lineations (SASZ).

Each of them represents an element of the first branching level of the seismic source zone logic tree, described below. This differentiation into five areal source zone models; i.e. the above mentioned basic principles (1) and (2), follows the concept of Grünthal et al. (2009a). A new addition in the current model is the incorporation of composite seismic fault zones, the use of a zoneless approach and the areal extension of the models in order to include areal source zones (ASZ) at distances of up to $250 \mathrm{~km}$ around the target area. The calculation of seismicity parameters characterizing each seismic source is treated in Sect. 5.2.

\subsection{Models of tectonically based large scale areal seismic source zones- models A and B}

We employ here, firstly, the tectonically based model of LASZ as model A, which contains 31 zones automatically numbered north to south from A1 to A31 (Fig. 5). This model represents a somewhat northward and southward extension of the large scale model by Grünthal et al. (2009a), which itself has its origin in Burkhard and Grünthal (2009) concerning its SW part. The outcome of the latter paper was already finished as part of NAGRA (2004), described also in Coppersmith et al. (2009). Model A displays the large scale geological structure and tectonic architecture. Its backbone is the Cenozoic rift system with the graben formations of Bresse (A30), Upper Rhine (A22), Lower Rhine (A12), Eger with the Cheb basin (A19) and the Central Graben (A03) in the North Sea. Along the Alpine chain, the model A differentiates the external, central and internal Alps as LASZ. At distances larger than $100 \mathrm{~km}$ around Germany, our target area for the PSHA, 


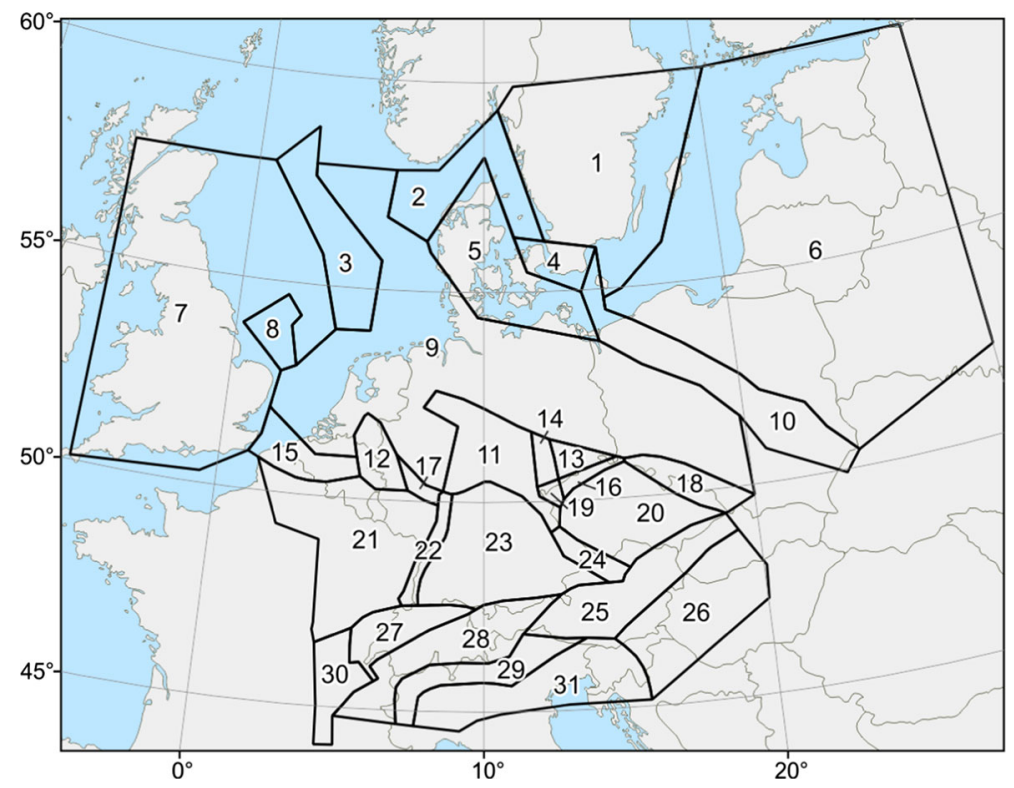

Fig. 5 The large scale areal seismic source zone (LASZ) model A with the 31 source zones. For a better readability of the figure the leading $\mathrm{A}$ of each zone is omitted here and correspondingly in further figures

we use a simplified model. The association of the 31 LASZ with their corresponding tectonic units is shown in the first two columns of Table 1. The description of the further columns of this table are the subject of the next subsection. This model does not image the smaller scaled pattern of historical and modern seismicity, but rather it assumes the occurrence of seismicity at any place within the larger zone; including places other than those with historically known activity concentrations. This means it accounts for the possibility that the very local spot of elevated seismicity at the HZA, which commenced with the 1911 M5.7 earthquake with four successive damaging earthquakes there, can occur everywhere in the respective LASZ; i.e. the South German block, (A23). Before 1911, no relevant seismicity is known from this area in historically sufficiently well documented times. Since such seismological surprises cannot be excluded to occur at other places, the concept of LASZ is introduced. It enables, at least to a certain extent, the possibility of temporal changes in the occurrence of locally increased seismicity spotseven using a formally stationary approach.

Model B represents a slight modification of model A. It corresponds to a respective model in Grünthal et al. (2009a). Figure 6 shows a part of model B covering the SW and central part of the study area with the major seismic zones of Germany. Elevated blocks west and east of the URG are separated as LASZ in this model, forming in the west the block of the Vosges (B28), and in the east the block of the Black Forest in a broader sense (B26, 30) with the elongated area (B27) where a kind of book shelf tectonics seems to occur (Bankwitz et al. 2003). It can be seen as a northeasterly extension of the BresseRhine transitional zone (BRTZ, B35), as already indicated in Illies $(1972,1981)$ and even better constrained in Ustaszewski et al. (2005) or Ustaszewski and Schmid (2007). The assembly of tectonic fractures of Fig. 4 underpins the layout of the BRTZ with its apparent extension further to the ENE east of the URG. 
Table 1 The 31 large scale areal seismic source zones (LASZ) of model A numbered from $\mathrm{N}$ to $\mathrm{S}$ (column 1) with the corresponding tectonic units and superzone numbers of $b$-values, $M_{\max }$, kernels and depths, tectonic regime parameters and description of tectonic terranes

\begin{tabular}{|c|c|c|c|c|c|c|}
\hline \multirow{2}{*}{$\begin{array}{l}\text { LASZ } \\
\text { Model A }\end{array}$} & \multirow[t]{2}{*}{ Tectonic units or regions } & \multicolumn{4}{|c|}{ Corresponding superzone numbers of } & \multirow{2}{*}{$\begin{array}{l}\text { Tectonic } \\
\text { terranes }\end{array}$} \\
\hline & & $b$ values & $M_{\max }$ & $\begin{array}{l}\text { Kernels } \\
\text { and } \\
\text { depths }\end{array}$ & $\begin{array}{l}\text { Tectonic } \\
\text { regimes }\end{array}$ & \\
\hline A01 & Baltic Shield S & 4 & 5 & 1 & 1 & Non-extended \\
\hline A02 & Skagerrak and Kattegat & 3 & 4 & 1 & 1 & Non-extended \\
\hline A03 & Central Graben & 2 & 2 & 1 & 1 & Extended \\
\hline A04 & Sorgenfrei-Tornquist zone east & 4 & 5 & 1 & 1 & Non-extended \\
\hline A05 & Danish Embayment & 2 & 3 & 1 & 1 & Non-extended \\
\hline A06 & Baltic Belarus Syneclise & 4 & 5 & 1 & 1 & Non-extended \\
\hline A07 & Great Britain & 1 & 1 & 9 & 9 & Non-extended \\
\hline A08 & Doggerbank W & 1 & 1 & 9 & 9 & Non-extended \\
\hline A09 & Central European basin zone & 2 & 3 & 1 & 1 & Non-extended \\
\hline A10 & $\begin{array}{l}\text { Rønne Graben, Tornquist-Theisseyre } \\
\text { zone, Polish trough }\end{array}$ & 4 & 6 & 1 & 1 & Extended \\
\hline A11 & $\begin{array}{l}\text { Lower Saxonian tectogene, Thuringian } \\
\text { basin, Franconian line }\end{array}$ & 7 & 10 & 5 & 5 & Non-extended \\
\hline A12 & Lower Rhine Graben, Ardennes massif E & 5 & 8 & 3 & 10 & Extended \\
\hline A13 & Saxony & 8 & 11 & 5 & 5 & Non-extended \\
\hline A14 & Vogtland-Leipzig zone $\mathrm{N}$ & 8 & 11 & 5 & 5 & Non-extended \\
\hline A15 & London Brabant massif & 1 & 7 & 2 & 2 & Non-extended \\
\hline A16 & Eger Graben $\mathrm{N}$ & 8 & 12 & 5 & 5 & Extended \\
\hline A17 & Middle Rhine zone & 6 & 9 & 3 & 11 & Extended \\
\hline A18 & Lugicum & 4 & 5 & 5 & 5 & Non-extended \\
\hline A19 & Vogtland-Cheb basin & 8 & 12 & 5 & 5 & Magmatic \\
\hline A 20 & Bohemian massif & 4 & 5 & 5 & 5 & Non-extended \\
\hline A21 & $\begin{array}{l}\text { West-Rhenish Massif, Lorraine, Paris } \\
\text { Basin E }\end{array}$ & 9 & 13 & 2 & 2 & Non-extended \\
\hline A22 & Upper Rhine Graben & 10 & 14 & 3 & 3 & Extended \\
\hline A23 & South German block & 11 & 15 & 5 & 5 & Non-extended \\
\hline A24 & Pfahl line & 11 & 15 & 5 & 5 & Non-extended \\
\hline A 25 & $\begin{array}{l}\text { Eastern Alps, Mur-Mürz zone, Western } \\
\text { Carpathians }\end{array}$ & 12 & 16 & 6 & 6 & Alpidic A \\
\hline A26 & Western Pannonian basin & 13 & 17 & 8 & 8 & Alpidic A \\
\hline A27 & Extern Alps & 14 & 18 & 4 & 4 & Alpidic A \\
\hline A28 & Central Alps & 15 & 19 & 4 & 4 & Alpidic A \\
\hline A29 & Internal Alps & 17 & 21 & 4 & 4 & Alpidic B \\
\hline A30 & Bresse Graben S & 16 & 20 & 2 & 2 & extended \\
\hline A31 & Po Plain and Apulian promontory & 18 & 22 & 7 & 7 & Alpidic B \\
\hline
\end{tabular}

The LRG is subdivided in this model to indicate a crossing area (B16) of the NW trending active faults of the LRG with the SW-NE faults of the adjacent most easterly Ardennes, respectively the London-Brabant massif. This area is the transitional zone from the active Middle Rhine zone towards the LBM. Since the basic and large scale tectonic architecture is, in general, well constrained, the modelling of the LASZ does not leave much freedom to modellers. Thus, our model A in combination with modifications in form 

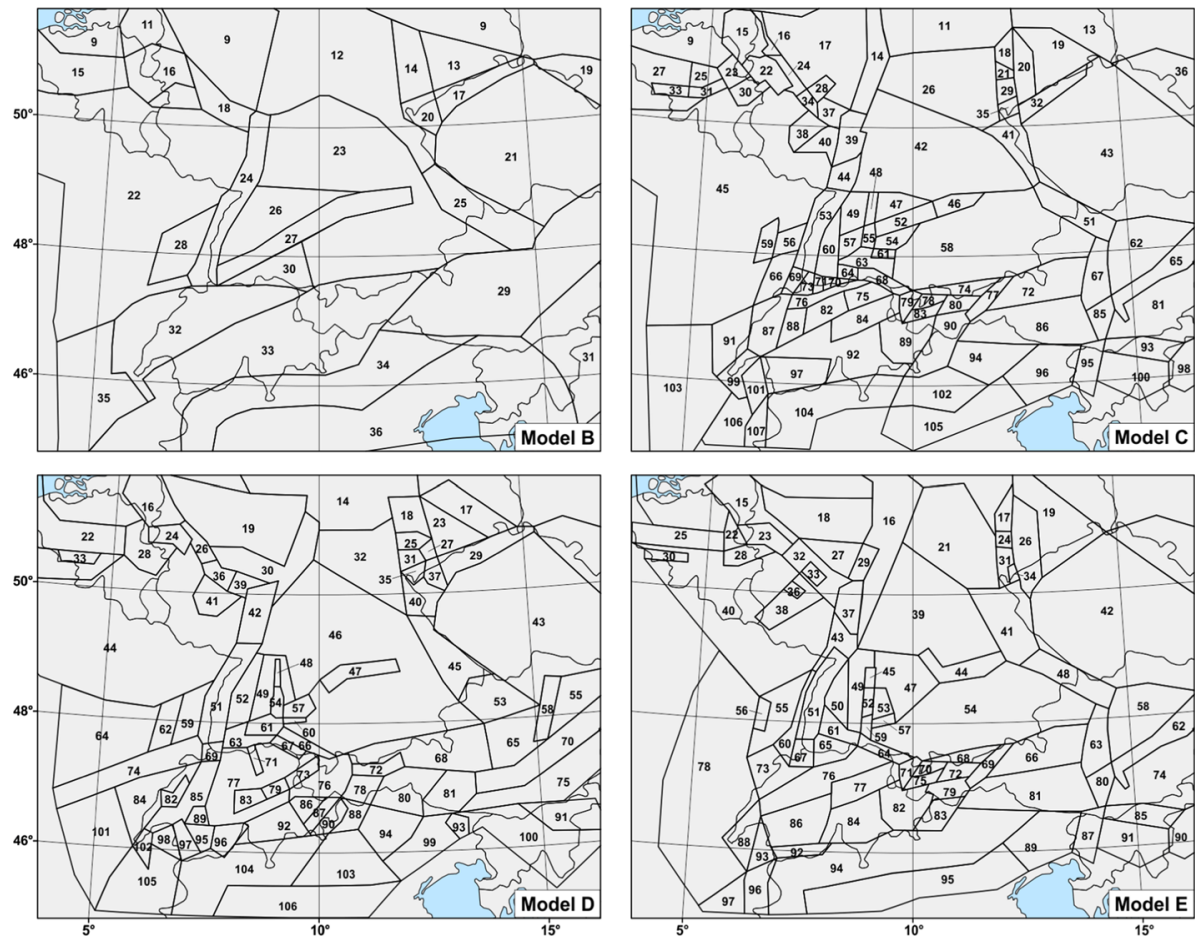

Fig. 6 The seismic source zone models B, C, D, and E as clipping of their respective SW parts covering the target area of this study. Concerning the full models see the accompanying report (Grünthal et al. 2017)

of model B seems to be sufficient to cover the uncertainties related to a basic tectonic zonation.

\subsection{The concept of superzones as derivatives of SSZ model A}

The tectonically reasoned LASZ model A is also used in our approach as basis for the determination of superzones to ascertain parameters and distribution functions based on sufficiently large data sets; i.e. these superzones are all derivatives of model A. Therefore, the five superzones are already introduced in this subsection, although their detailed treatment will be the subject of later parts of this paper.

That superzone model, which is nearest in shape to our model A, is the one for the derivation of seismicity rates per zone (cf. Sect. 5.2), where a minimum of 70 events in a respective zone are required for the calculation of the frequency-magnitude parameter $b$. This necessitates the combination of zones of model A with very low seismicity that are related to one another tectonically. Figure 7 a shows the $b$-value superzone model with the delineation of the zones of model A. The colour code of this figure illustrates that this combination of model-A zones applies only in the north of our study area; i.e. for the region in the northeast, where the zones of the EEC (cf. Fig. 3) with related and border elements are joined as one superzone (no. 4 in Fig. 3) to fulfill the aforementioned requirement. Similar combinations of model-A zones were then applied to model-A zones bordering to the Central European basin to build further b-value superzones. In this way, 

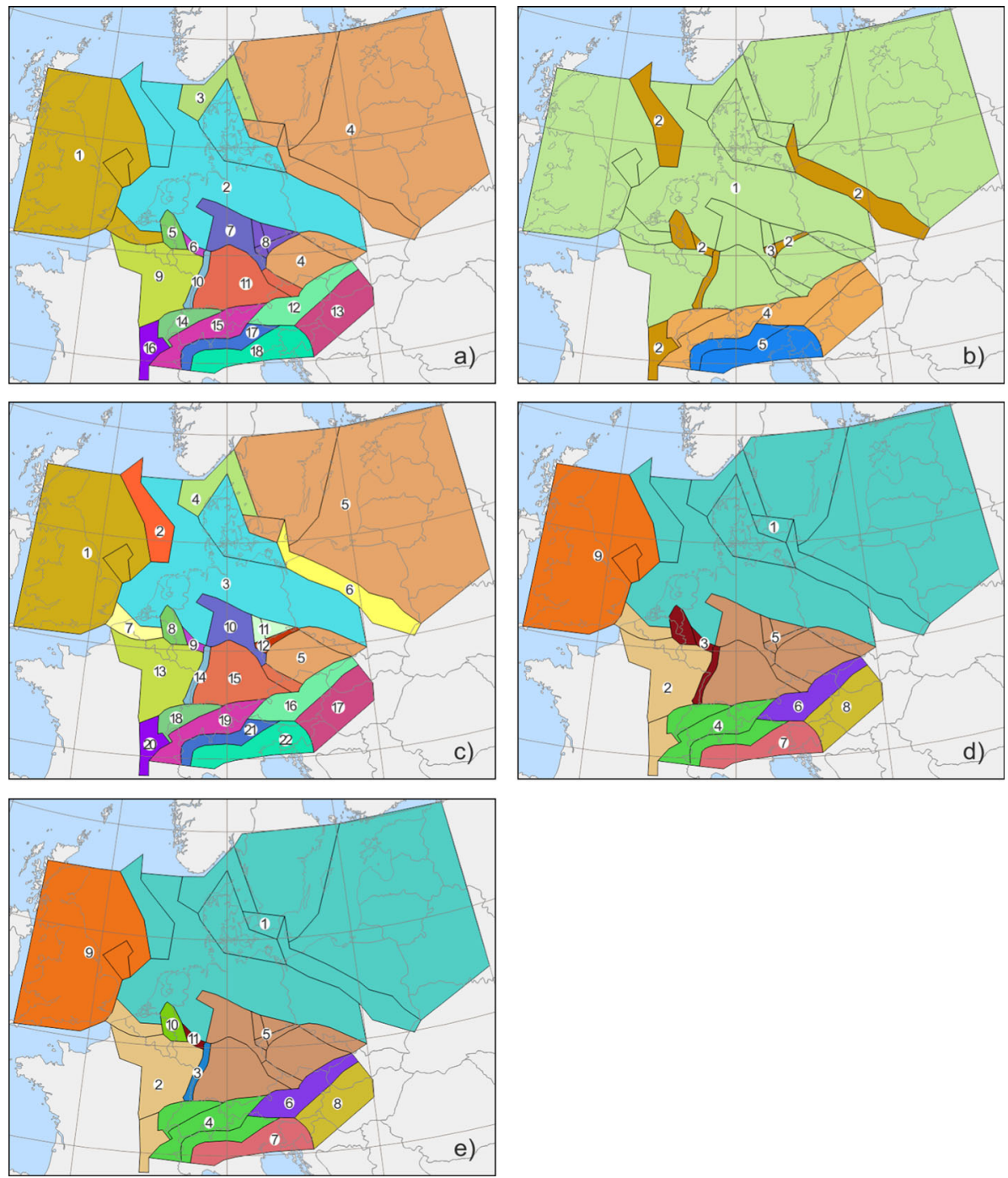

Fig. 7 The superzones used in the approach as derivatives of LASZ model A, applied for the determination of the frequency-magnitude parameter b (a), the model of tectonic terranes (b), the probability density functions of maximum magnitude $M_{\max }(\mathbf{c})$, parameters of earthquake depth distributions and kernel functions (d), and for the characterization of the tectonic regime (e)

the $b$-value superzone model applies with 18 superzones. Table 1 summarizes which of the model-A zones were combined for this superzone model.

The derivation of probability density functions (PDF) of maximum magnitudes $M_{\max }$, as described in Sect. 5.1, requires the introduction of two superzone models, one defining tectonic terranes and the other the superzones for the calculation of their PDF. The applied tectonic terranes differentiate between non-extensional (terrane number 1) and extensional earth crust (2), where different prior functions of $M_{\max }$ are used. The usage of different truncations of the PDFs necessitates the further distinction of a seismically active 
magmatic region (3) and of the Alpine region into the external, central and eastern Alps (4, Alpidic A) and the internal Alps with the adjacent Po Plain and Apulian promontory (5, Alpidic B). Figure $7 \mathrm{~b}$ and Table 1 show which of the model-A zones belong to which of the five different tectonic terranes.

The $M_{\max }$-superzone model itself is based on that described for the $b$-values, where those require a division according to different tectonic terranes. This applies to four of the $b$-value superzone-models, resulting in $22 M_{\max }$ superzones (Fig. 7c and Table 1).

The calculation of discretized focal depth density functions (cf. Sect. 8.3) requires a sufficient number of catalogued earthquakes with the information on their focal depths. Tectonically related model-A zones were combined in a way that usually more than 25 events are assembled in a respective focal-depth superzone. The resulting depth superzone model is shown in Fig. 7d and tabulated concerning the association of combined LASZs of model $\mathrm{A}$ in Table 1.

Also the determination of the parameters of kernel function for the application of a zoneless approach (cf. Sect. 4.4) necessitates a sufficient number of earthquakes. It proved to be suitable to apply the superzone model for this approach, which was derived already for the focal depth density functions; i.e. there holds also Fig. $7 \mathrm{~d}$ for the different kernel functions.

Finally, a superzone model is needed for the derivation of tectonic regime parameters (cf. Sect. 8.5). Concerning this model we could also proceed from the depth superzone model, which required a partition of the depth superzone of the Rhine chain into three tectonic regime superzones, since a sufficiently large volume of tectonic regime data constrains such a differentiation into Upper Rhine Graben, Middle Rhine and Lower Rhine Graben. The resulting eleven superzones of the model for the tectonic regime are shown in Fig. 7e and their relation to LASZs of model A in Table 1.

\subsection{Models of small scale areal seismic source zones: models $\mathrm{C}$ to $\mathrm{E}$}

Our principle of the delineation of small scale areal seismic source zones (SASZ) is quite different from the one that is applied for the LASZ models. For the definition of SASZ, we consider the detailed pattern of both the fault lineations and the historically observed seismicity, presuming areal stationarity of the latter. The SASZ models can be connected with large uncertainties in areas of diffuse seismic activity, which can lead to greater variability. Therefore we employ three SASZ models, which were originally derived independently from each other.

SASZ model C is based on Burkhard and Grünthal (2009), which was extended by Grünthal et al. (2009a) and later provided for the project SHARE (Woessner et al. 2015) as model for Germany. For its application in SHARE, it needed simplifications concerning those SASZs with too small seismic activity because of a higher magnitude threshold used in the SHARE project. Model D is basically that of the D-A-CH study (Grünthal et al. 1998a) with simplifications in larger distances from the target area. It benefited much from advice by G. Schneider (Stuttgart). Finally, we employ model E, which largely corresponds to the model by Ahorner and Rosenhauer (1986). These models have been used already in Grünthal et al. (2009a), albeit without the slight areal extension to include SSZ up to distances of $250 \mathrm{~km}$ around the target area, which were added for this study. Their SW parts for the most seismically active parts of Germany are shown in Fig. 6. All these models are depicted in full in the accompanying report together with coordinates of their respective polygon traces. The areal differences in their variability, as an expression of uncertainties in modelling, are small along the boundaries of the URG, but large in 
northern Germany, where the dissimilarity of the models can be seen as an expression of large model uncertainties. The seismicity spot of the HZA, as mentioned above, is modelled in the SASZ in form of the SSZ C55, D54, E52 (cf. Fig. 6).

There is one basic difference in model $\mathrm{C}$ as it is used here in comparison with its earlier applications since Grünthal et al. (2004). This concerns the area of the LRG, where we modelled so far the fairly well known seismogenic normal faults by a set of SASZ as proxies to these faults. They are modelled now as composite seismic faults, described in the following subsection.

\subsection{Model of composite seismic fault sources as part of the SASZ model C}

Tectonic faults are used as seismic sources for the analysis, in particular as part of our SASZ model C, inasmuch as respective reliable information is available for the target area. This is solely the case for the LRG (Vanneste et al. 2014). Other areas of enlarged seismicity, such as the region of the HZA or the URG, could not yet be incorporated as fault source models as their respective data are incomplete. However, the data available for the LRG allow at least the construction of 15 composite seismic sources (CSS) (Vanneste et al. 2013) combining an unspecified number of individual sources according to Haller and Basili (2011). We make direct use of the fault geometry including dip, rake and depth range of the NW-SE striking CSS model by Vanneste et al. (2013), except for the two most northwestern ones. They have the largest distance to the target area and show very low seismicity. The determination of rates for the CSS requires a related catchment area of seismicity covering the region of the LRG or basically the largest part of the LASZ A12. This area is subdivided into two catchment sub-areas C15 and C22.

The geometry of our CSS model is shown in Fig. 8 as top-view of the 3D model. One of the two catchment sub-areas covers the seismically more active SE part, where SW-NE trending Variscian faults intersect the dominating NW-SE faults of the LRG. The other catchment sub-area covers the NW part with lower seismicity. The assignment of ranges of maximum magnitudes to each CSS is treated in Sect. 5.1 and the calculation of seismicity rates with their uncertainties in Sect. 5.2.

\subsection{Zoneless models}

An alternative to a SSZ based approach is a pure zoneless approach. These zoneless approaches use seismicity models based on smoothed epicentral locations of past earthquakes (Beauval et al. 2006; Stock and Smith 2002; Zechar and Jordan 2010) and require neither any definition of source zones nor earthquake recurrence models. But there are intrinsic uncertainties resulting from the choice of the smoothing functions and the impossibility to account for the occurrence of magnitudes larger than the observed maximum. Zoneless approaches are, according to Beauval et al. (2006), particularly useful for PSHA in low seismicity areas and can contribute to stabilize the results. Our basic motivation for its usage was to consider an antagonist view with respect to the large scale source zone concept, where the precise location of historically observed seismicity does not play any or even a very minor role. With the parallel use of zoneless approaches, we extend and round off the range of models to define sources of expected future earthquakes.

Specific zoneless methods in addition to a zone-based approach were also employed by Burkhard and Grünthal (2009) and by Wiemer et al. (2016). Here, we use a zoneless approach with a finite-range power-law kernel $K(r, M)$ and a magnitude dependent bandwidth function $H(M)$ 
Fig. 8 Geometry of composite seismic sources for the LRG (Vanneste et al. 2013) and corresponding catchment areas of the SASZ model C

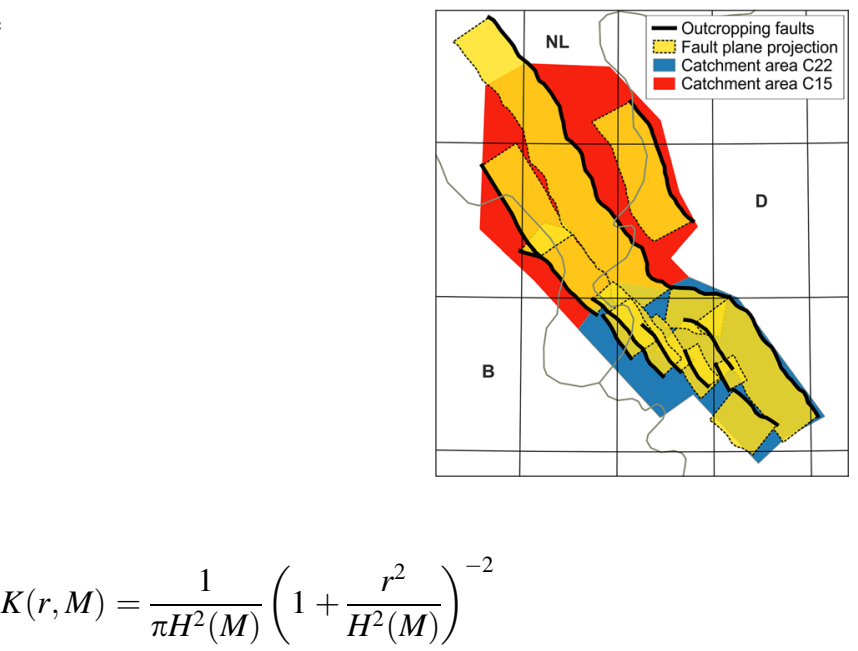

proposed by Vere-Jones (1992). Following Woo (1996) and Molina et al. (2001), $H(M)$ is growing exponentially with magnitude; i.e. $H(M)=c_{1} \exp \left(c_{2} M\right)$. Parameters $c_{1}$ and $c_{2}$ control the shape of the kernel. They are derived from the mean nearest event distance of epicenters in different magnitude bins by performing a non-linear regression with statistical weights. In large extended regions with low seismicity, this adaptive bandwidth estimation can result in high values of $H(M)$, which distribute the observed seismicity of the rare significant events to an extreme extent. Therefore, a truncated version, $H(M) \leq 25 \mathrm{~km}$ if $c_{1} \exp \left(c_{2} M\right)>25$, is additionally employed as an alternative bandwidth model. Both variants are used with equal weights in the logic tree. Since the bandwidth parameters can differ from region to region, Chan and Grünthal (2010) developed a hybrid approach using a Pan-European superzone model with characteristic kernel parameters for different regions. This method has been adopted for this study, which has here nine superzones (cf. Sect. 4.2, Fig. 7 and Table 1).

The resulting hazard according to the zoneless approach is very similar to that of the zone-based models for about $80 \%$ of the target area. Concerning the LASZ approach, as an antagonistic view with respect to the zoneless method, the latter yields significantly higher values in the localized parts of increased seismicity (up to $30 \%$ or $0.4 \mathrm{~m} / \mathrm{s}^{2}$ for the level of the mean return period $\mathrm{RP}=475 \mathrm{a}$ ). Concerning the SASZ model, the effect with respect to the resulting hazard is opposite. Here, the hazard according to the zoneless technique is about $10-20 \%$ lower (with the highest differences of about $0.2 \mathrm{~m} / \mathrm{s}^{2}$ ) in seismically exposed areas, but a little higher in rims surrounding areas of locally increased activity. This is due to the smearing effect of the bandwidth function.

\subsection{Logic tree of seismic source models}

The SSZ models A to E, as well as two zoneless models, are treated in the PSHA as branches of a first part of our logic tree (Fig. 9). Its first branching level is related to the principal differentiation into models of LASZ, SASZ and zoneless kernel smoothing. We gave the set of SASZ models the largest weight of 0.5. Herewith, we followed the rationale to give the highest weights to the models that presume areal stationarity of seismicity. In a short- and medium-term perspective, this is justified since this contributes to a certain recognition value of our seismic hazard maps with respect to the observed seismicity. On 
the other hand, we are well aware that the assumption of stationarity is not always fulfilled and seismological "surprises" cannot be excluded. Therefore, we gave the LASZ models a weight of 0.25 . In order to consider the range of epistemic uncertainty in the modelling, we applied also the antagonistic view with respect to the concept of LASZ in form of the zoneless models. Therefore, we gave them the same weight of 0.25 as the LASZ models received.

The next branching level in Fig. 9 describes the bifurcation of the LASZ approach into the two variants, the models A and B. We found both to be equally important, resulting in equal weights of 0.5. Equal weighting for a branching level is not explicitly indicated as such in Fig. 9. The following branching level concerns the breakdown of the SASZ models. The most modern model $\mathrm{C}$ with the composite seismic fault modelling is assigned the highest weight of 0.5 , which is the same as the other two SASZ models combined, each having a weight of 0.25 . Finally, the two kernel smoothing models have the same weights of 0.5 each, since both were estimated as equally significant.

\section{Parameters with epistemic uncertainties characterizing each seismic source}

The parameters and models with epistemic uncertainties which characterize each source zone include (1) the parameters of the Gutenberg-Richter relation, which control the rates of seismicity and depend on (2) maximum magnitudes. The final branching level of the logic tree is that of the ground motion prediction equations (GMPE), discussed further in Sect. 6 .

\subsection{Maximum magnitudes $M_{\max }$}

\subsubsection{Probability density functions of $M_{\text {max }}$ in respective superzones and areal seismic source zones}

The definition of a magnitude describing the largest possible earthquake within a certain region, i.e. $M_{\max }$, has been introduced into PSHA by Cornell and Vanmarcke (1969). Based on Cornell (1971), Algermissen and Perkins (1976) related $M_{\max }$ to specific source zones. The enigmatic nature of $M_{\max }$, due to obvious limitations of its observability, associates this parameter with a considerable epistemic uncertainty. This holds especially for regions with low to moderate seismicity, where the historical record of about a millennium is usually too short to constrain the largest possible earthquake. Consequently, we prefer methods to describe $M_{\max }$ with respective density functions ranging over a broad span of magnitudes.

A considerable number of methods are in use that attempt to extend the conceivable range of $M_{\max }$ up to its possible upper range. We employ here, as in all our previous studies on PSHA in Europe north of the Mediterranean region since Grünthal and Wahlström (2001) and Wahlström and Grünthal (2000, 2001), a Bayesian approach based on the ergodic principle; i.e. the substitution of temporal limitations in the observational record using observations of the same phenomenon taken from a larger spatial domain. Such an approach was proposed by Cornell (1994) in the frame of the analysis of the largest globally observed earthquakes in stable continental regions (SCR) (Johnston 1994). Coppersmith (1994) gave the description of the elements in implementing this approach, 


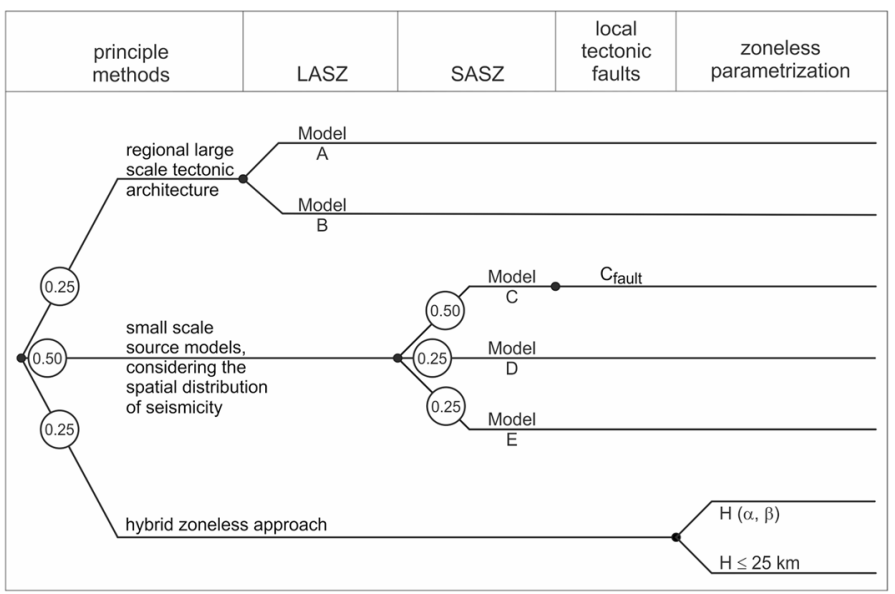

Fig. 9 Logic tree (lower part) seismic source zone models including both zoneless models

which makes use of the multiplication of one of two types of a priori distribution of $M_{\max }$ according to the global data and a likelihood distribution function derived from the seismicity features of the source zone to which the approach is applied. The likelihood distribution function is zero below the largest observed magnitude of a respective source. This considers the unarguable fact that $M_{\max }$ has to be larger than or equal to the largest observed earthquake in a source zone. The multiplication yields the a posteriori probability density function (PDF) of $M_{\max }$. We truncate this a posteriori PDF of a source zone according to suitable constraints as described below. For implementing the a posteriori PDF into PSHA, it is discretized by five sample values of $M_{\max }, i=1 \ldots 5$, of equal weights, according to the approach described by Miller and Rice (1983). The two a priori normal distributions characterize extended and non-extended crustal terranes. Since we described the basics of the respective approach in detail in Grünthal et al. (2009a), we can generally be brief and will highlight here those elements which are new with respect to our previous procedures.

The application of the Bayesian approach requires the subdivision of the crustal domains into extensional and non-extensional terranes for the use of one of the two a priori functions (Kanter 1994; Johnston 1994; Cornell 1994). Here, we follow our scheme, as it is described in Grünthal et al. (2009a) or in Burkhard and Grünthal (2009), with the Cenozoic graben structures as extended terranes and the regions north of the Alpidic parts of the study area as non-extensional terranes. The Alpidic parts are, according to the recommendation for the PEGASOS project by Coppersmith (pers. communication; cf. Burkhard and Grünthal 2009), treated with the extensional type of the a priori function. The basic scheme for the construction of respective superzones of crustal domains follows the LASZ of our model A. The association of the types of crustal terranes to certain LASZ of model A has been described already in Sect. 4.2.

The PDFs of $M_{\max }$ were derived, as in our previous works, for respective superzones. LASZs of model A are combined according to tectonic constraints (cf. Grünthal et al. 2009a and Burkhard and Grünthal 2009) to build the $22 M_{\max }$ superzones for this study (cf. Sect. 4.2). PDFs of $M_{\max }$ of superzones are applied to the areal source zones of the LASZ models A and B and to those of the SASZ models C, D and E as they are covered by respective superzones. 
As described above, the likelihood distribution functions for the superzones are truncated towards lower magnitudes according to the magnitude of the maximum observed earthquake in a particular superzone. Additionally, we assumed $M_{w}=5.5$ to be the smallest lower cut for any zone. In case of paleoseismological findings (e.g. Camelbeeck et al. 2007; Ferry et al. 2005; Brandes and Winsemann 2013), their magnitudes are used for the lower truncation. The upper truncation of the distribution function is based on increments added to the maximum historically observed $M_{w}$, which are dependent on the level of seismic activity of five different tectonic terranes, where we distinguish (with the increments in parentheses): non-extended (1.3), extended (1.3), magmatically active extended (1.3), Alpidic A with the external, central and eastern Alps (0.8) and Alpidic B with the internal Alps and the southerly adjacent Po Plain (0.7); see also Table 2. The increment is decreasing with increasing level of seismic activity. The non-extended part has the $M_{w} 5.71911$ Nov. 16 Albstadt as its maximum observed earthquake, which yields a truncation of the distribution function of $M_{\text {max } \text {,trunc }}=7.0$. The extended areas, with the $M_{w}$ 6.11692 Sept. 18 Verviers earthquake as their maximum observed, are truncated at $M_{\text {max } \text { trunc }}=7.4$. The seismically very active Vogtland pronounced swarm quake area, with intensive volcanic $\mathrm{CO}_{2}$ degassing, has the $M_{w} 4.71908$ Nov. 6 shock as its largest, resulting in $M_{\text {max } \text { trunc }}=6.0$, whilst the Alpidic A and Alpidic B regions, with the $M_{w} 6.6$ 1356 Oct. 18 Basel earthquake and the $M_{w} 6.91511$ March 26 West Slovenia as their largest observed events, are assigned $M_{\text {max, trunc }}=7.4$ and $M_{\text {max }, \text { trunc }}=7.6$, respectively. Figure 10 shows exemplary four of these 22 PDFs of $M_{\max }$. The parameters of the depicted PDF of all $M_{\max }$ superzones are provided in the associated technical report to this paper (Grünthal et al. 2017).

\subsection{2 $M_{\max }$ of composite seismic sources CSS}

Each of the CSS was associated with the mean values of $M_{\max }$ within the range of $6.3 \leq M_{\text {max,mean }} \leq 7.1$ with standard deviations $\sigma$ of 0.3 according to Vanneste et al. (2013). We assume normal distributions on $M_{\max }$ and cut these at their lower bounds at the respective $M_{\max }-\sigma$ and at their upper bounds always at $M_{\text {max, trunc }}=7.4$, which is the above described truncation applied for the LRG. We use also here the method by Miller and Rice (1983) for discretization into five values of $M_{\max }$ of equal weights.

\subsection{Seismicity rates of seismic source zones depending on $M_{\max }$}

The estimation of the seismicity rates based on catalogued earthquake data is an essential step within a PSHA. It requires the consideration of the uncertainties associated with the observed annual seismicity rates to quantify the resulting uncertainties in the hazard (Abrahamson and Bommer 2005; Bommer et al. 2005).

\subsubsection{The methodology}

The seismicity rates of the SSZs are modelled by a double-truncated exponential frequency relation

$$
v(M)=\int_{M}^{M_{\max }} 10^{a-b m} d m
$$


Table 2 Differentiation of tectonic terranes for the upper truncation of the $M_{\max }$ distribution

\begin{tabular}{llll}
\hline $\begin{array}{l}\text { Tectonic } \\
\text { terranes }\end{array}$ & LASZ & $\begin{array}{l}\text { Max. observed } \\
\text { magnitude }\end{array}$ & $\begin{array}{l}\text { Magnitude } \\
\text { increment }\end{array}$ \\
\hline $\begin{array}{c}\text { Non- } \\
\text { extended }\end{array}$ & $\begin{array}{c}\text { A01, A02, A04, A05, A06, A07, A08, A09, A11, A13, A14, } \\
\text { A15, A18, A20, A21, A23, A24 }\end{array}$ & 1.3 \\
$\begin{array}{c}\text { Extended } \\
\text { A03, A10, A12, A16, A17, A22, A30 }\end{array}$ & 6.1 & 1.3 \\
$\begin{array}{c}\text { Magmatic } \\
\text { active }\end{array}$ & A19 & 4.8 & 1.3 \\
Alpidic A & A25, A26, A27, A28 & 6.6 & 0.8 \\
Alpidic B & A29, A31 & 6.9 & 0.7 \\
\hline
\end{tabular}


Fig. 10 Examples of probability distribution functions (PDF) of $M_{\max }$ for the superzones: a Extern Alps, b Lower Rhine Graben, c Upper Rhine Graben, d South German Block

where $v(M)$ describes the total number of earthquakes equal to and above magnitude $\mathrm{M}$ of a specific region observed in a fixed time period. It should be noted that there is a small difference in the meaning of the parameter $a$ in comparison with the classical GutenbergRichter relation (Gutenberg and Richter 1944). The modified maximum likelihood estimation after Weichert (1980) provides expectations and the covariance matrix $C(a, b)$ for both $a$ and $b$ based on binned magnitude rates and different completeness periods (Stromeyer and Grünthal 2015). Therefore, the uncertainties of the linear term $a-b m$ are 
assumed to be normally distributed and can be discretized for a fixed magnitude in an optimal sense with the approved procedure by Miller and Rice (1983).

This allows for the full consideration of the uncertainties of a magnitude frequency relation in a hazard project. For an arbitrarily chosen number $k$ of sample points $z_{i}$ of the normal distribution, the cumulative seismicity rates can be split up into $k$ different magnitude frequency relations

$$
v_{i}(M)=\int_{M}^{M_{\max }} 10^{a-b m+\sigma(m) z_{i}} d m, \quad i=1 \ldots k, \sigma(m)^{2}=C_{a a}-2 C_{a b} m+C_{b b} m^{2}
$$

capturing the uncertainties of the seismicity rates together with the corresponding weights $w_{i}$ (Stromeyer and Grünthal 2015). Table 3 lists the four optimal sampling point positions and corresponding weights of the standard normal distribution chosen for this project. Figure 11 shows as an example the four magnitude frequency graphs capturing the uncertainties of the estimated seismicity rate of source zone A11 (see Table 1). Further magnitude-frequency graphs of SSZ of model A are shown in Fig. 12. Here we focus on the comparison of non-cumulative and cumulative displaying of observed rates. Graphs of six SSZ are selected. Exemplarily, they indicate their overall robustness in deriving their parameters. For further information concerning the corresponding full set of graphs for all $18 b$-value superzones, we refer to the supporting material by Grünthal et al. (2017).

The truncated exponential seismicity model is strongly dependent on $M_{\max }$. To capture the total uncertainties corresponding to the seismicity rates of areal source zones, the $M_{\max }$ distribution must be combined with the uncertainties of the model parameters $a$ and $b$. Figure 13 shows as an example the resulting rate model with regard to the uncertainties of both components for the above mentioned source zone A11.

\subsubsection{Seismicity parameters in superzones of common-b values}

The derivation of reliable $b$-values of a magnitude frequency relation requires a certain minimum number of earthquakes per seismic zone. We have chosen 70 events as the minimum per zone; otherwise we apply a common- $b$ value to a group of neighbouring and tectonically related zones, albeit with their respective $a$-values determined according to the seismicity of the respective individual zone (Stromeyer and Grünthal 2015). This grouping of zones builds the $b$-value superzone-model (cf. Sect. 4.2 and Fig. 7a). The seismicity parameters of the $b$-value superzones are listed in Table 4 . The uncertainties are given by standard deviations of the respective parameters. The small uncertainties of both $a$ and $b$ of all zones are an indication of the overall reliability of the derived rates. Even the upper and lower outliers in the $b$-value are well constrained by frequency data. Respective figures of the magnitude frequency relations and tabulated rates for all magnitude bins are given in the accompanying report to this paper.

Table 3 Optimal sampling point positions and corresponding weights of the standard normal distribution for $k=4$

\begin{tabular}{lllll}
\hline Sample points $z_{i}$ & $-\sqrt{3+\sqrt{6}}$ & $-\sqrt{3-\sqrt{6}}$ & $\sqrt{3-\sqrt{6}}$ & $\sqrt{3+\sqrt{6}}$ \\
Weights $w_{i}$ & $\frac{3-\sqrt{6}}{12}$ & $\frac{3+\sqrt{6}}{12}$ & $\frac{3+\sqrt{6}}{12}$ & $\frac{3-\sqrt{6}}{12}$ \\
\hline
\end{tabular}




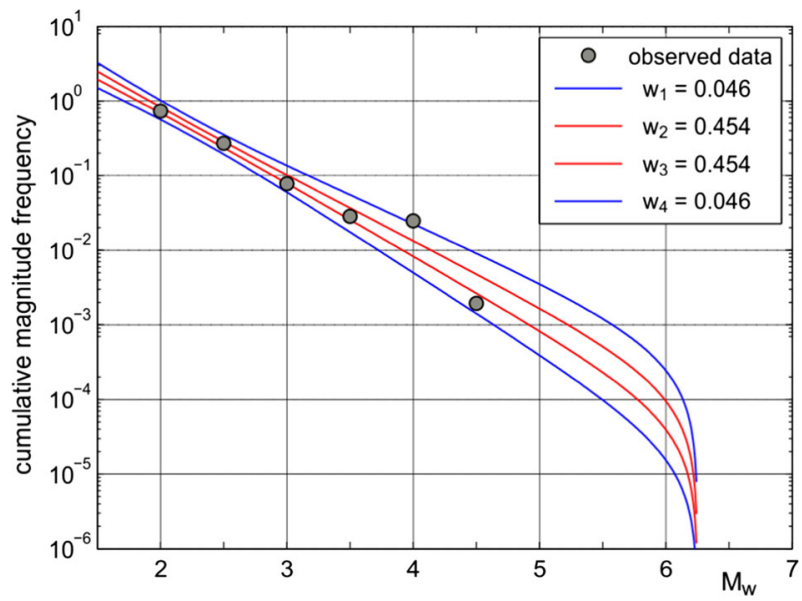

Fig. 11 Observed cumulative seismicity rates (circles) and magnitude frequency graphs with annotated weights $w_{i}$ capturing the uncertainties of the estimated seismicity rate by a four-point discretization of the resulting distribution of source zone A11 for $M_{\max }=6.25$

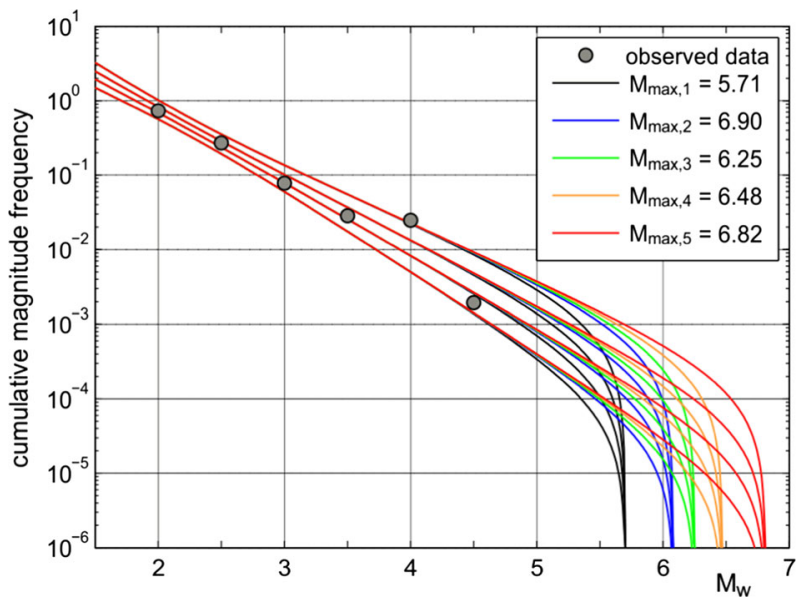

Fig. 12 Observed cumulative seismicity rates (circles) and magnitude-frequency graphs of source zone A11 corresponding to the five-point discretization of the $M_{\max }$ posterior distribution as it is applied here. The annotated magnitudes refer to the discretized distribution of $M_{\max }$ of the corresponding $M_{\max }$ superzone

\subsubsection{Differentiation of the minimum magnitude for fit for the calculation of frequency-magnitude parameters}

A specific feature concerns differences in the frequency of observed yearly rates of smaller versus larger magnitudes, as it was also observed by Woessner et al. (2015). We found a considerable difference in the annual frequencies of smaller and larger magnitude earthquakes in, for example, SSZ of the URG (Fig. 14). 

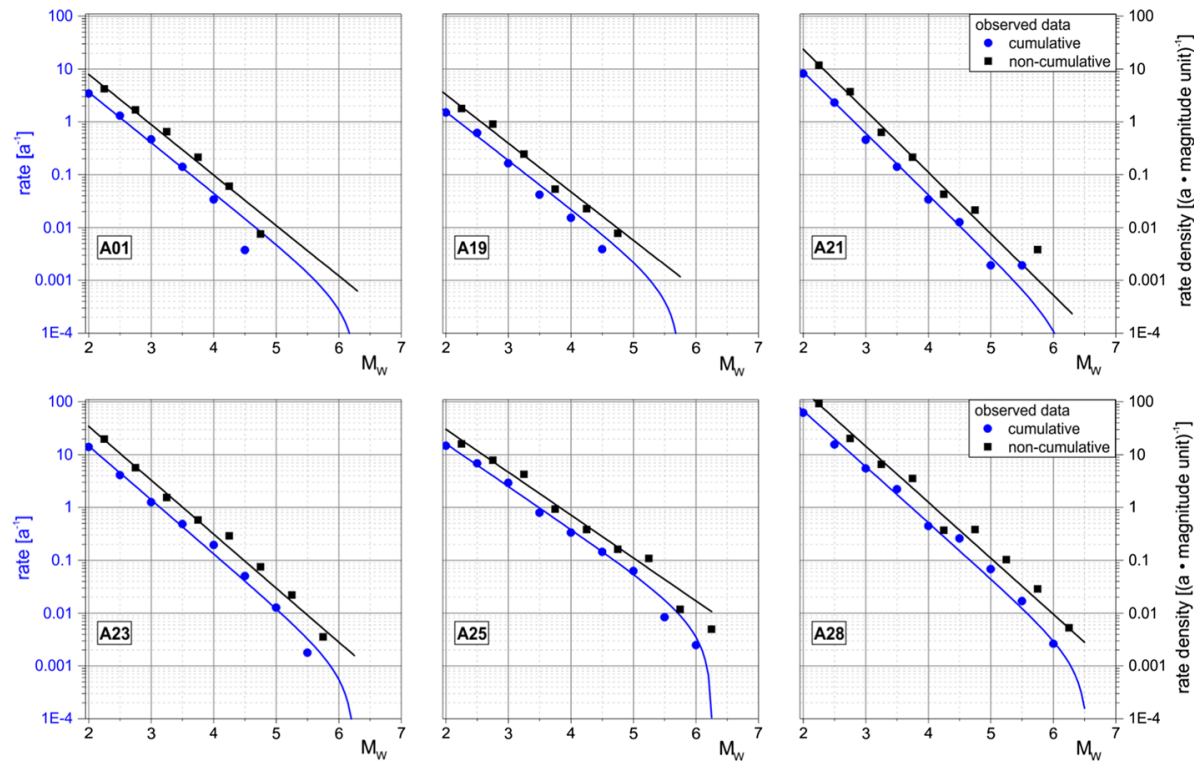

Fig. 13 Selected magnitude-frequency graphs of six SSZ of model A. Non-cumulative graphs represent rate density normalized to magnitude unit

Barth et al. (2015) described that difference for the URG as well. Both papers discuss possible reasons. As illustrated in the figure, the smaller magnitude events reflect basically the frequency of occurrence of more modern instrumental earthquakes, while the larger ones represent mainly historical earthquakes. Maximum likelihood estimates are driven by the numerous smaller magnitude events, which would lead to an underestimate of the rate of larger magnitude events with respect to the catalogued data, in case their rates do not fit with those of the many small magnitude events. Assuming an exclusive log-linear relation of the rates also for these SSZs these uncertainties are treated as two logic tree branches: one branch takes into account all data and another one uses a fit to the data for the larger magnitudes. As it is clearly shown in Fig. 14, the uncertainty in fitting all data is much smaller than for the case when the minimum for the fit is set at larger magnitudes. About $35 \%$ of the SSZ allow the described differentiation in performing the fit to the data. Otherwise, the minimum magnitude for the fit at small $M$ is used for both branches of the LT. The example in Fig. 14 shows one of the most striking differences in the fit to small and larger magnitudes. With respect to the explicit parameters $a$ and $b$ for each SSZ and for both types of fit, we refer to the accompanying report. There both values are provided together with the parameters of the covariance matrix as a measure of uncertainty for the different $M_{\max } i$ per zone for all five models and for the two different versions of the minimum for fit.

\subsubsection{Seismicity rates of composite seismic sources (CSS)}

The slip rates at the different fault segments of the CSS model were derived by Vanneste et al. (2013) from geologically based long-term vertical displacements. They are rather low and connected with relatively large uncertainties. As we do not know which portion of the slip is released aseismically and which portion in the form of seismic events, we did not 
Table 4 Parameters $a$ and $b$ of the magnitude frequency relation for the 18 common $b$ superzones

\begin{tabular}{llllc}
\hline Common $b$ superzones & $b$-value & $a$-value & Normalized $v(4.0)$-value & Number of events for fit \\
\hline 1 & $0.80 \pm 0.04$ & $2.85 \pm 0.17$ & 0.054 & 185 \\
2 & $0.95 \pm 0.08$ & $2.49 \pm 0.24$ & 0.004 & 88 \\
3 & $0.83 \pm 0.05$ & $2.45 \pm 0.14$ & 0.130 & 120 \\
4 & $1.01 \pm 0.03$ & $3.52 \pm 0.09$ & 0.012 & 305 \\
5 & $0.78 \pm 0.03$ & $2.27 \pm 0.09$ & 0.454 & 223 \\
6 & $1.05 \pm 0.06$ & $2.96 \pm 0.17$ & 0.440 & 135 \\
7 & $0.93 \pm 0.07$ & $2.06 \pm 0.20$ & 0.020 & 98 \\
8 & $0.92 \pm 0.03$ & $2.71 \pm 0.09$ & 0.198 & 546 \\
9 & $1.16 \pm 0.05$ & $3.70 \pm 0.12$ & 0.004 & 369 \\
10 & $1.07 \pm 0.04$ & $3.34 \pm 0.12$ & 0.415 & 304 \\
11 & $1.02 \pm 0.03$ & $3.59 \pm 0.07$ & 0.128 & 718 \\
12 & $0.81 \pm 0.02$ & $3.10 \pm 0.07$ & 0.608 & 638 \\
13 & $0.73 \pm 0.03$ & $2.74 \pm 0.13$ & 0.492 & 366 \\
14 & $0.98 \pm 0.02$ & $3.53 \pm 0.05$ & 0.623 & 902 \\
15 & $1.06 \pm 0.01$ & $4.34 \pm 0.03$ & 0.836 & 3752 \\
16 & $0.81 \pm 0.04$ & $2.32 \pm 0.10$ & 0.238 & 188 \\
17 & $0.80 \pm 0.04$ & $3.35 \pm 0.18$ & 2.099 & 93 \\
18 & $0.89 \pm 0.04$ & $4.34 \pm 0.19$ & 3.779 & 210
\end{tabular}

The parameters are derived for the middle of the five individual $M_{\max }$ values of each superzone. The cumulative seismicity rate $v(4.0)$ is area-normalized (per $10,000 \mathrm{~km}^{2}$ ) to compare the superzone activity

convert slip rates to activity rates. Instead, we relate the seismicity of events with $M_{w} \geq 5.3$ to the $3 \mathrm{D}$ planes of CSSs according to the observed rates of the corresponding catchment sub-areas. The calculation of the seismicity rates is performed also according to the method by Stromeyer and Grünthal (2015). The distribution of the seismicity rates to the individual faults is assumed to be proportional to their length while preserving the overall rate. This approach combines each of the five $M_{\max }$ dependent areal rates with the respective set of maximum magnitudes of the faults that means the $M_{\max , i}$ of the catchment area with the $M_{\max , i}$ of the respective CSS. The occurrence of smaller magnitude earthquakes is assumed as equally distributed seismicity within the respected catchment subareas.

\section{Challenges and strategy to select a set of GMPEs}

The prediction of ground-motion in low-to-moderate seismicity areas like Germany and the consideration of the epistemic uncertainty is challenging due to the lack of strongmotion data (PEER 2015). This leaves us with two options: the development of stochastic ground-motion models derived from weak motion analysis (e.g. Drouet and Cotton 2015; Edwards et al. 2016) or the selection of models calibrated on data from other regions of the world (Cotton et al. 2006). The second option was, however, the only possible choice since high-quality weak-motion databases are not available yet in Germany. The selection of GMPE calibrated on data from other regions was driven by three motivations: the 

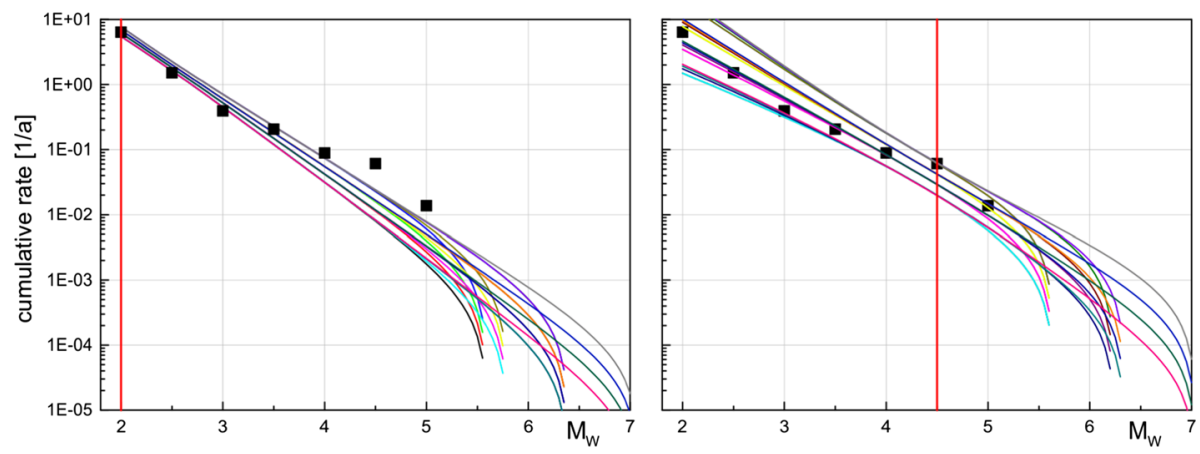

Fig. 14 MLE of the frequency-magnitude parameters taking into account $M_{w} \geq 2.0$ (left) and fitting to the magnitude classes $M_{w} \geq 4.50$ (right) respectively for the source zone URG

consistency between the GMPE host regions and the German tectonic regime, the results of recent GMPE testing and the particular needs of our hazard approach.

The tectonic context, as described in Sect. 3, is complex with active structural elements mainly along the chain of the Rhine up to rather stable parts towards the north and northeast. While formerly such regionalization processes were mainly based on hardly reproducible expert judgements (e.g. Delavaud et al. 2012), we employ more objective and replicable data-driven methodologies (Chen et al. 2016). The results of these data-driven regionalization schemes corroborate the suggestion that the area of Germany displays attenuation properties that are similar to those of active crustal regions. However, the seismic activity is low, which makes it difficult to predict future properties of major earthquakes. The key parameter in this context then is the stress drop, which controls the high-frequency content of ground motions (Cotton et al. 2013). Stress-drop analyses of earthquakes within or close to the target area are rare because of the scarce seismicity. Some quakes recorded in Western Europe, like Saint Dié (2003, $M_{w}=4.8$, eastern France) or Market Rasen $\left(2008, M_{w}=4.5\right.$, UK) have, however, shown stress-drop values (Scherbaum et al. 2004a; Rietbrock et al. 2013) that are larger than the average observed in active parts of Europe. This analysis then favours the use of models from active crustal regions (in terms of attenuation) with the need to take into account a large epistemic uncertainty associated to future stress-drops.

The number of recordings of small-to-moderate earthquakes has increased in northwest and western Central Europe in the last decade. Several authors have then been taking advantage of these weak motions to test and select respective GMPEs (Beauval et al. 2012; Drouet and Cotton 2015; Rietbrock et al. 2013; Edwards and Fäh 2013). These testing results confirm that ground-motion models according to active crustal regions should be considered for hazard evaluations in Germany.

The selection of GMPEs was finally driven by the particular needs of our hazard approach:

- The hazard computed at a given location depends on both the seismic source model and on the ground motion model. Preliminary deaggregation results and earlier German seismic hazard projects have shown that the hazard results are mainly controlled by ground-motion due to moderate earthquakes 4.5-5.5 located at short distances (below $25 \mathrm{~km}$ ). Regional variations of ground-motions are mostly observed for distances larger than 50-60 km (e.g. Boore et al. 2014; Kotha et al. 2016). The deaggregation 
results show that the magnitude scaling of ground-motion in the magnitude range 4.5-6.5 is critical-a criterion that was part of the GMPE selection process.

- A problem often encountered in the application of recent GMPEs based on complex functional forms (e.g. NGA-West 2) is also related to the availability of suitable metadata in the target region. In low to moderate seismic regions the source and site characterizations are generally not as detailed as in the data set used to derive the GMPE (host region). In such cases, the GMPEs are applied in simplified forms, where one or more variables (e.g. basin depth, hanging wall foot wall effects) are constrained to default values. This operation should be accompanied by either a proper handling of the epistemic uncertainty introduced when fixing some variables, or by propagating the uncertainty to the aleatory component (Bommer et al. 2005). Both choices imply some additional work and tricky expert decisions. We therefore have chosen to favour models derived with simple functional forms and to develop a new model calibrated on the NGA-West 2 database since such simplified "NGA-West 2" functional form was not available (Bindi et al. 2017).

\subsection{A logic tree built to capture three types of uncertainties: dataset, functional form and stress-drop}

Given the results of recent testing in Western Europe and the tectonic context discussed above, the logic tree is based on active shallow crustal earthquake ground-motions models and the need to take into account sources of three main epistemic uncertainties:

- empirical models are dependent on the selected databases used to calibrate the models;

- empirical models depend on the developers functional form choices;

- average stress-drops may be larger in the stable (non-cratonic) part of Europe compared to active regions where the models have been developed.

\subsection{New high-quality ground-motion datasets}

During the course of this national hazard project, several high quality strong-motion datasets became available: the RESORCE European and Middle East Reference database for seismic ground-motions in Europe (Akkar et al. 2014; Douglas et al. 2014a) and the NGA-West2 dataset (Ancheta et al. 2014; Gregor et al. 2014). A major update of the broadband (mainly Japanese based) model of the Cauzzi and Faccioli (2008) model was also published (Cauzzi et al. 2015).

Key improvements of these recent databases are the increase in the number of records from moderate-magnitude events $(M<5)$, the high quality of the metadata associated with these earthquakes and the homogeneous processing of both large and moderate earthquakes. These new datasets offer a new opportunity to capture the magnitude scaling of ground-motion for $M_{w}$ between 4.5 and 6.5, which is precisely the magnitude target of seismic hazard assessments of countries like Germany. This better data-coverage of moderate magnitude earthquakes is important since several studies (e.g. Cotton et al. 2008) have shown that ground-motion models derived from large-magnitude datasets will tend to overestimate the ground motion from small and moderate earthquakes.

Recent analyses (Boore et al. 2014; Kotha et al. 2016) have shown that regional variations of ground-motions of active shallow earthquakes may be significant only for distances larger than 50-60 km. Most of the hazard in Germany is driven by events in short- 
to-moderate distances and, therefore, models derived from these three databases are acceptable. They have different strengths: the European RESORCE records may be more representative of future German ground-motion because of a closer tectonic similarity. The NGA-west database is, however, more complete at short distances $(R<20 \mathrm{~km})$. Japanese stations have all measured soil $v_{S 30}$. Soil and rock stations have been correctly identified which may contribute to a better evaluation of site responses at the $v_{S 30}=800 \mathrm{~m} / \mathrm{s} \mathrm{target}$. We then have chosen to select models based on these three databases and give half of the total weight (0.5) to the European (RESORCE) branch. Equal weights $(0.25)$ were assigned to the Japanese and NGA-west-2 branches.

\subsection{Taking into account functional form variations}

Despite all the developers having started with a same common strong-motion archive, the predicted spectral accelerations from the models usually show significant differences, which can be related to varying data selection criteria but also modellers choices. For example and as discussed by Bindi et al. (2017), some NGA-West 2 models have chosen functional forms with a magnitude hinge around $M_{w}=5.5$. Such choice has a low impact on hazard computations in high seismicity regions but a larger one in moderate seismicity regions. Selecting models based on multiple approaches is, however, a way towards more effectively capturing epistemic uncertainty in terms of the centre, the body and the range of technically-defensible interpretations of the available data (USNRC 2012). The main "European" branch of the logic tree includes for this reason two models based on the classical random-effects approach (Akkar et al. 2014; Bindi et al. 2014) but also a model based on the neural-network, data-driven and calibration method (Derras et al. 2014). Equal weights were assigned to these three.

\subsection{Taking into account stress-drop uncertainties}

The final stage of developing our logic-tree concerning ground-motions was to apply scaling factors to the selected equations in order to capture epistemic uncertainty due to stress-drop. Such final logic-tree branches have been adopted by the recent ground-motion logic trees developed in moderate seismicity region like Switzerland (Edwards et al. 2016) and South Africa (Bommer et al. 2015).

It could be shown by Bommer et al. (2015) that changing of stress drop results in relatively constant changes in the ground-motion amplitudes across ranges of magnitude and response periods. The only departures from this constant scaling occur for long response periods and small earthquakes. Given that the dominant scenarios identified in deaggregation of the hazard at longer response periods are typically associated with larger magnitudes, it seems reasonable to adopt constant scaling factors across all periods. This assumption renders the amplitude-scaling process transparent, simple and predictable.

Bommer et al. (2015) have also selected «host» models from active crustal regions and they have considered that the stress-drops of these «host» regions were around 8-10 MPa. Such a value is consistent with our recent analysis (Bora et al. 2017) of European stressdrops. For the target region (South Africa), the values were inferred from an extensive literature review of values used for the development of hybrid-empirical and stochastic GMPEs in SCRs, which are generally higher. As discussed above, the potential for higher values of stress-drop in the stable part of Europe (non-cratonic and cratonic) is consistent with stress-drop analyses (Scherbaum et al. 2004a; Rietbrock et al. 2013) of a couple of European earthquakes like Saint Dié (2003) and Market Rasen (2008). However, our recent 
analysis of the European, large stress-drops of $M>4$ crustal earthquakes (Bora et al. 2017) does not indicate clear regional variations of stress-drops in Europe. The origin of "energetic" earthquakes (Baltay et al. 2011) is then still unclear.

We finally have chosen scaling factors greater than unity (1.0, 1.25 and 1.5) similar to the one chosen by Bommer et al. (2015). A branch was also added for potentially lower values (with a scaling factor of 0.75) given that part of Germany, unlike most stable continental regions, is under an extensional tectonic regime. The amplitude scaling factors of 1.25 and 1.5 roughly correspond to factors related to the stress drop of about 1.5 and just over 2, respectively. Starting with nominal native stress drops of around 8-10 MPa for the models means that the amplitude scaled models represent median stress drop levels from around $6 \mathrm{MPa}$ to just over $20 \mathrm{MPa}$. This LT scheme is considering a slightly larger epistemic uncertainty compared to the one adopted recently by Edwards et al. (2016) in Switzerland. Their logic tree branches show values between 5 and $9 \mathrm{MPa}$ for deep $(H>6 \mathrm{~km})$ events located in the foreland. Lower stress-drop values and larger ranges of uncertainty have been chosen for shallow events (values between 1 and $7.5 \mathrm{MPa}$ ).

The chosen weighting is symmetric and reflects the belief that stress-drops (and associated ground-motions) may be higher in Germany than in the more active tectonic regions from which the ground-motion models were selected: weights of 0.36 have been given to the factors 1.00 and 1.25 , smaller weights $(0.14)$ to the outer branches representing the factors 0.75 and 1.5 .

\subsection{Selected GMPEs and their model parameters}

In summary, the RESOURCE data branch of the logic tree is represented by the models of Akkar et al. (2014), Bindi et al. (2014) and Derras et al. (2014). The NGA-West-2 database branch is considered by the GMPE of Bindi et al. (2017) and the mainly Japanese based data by Cauzzi et al. (2015). Starting from the NGA-West 2 flat-file (Ancheta et al. 2014), the Bindi et al. (2017) model proposes a model tailored to hazard application in moderate and low seismicity areas in terms of data selection and implemented functional form (e.g. development of pairs of equations, one using an extended-source distance metric, the other a point-source measure). The complexity of the considered functional form is reflecting the availability of information in moderate seismicity areas like Germany, avoiding the a priori assumption of not-known variables (e.g. in the source characterization or in the site effect description), which would require the refinement of the aleatory variability. The parameters of the selected GMPE, which are of importance in the PSHA are summarized in Table 5. To them belong the range of $M_{w}$ to which the GMPEs are applicable, their covered distance ranges, the considered distance metrics, the considered components of ground motion, the specification of tectonic regimes, the range of parametrized spectral periods and if parameters for PGA are given.

The main use of areal sources in our approach requires the preference of the hypocentral distance $r_{\text {hypo }}$ as distance metric. Three of the five selected GMPE can consider $r_{\text {hypo }}$ as distance metric. The parameters $r_{J B}$ and $r_{r u p}$ of the other two GMPEs were transformed into $r_{\text {hypo }}$ according to a procedure of Scherbaum et al. (2004b), which had to be modified for a better numerical handling. This modification is described in Grünthal et al. (2009a). 
Table 5 Parameters of selected GMPE

\begin{tabular}{|c|c|c|c|c|c|c|c|}
\hline References & $\begin{array}{l}\text { Range of } \\
M_{w}\end{array}$ & $\begin{array}{l}\text { Range of } R \\
(\mathrm{~km})\end{array}$ & $\begin{array}{l}\text { Distance } \\
\text { metric }^{a}\end{array}$ & $\begin{array}{l}\text { Tectonic } \\
\text { regime }^{c}\end{array}$ & Component & $\begin{array}{l}\text { Range of } \\
T \text { (s) }\end{array}$ & PGA \\
\hline $\begin{array}{c}\text { Akkar et al. } \\
(2014)\end{array}$ & $4.0-7.6$ & up to 200 & $\begin{array}{c}\text { epi, JB, } \\
\text { hypo }\end{array}$ & $\mathrm{N}, \mathrm{R}, \mathrm{S}$ & $\begin{array}{c}\text { geometric } \\
\text { mean }\end{array}$ & $0.01-4.0$ & given \\
\hline $\begin{array}{l}\text { Bindi et al. } \\
\text { (2014) }\end{array}$ & $4.0-7.7$ & up to 300 & JB, hypo & $\mathrm{N}, \mathrm{R}, \mathrm{S}, \mathrm{U}$ & $\begin{array}{c}\text { geometric } \\
\text { mean }\end{array}$ & $0.02-3.0$ & given \\
\hline $\begin{array}{l}\text { Derras et al. } \\
(2014)\end{array}$ & $4.0-7.0$ & $5-200$ & $\mathrm{JB}^{\mathrm{b}}$ & $\mathrm{N}, \mathrm{R}, \mathrm{S}$ & $\begin{array}{l}\text { geometric } \\
\text { mean }\end{array}$ & $0.01-4.0$ & given \\
\hline $\begin{array}{l}\text { Bindi et al. } \\
\text { (2017) }\end{array}$ & $3.0-7.9$ & $4-300$ & JB, hypo & $\mathrm{U}$ & $\operatorname{RotD} 0^{\mathrm{d}}$ & $0.01-4.0$ & given \\
\hline $\begin{array}{l}\text { Cauzzi et al. } \\
\text { (2015) }\end{array}$ & $4.5-7.9$ & up to 150 & rup & $\mathrm{N}, \mathrm{R}, \mathrm{S}$ & $\begin{array}{l}\text { geometric } \\
\text { mean }\end{array}$ & $0.01-10.0$ & $0.01 \mathrm{~s}$ \\
\hline
\end{tabular}

a epi: epicentral distance, JB: Joyner-Boore distance, hypo: hypocentral distance, rup: rupture distance

${ }^{\mathrm{b}}$ Conversion to hypocentral distance

${ }^{\mathrm{c}} \mathrm{N}=$ normal, $\mathrm{R}=$ reverse, $\mathrm{S}=$ strike slip, $\mathrm{U}=$ unspecified

${ }^{\mathrm{d}}$ Median single-component horizontal ground motion across all non-redundant azimuth

\section{Logic tree for epistemic model parameters characterizing seismic source zones}

The handling of epistemic uncertainties of the models, with their parameters characterizing each SSZ, described in Sects. 5 and 6, is performed as an extension of our logic tree and illustrated in Fig. 15. The first branching level of this continuation concerns the differentiation of the minimum magnitude for fitting to calculate the seismicity rates (cf. Sect. 5.2). We give the fitting to the larger magnitudes (with higher rates for the clear majority of cases; cf. Grünthal et al. 2017) the weight of 0.8 and the adaptation to all data with a low minimum magnitude only a weight of 0.2 ; i.e. we model the seismic hazard in a way to give the historically constraint higher rates of earthquakes with larger magnitudes a higher expectation than would be predicted from the recently observed seismicity dominated by small magnitude events. Or in other words, the given significant difference in weighting reflects our view that the larger events with engineering relevance would rather occur with similar yearly rates as they were observed in the past than with rates extrapolated from small and mostly modern earthquakes. We are, however, aware of the uncertainty connected with this choice in weighting. Deliberately, we avoided to model this epistemic uncertainty in weighting, since the fitting to larger magnitude classes is already related with a considerable uncertainty in deriving the frequency-magnitude parameters (cf. Fig. 14).

The next branching level concerns the discretization of the PDF of $M_{\max }$ into five values $M_{\max , i}$ of equal weight of 0.2. Each $M_{\max , I}$ is combined with the four discretized distributions of seismic rates, with the weights derived in Sect. 5.2.

The following set of branching levels considers the handling of GMPE, whose selection is described above in Sect. 6. First, we differentiate the principle data source of GMPEs with European-Middle East data with the weight of 0.5. Global and Californian recordings, specifically the NGA2-West data (Ancheta et al. 2014), were represented by the GMPE of Bindi et al. (2017) and given a weight of 0.25. The same weight is given to the other global data set with the focus on Japanese recordings with the respective GMPE by Cauzzi et al. 


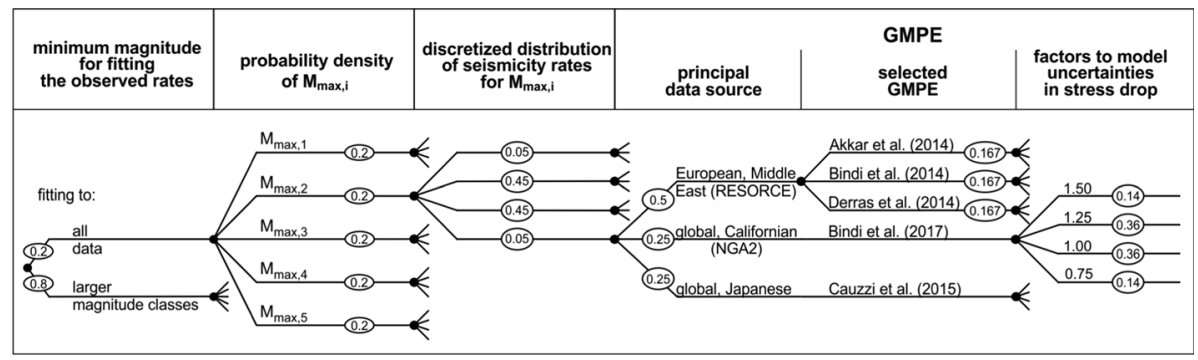

Fig. 15 Logic tree (continued) for each seismic source for handling the epistemic uncertainties in the considered models and parameters. The weights of the branches are given in respective ellipses

(2015). Concerning the European-Middle East data we have selected the GMPEs of Akkar et al. (2014), Derras et al. (2014) and Bindi et al. (2014) as additional branches with equal weights of 0.167 each. In the final branching level, each of the five selected GMPEs is then connected with a variation of expected stress drop, which is modelled in form of four branches representing respective factors and weights as already described above in Sect. 6.

Altogether the combined logic tree contains 4040 final branches; five source zone models, plus the two zoneless models combined with the 20 GMPE branches. Each seismic source is modelled with four rate models in combination with five $M_{\max , i}$ yielding 20 branches, plus two branches of the minimum for fitting the observed yearly rates of magnitudes, five GMPEs combined with four variants characterizing the uncertainties in stress drop, which results in 800 branches. We use the entire LT as it is presented; i.e. we do not allow any pruning of the LT for the hazard calculations.

\section{Parameters with aleatory uncertainty: the hazard integral}

The parameters of SSZ characterized by aleatory variabilities are subject of the hazard integral over the density functions of magnitudes $m$, distances $r$ and focal depths $h$; ground motion variability $\varepsilon$ as well as tectonic regimes $t r$.

$$
\begin{aligned}
P[A \geq a \mid m, r, h, \varepsilon, t r]= & \int_{h_{\min }}^{h_{\max }} \int_{0}^{r_{\max }} \int_{m_{\min }}^{m_{\max }} \int_{\varepsilon_{\min }}^{\varepsilon_{\max }} \int P[A \geq a \mid m, r, h, \varepsilon, \operatorname{tr}] f_{T R}(t r) f_{E}(\varepsilon) f_{M}(m) f_{R}(r \mid h) f_{H}(h) \\
& d F_{T R}(t r) d \varepsilon d m d r d h
\end{aligned}
$$

Features of these integration ranges and density functions are given as follows.

\subsection{Magnitude}

The density function of seismicity rates (cf. Sect. 5.2) is integrated from a minimum magnitude $M_{\min }$ up to $M_{\max }$ (cf. Sect. 5.1) in increments of 0.05 magnitude units. A pragmatic choice of $M_{\min }$ was often to adapt the lower common validity range of magnitude for the applied GMPE, which was in many cases $M_{w} 4.5$.

Our rationale for choosing $M_{\min }$ is, according to McGuire (2004), based on the intensity threshold of engineering relevance, which is $I=5-6$. This is also the lower limit of seismic zones of the current building code (DIN EN 1998-1/NA 2011). The corresponding 
magnitude would be $M_{w}=4.3$ according to the master event relation in Grünthal et al. $\left(2009\right.$ c) under consideration of minus $1 \sigma$ as safety margin. Therefore, $M_{\min }=4.3$ is applied in our PSHA.

\subsection{Distance}

The integration over the areal distribution of randomly distributed seismic activity within each seismic source zone was accomplished according to the validity ranges of distances of the five selected GMPEs (cf. Table 5). Therefore, we use $200 \mathrm{~km}$ as upper limit, although one of them has a lower scope of application of $150 \mathrm{~km}$ only. We apply 20 steps for integration per area source and a $5 \mathrm{~km}$ increment along the faults.

\subsection{Discretized focal depth density functions}

The focal depth of an earthquake is a sensitive parameter in PSHA (Grünthal and Wahlström 2001). It appears as aleatory variability (Bommer et al. 2005) in form of a probability distribution function in the hazard integral. The used earthquake depth distributions are based on a statistical analysis of the seismicity database of the study area. We restricted
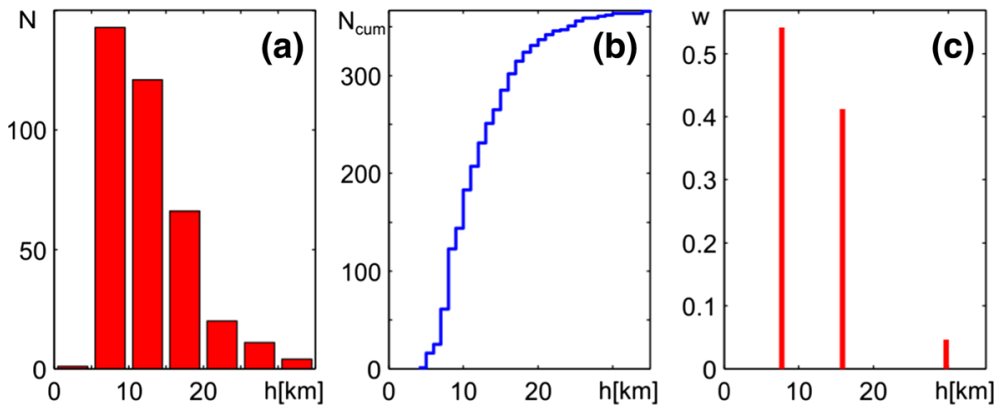

Fig. 16 Earthquake depth distribution of the study area: a binned depth frequency $N$, b cumulative frequency $N_{\text {cum }}$ and c weights $w$ of frequency distribution discretized at three optimally selected sampling depths (Miller and Rice 1983)

Table 6 Sampled depths distribution for each DSZ at three optimally selected depths with their corresponding weights

\begin{tabular}{llllllll}
\hline DSZ & LASZ (model A) & \multicolumn{7}{c}{ Depths $(\mathrm{km})$} & \multicolumn{7}{l}{ Weights } \\
\hline 1 & A09, A05, A04, A01, A10, A06, A03, A02 & 9.6 & 19.5 & 32.0 & 0.421 & 0.376 & 0.203 \\
2 & A21, A30, A15 & 5.2 & 13.4 & 23.1 & 0.309 & 0.470 & 0.221 \\
3 & A12, A17, A22 & 7.7 & 13.7 & 20.9 & 0.513 & 0.338 & 0.149 \\
4 & A27, A28, A29 & 6.3 & 10.6 & 16.2 & 0.341 & 0.446 & 0.213 \\
5 & A11, A23, A14, A13, A19, A16, A24, A20, A18 & 8.0 & 16.4 & 32.7 & 0.603 & 0.333 & 0.064 \\
6 & A25 & 7.6 & 12.4 & 28.6 & 0.672 & 0.306 & 0.022 \\
7 & A31 & 6.4 & 11.7 & 17.6 & 0.327 & 0.490 & 0.183 \\
8 & A26 & 7.3 & 14.4 & 24.2 & 0.467 & 0.442 & 0.091 \\
9 & A07, A08 & 8.5 & 15.5 & 23.9 & 0.261 & 0.486 & 0.253 \\
\hline
\end{tabular}


this analysis on events with $M_{w} \geq 4$, where 367 of them have a focal depth entry with depths less than $35 \mathrm{~km}$. There are additional five events (with $M_{w} \leq 4.5$ ) at the northern border of our catchment area $\left(57.2^{\circ}<\right.$ lat $<57.9^{\circ} ; 6.4^{\circ}<$ lon $\left.<8.3^{\circ}\right)$ with focal depths of $40-80 \mathrm{~km}$, which are not used. Figure 16 shows the depth frequency distribution binned in classes of $5 \mathrm{~km}$ for the study area, the corresponding cumulative distribution and an optimally generated discrete distribution (Miller and Rice 1983) for three sampling points. The application of this method avoids the subjective choice of binning classes.

The number of known depth values is not sufficient to determine a separate distribution for each of the sources in the different models. Appropriate LASZ of model A are combined according to tectonic constraints to define nine respective superzones with their specific depth distributions (cf. Sect. 4.2, Fig. 7d and Table 1, which shows which of the LASZs of model A build the respective superzones). Table 6 provides the parameters of each superzone as a discrete distribution sampled at three depth values. No magnitude dependence could be found, probably due to the small relevant magnitude range above $M_{w}$ 4 according to the low to moderate seismic activity of the study area. Corresponding assignments for the other models B-E are generated by matching their areas to the areas of the depth superzones of model A.

\subsection{Limitation of the ground-motion residuals}

The integration over the ground-motion residuals of a GMPE requires a truncation of the respective lognormal distribution. It is now common to have ground-motion data points with at least three standard deviations $(3 \sigma ; \varepsilon=3)$ above the logarithmic mean (Bommer et al. 2004). Therefore, this could be one reason for the limitation at $\varepsilon_{\max }=3$, as it is used e.g. by Woessner et al. (2015). Another rationale would be tests to check, what values of $\varepsilon_{\max }$ would result in calculated load parameters, which would be sufficiently near to the case that no truncation at all is applied. As it is well known, the transfer from $\varepsilon_{\max }=2$ to $\varepsilon_{\max }=3$ yields a significant growth of amplitudes. We took then calculations for $\varepsilon_{\max }=6$ as a de facto upper bound, where the portion beyond is, with only $1.973 \mathrm{ppb}$, vanishingly small. In case of a PGA based hazard curve for Cologne, the deviation of the $\varepsilon_{\max }=4$ curve from the one for $\varepsilon_{\max }=6$ is for PGA $\leq 0.5 \mathrm{~m} / \mathrm{s}^{2}$ smaller than $0.035 \%$ and for $\mathrm{PGA}=1.0 \mathrm{~m} / \mathrm{s}^{2}$ just $0.097 \%$. The corresponding deviation of the $\varepsilon_{\max }=3$ curve from the one for $\varepsilon_{\max }=6$ is for PGA $\leq 0.5 \mathrm{~m} / \mathrm{s}^{2}$ in this case smaller than $0.72 \%$ and for $\mathrm{PGA}=1.0 \mathrm{~m} / \mathrm{s}^{2}$ only $1.78 \%$. Therefore, we concluded that we have a sufficient saturation already with the usage of $\varepsilon_{\max }=3$. To conserve the median of respective GMPE, we perform the truncation symmetrically; i.e. the integration limits are $-\varepsilon_{\max }$ and $+\varepsilon_{\max }$.

\subsection{Tectonic regime}

Four of the five GMPEs used in this study differentiate the tectonic regime by an appropriate style-of-faulting coefficient. Only Bindi et al. (2017) leaves it unspecified. Our assignment of the tectonic regime to the sources is based on the data of the World Stress Map (WSM) 2016 (Heidbach et al. 2016). 513 data records within the study area provide information on the tectonic regime, where we restrict us on the data with A-C qualities according to the latest WSM quality ranking scheme (Heidbach et al. 2016).

Similar to the depth distributions we defined eleven superzones characterizing the tectonic regime on the basis of the LASZ model A (cf. Sect. 4.2, Fig. 7e and Table 1, which show the zones of the model-A LASZs that are combined to the respective superzones). Table 7 shows the superzones of the tectonic regime as a combination of the LASZ 
Table 7 Combination of LASZs of model A to build eleven tectonic superzones TSZ

\begin{tabular}{lllll}
\hline TSZ & LASZ (model A) & Strike-slip & Normal & Thrust \\
\hline 1 & A09, A05, A04, A01, A10, A06, A03, A02 & 0.632 & 0.263 & 0.105 \\
2 & A21, A30, A15 & 0.571 & 0.214 & 0.214 \\
3 & A22 & 0.500 & 0.500 & - \\
4 & A27, A28, A29 & 0.538 & 0.299 & 0.167 \\
5 & A11, A23, A14, A13, A19, A16, A24, A20, A18 & 0.727 & 0.258 & 0.015 \\
6 & A25 & 0.816 & 0.053 & 0.132 \\
7 & A31 & 0.315 & 0.076 & 0.609 \\
8 & A26 & 0.520 & 0.080 & 0.400 \\
9 & A07, A08 & 0.594 & 0.250 & 0.156 \\
10 & A12 & 0.267 & 0.733 & - \\
11 & A17 & - & 0.750 & 0.250 \\
\hline
\end{tabular}

Weights of style-of-faulting for each TSZ according to the WSM database

model A, together with the percentage of different tectonic signatures statistically derived from the WSM data. A more qualitative impression is given by the tectonic sketch of Fig. 3.

We are aware that uncertainties of the chosen tectonic regime parameters may be significant. However, variations of the rupture mechanisms of earthquakes of up to $10 \%$ have an almost negligible effect on source zone based PSHA, especially in regions of low seismicity.

\section{Results of the PSHA}

The hazard calculations were accomplished for rock underground conditions, characterized by an average shear wave velocity of the upper $30 \mathrm{~m} v_{S 30}=800 \mathrm{~m} / \mathrm{s}$ for the hazard levels of occurrence, or exceedance probabilities, of 10,5 and $2 \%$ within 50 years, which correspond to the mean return periods $\mathrm{RP}=475,975$ and 2475 years. The horizontal 5\% damped Uniform Hazard response Spectra (UHS) were computed for the spectral range of periods $T$ of $0.02-3.0 \mathrm{~s}$, standardly for the weighted arithmetic mean of the logic tree, the median, the 84th and the 16th percentile. Seismic hazard maps were also generated for (1) the mean and the mentioned percentiles for selected horizontal 5\% damped spectral response accelerations (SRA) of the UHS, (2) for mean amplitudes of periods in the UHS representing the plateau, and (3) for peak ground accelerations PGA. Hazard maps in terms of (4) macroseismic intensities were also calculated for plausibility checking.

The hazard calculations were performed at nodes with a spacing of 0.1 times 0.1 geographic degrees, which corresponds to a grid of about 7 times $11 \mathrm{~km}$ in the middle part of the target area. Altogether, these are 6226 grid points within Germany plus a small belt around for technical reasons to generate the hazard maps. The latter are based on a 2Dinterpolation to receive $0.01 \times 0.01$ degree spacing. The seismic hazard was assessed with a modified version of the computer code FRISK88M (Risk Engineering 1997) for the seismic source zone based branches of the LT. On the basis of Woo (1996) we developed a 
code to compute the zoneless part, whose results were incorporated into the LT according to the formerly mentioned code.

\subsection{PSHA results at the grid points}

The basic hazard results are the occurrence or exceedance rates for each of the 4040 end branches of the LT for a given acceleration or site intensity at a grid point. Two examples are shown for the locations Aachen $\left(50.8^{\circ} \mathrm{N}, 6.1^{\circ} \mathrm{E}\right)$, and a local maximum of hazard near Gera $\left(50.8^{\circ} \mathrm{N}, 12.2^{\circ} \mathrm{E}\right)$ in form of a histogram and a distribution (Fig. 17).

For the histogram, the whole range of annual rates resulting from the LT was divided into 100 intervals. The distribution shows the cumulative weight of all end branches resulting in a rate less than or equal to a certain value versus that value. They are shown for PGA and RP $=475 \mathrm{a}$. The skewness of the resulting distributions becomes obvious. It is different for both locations. The positions of the respective values of the mean, median and the 84th percentile are marked. The relatively small difference between mean and median for Aachen is typical for the entire Rhine chain, SW Germany and most of the other areas, except for an area in eastern Thuringia with the centre near to Gera and low seismicity regions in central and northern Bavaria, where the difference between both parameters is particularly large because of remarkably pronounced epistemic uncertainties there.

Combinations of results, as shown in Fig. 17, for several given accelerations are derived from hazard curves for each grid point. Figure 18 shows a typical case for all percentiles from the 1 st, 2 nd, 3 rd, ... to the 99 th. The 50 th and the 84 th percentile as well as the mean are highlighted.

UHS are also shown for the city of Aachen as median, mean, 16th and 84th percentile for the three $\mathrm{RP}=475 \mathrm{a}, 975$ and $2475 \mathrm{a}$ (Fig. 19). To preserve the monotonicity of the data within the plateau part of the spectra, we used a monotone cubic spline interpolation. UHS are provided for each point within Germany via the portal established for the project (http://gfz-potsdam.de/EqHaz_D2016). The maximum amplitudes in the shown UHS occur
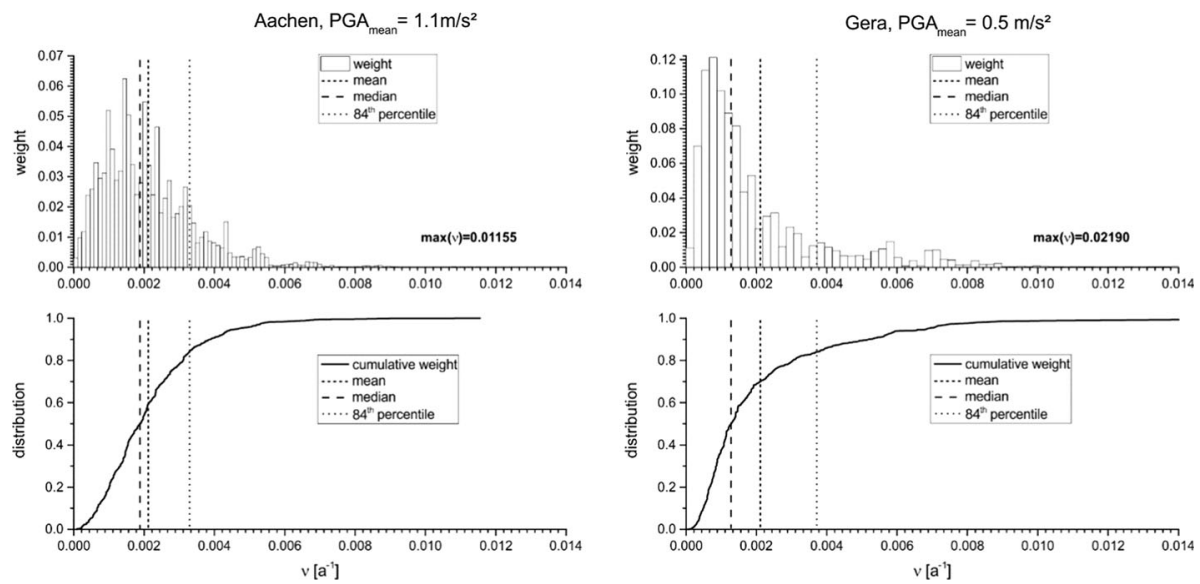

Fig. 17 Yearly rates $v\left[\mathrm{a}^{-1}\right]$ for each of the 4040 end branches of the logic tree as direct result of the PSHA for PGA for RP $=475$ a for the locations Aachen and Gera. Shown are the distributions of weights of rates in classes of $1 \%$ of the whole rate range filled by the LT with increasing rates. Below are the respective cumulative distributions. The positions of the values of mean, median and the 84th percentile on the rate axes are marked. The locations of Aachen and Gera are depicted in Fig. 3 
Fig. 18 Typical hazard curve; here for PGA for the location Cologne $\left(6.96^{\circ} \mathrm{E}, 50.94^{\circ} \mathrm{N}\right)$ for all percentiles from the 1 st up to the 99th. Median, mean and the 84th percentile are highlighted
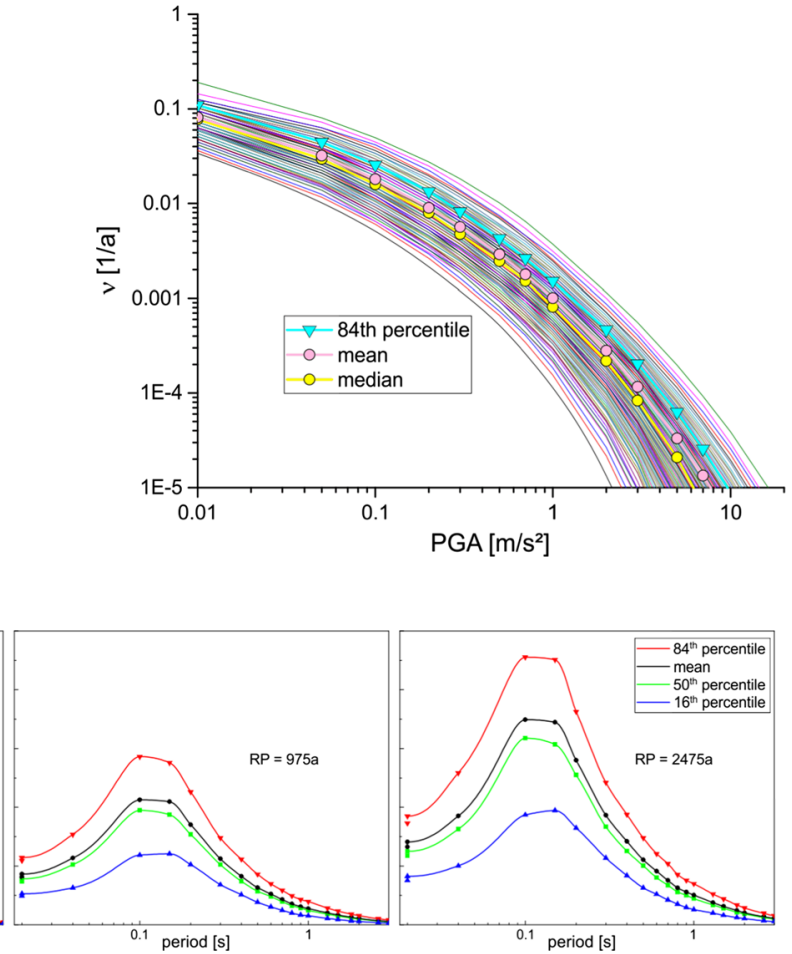

Fig. 19 UHS for the three hazard levels represented with RP $=475 \mathrm{a}, 975 \mathrm{a}$ and $2475 \mathrm{a}$ for the mean and the 16th, 50th and 84th percentile for Aachen

mostly at $T=0.1 \mathrm{~s}$ in areas of increased seismicity. A plateau is established, especially for the shown site, between 0.1 and $0.15 \mathrm{~s}$. However, these periods of maximum amplitudes in the UHS exhibit some variation among the grid points and the percentiles, as illustrated for the median and the mean (Fig. 20). These periods have values of $0.1,0.15$ and $0.2 \mathrm{~s}$ for the median (and cases where neighbouring periods are de facto the same) and 0.1 and $0.15 \mathrm{~s}$ for the mean. Maxima at the period $0.1 \mathrm{~s}$ are typical for the areas of increased seismicity. While the map for the periods of the median shows some scatter, this does not occur in the map for the mean. The maximum at the somewhat higher periods of $0.2 \mathrm{~s}$ occurs only for the median and especially in areas of very low seismicity due to dominating influence of more remote events. No periods are given for the northernmost parts with lowest seismic hazard because of the used lower threshold value of $0.01 \mathrm{~m} / \mathrm{s}^{2}$ for displaying results; i.e. the these parts of the map should not be misinterpreted that hazard could not be calculated there.

The fact that the maximum amplitudes are observed at different periods leads to the suggestion by the review teams to use the mean of the amplitudes at the periods of $0.1,0.15$ and $0.2 \mathrm{~s}$ [henceforth denoted as meanSRA $(0.1,0.15,0.2)$ ] for the code related maps, since only one map per hazard level should be implemented in the code, which represents periods of the plateau of the UHS. This suggestion has later been adopted by the respective committee of standardization. Since we attempted to consider epistemic uncertainties as much as possible according to our model, we also want to present the differences between 

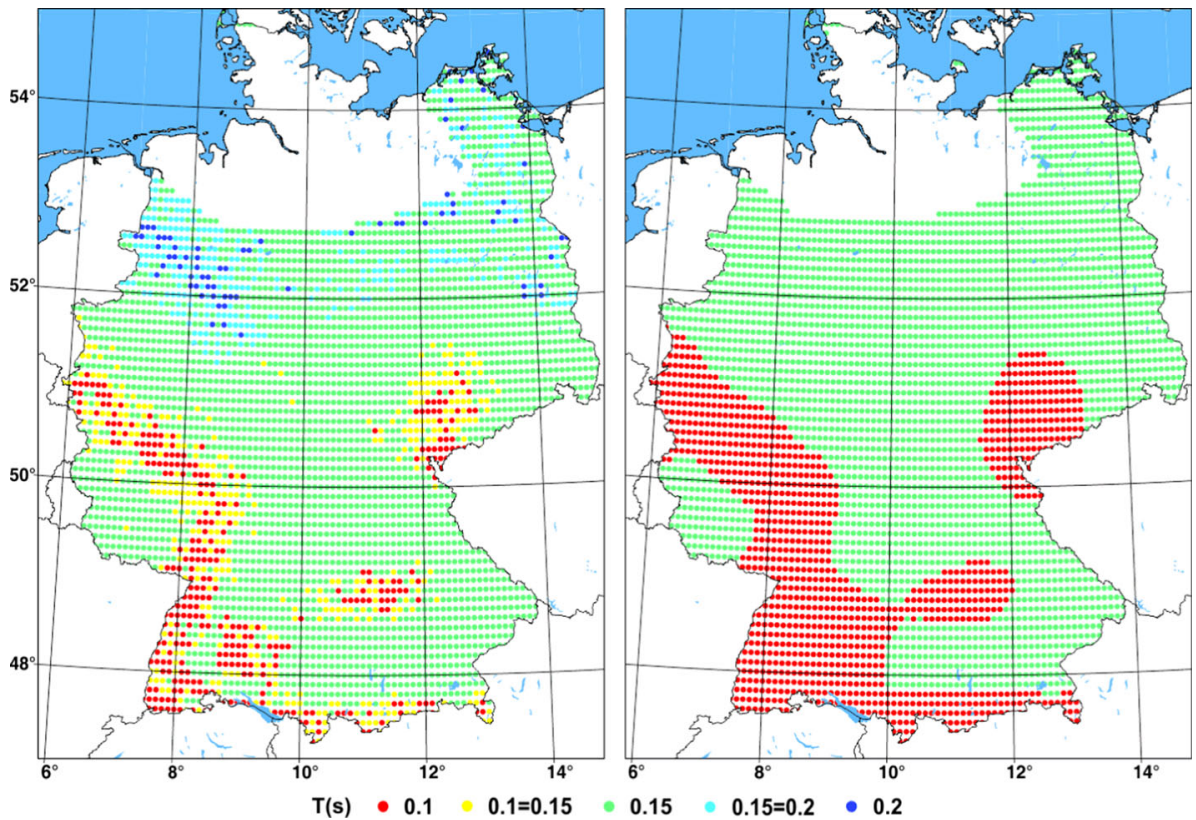

Fig. 20 Periods $\mathrm{T}$ at the grid points within Germany where the amplitudes in the UHS are maximally for the median (left) and mean (right). Somewhat lower periods are typical for the areas of increased seismicity. The scatter in $\mathrm{T}$ in the map of the median disappears for the mean

various percentiles; i.e. in particular the difference between the 84th and the 50th percentile. Corresponding quotient maps are discussed in the following subsection.

Important for engineering applications of UHS are the fittings of the calculated 19 spectral response amplitudes per grid point according to the Eurocode 8 (EC8) elastic response spectral shapes (CEN 2004) to generate the EC8 corner periods $T_{B}, T_{C}, T_{D}$ and the effective amplification factor, $F_{0}$, of spectral response acceleration. Weatherill et al. (2013) performed a similar study on the basis of the results by the project SHARE (Woessner et al. 2015). The adaptation to the EC8 elastic response spectra by means of the least square fit is rather stable because of the use of 19 spectral periods. Only the determination of $T_{D}$ can be connected with somewhat larger uncertainties. Figure 21 shows examples of such fittings for the centres of two given cities and the corresponding control parameters $T_{B}, T_{C}, T_{D}$ and $F_{0}$. The derived control periods $T_{B}, T_{C}$ and $T_{D}$ (cf. Fig. 21) are different from the parameters of the current German National Annex to EC8 (DIN EN 1998-1/NA 2011-1) for the subsoil class A-R with $F_{0}=2.5, T_{B}=0.05 \mathrm{~s}, T_{C}=0.2 \mathrm{~s}$ and $T_{D}=2.0 \mathrm{~s}$. The EC8 related elastic response spectra as in Fig. 21 are provided for each point within Germany via the portal established for the project (http://gfz-potsdam.de/ EqHaz_D2016). Exemplarily, the spatial variation of the parameter $F_{0}$ is illustrated in Fig. 22. $F_{0}$ takes values of 2.4-2.5 in areas of increased seismicity and can reach peaks up to 2.65. $F_{0}$ is less than 2.4 in areas of very weak seismicity. Concerning maps of $T_{B}$ and $T_{C}$ we refer to the accompanying material (Grünthal et al. 2017).

Deaggregations (McGuire 1995; Bazzurro and Cornel 1999; Harmsen et al. 1999) are another hazard product, which can be derived for each point and for each hazard parameter. They are an important instrument for understanding seismic hazard. Deaggregations represent multiple causal earthquake magnitude/distance values for a given SRA or PGA, 

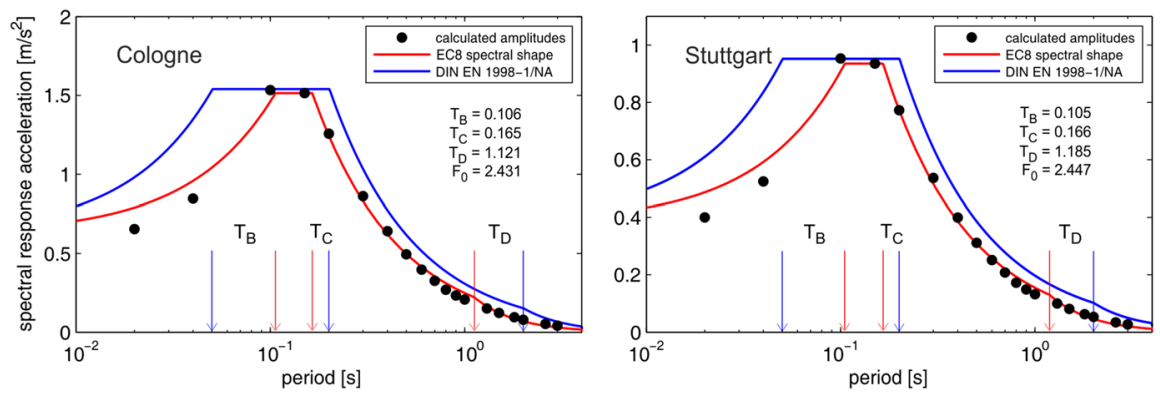

Fig. 21 EC8 related elastic response spectra fitted according to the calculated mean values of the 19 spectral response amplitudes for the hazard level of $\mathrm{RP}=475 \mathrm{a}$ as examples for the cities Cologne and Stuttgart. For comparison the corresponding response spectra of the current German National Annex to EC8 (DIN EN 1998-1 2011-01) for the subsoil class A-R

where the height of respective columns represents the contribution of such M/R combinations to the hazard at the respective SRA. Such data lead to tailored choices for design earthquakes and time histories. Two of the deaggregations are depicted in Fig. 23 for PGA of $\mathrm{RP}=475 \mathrm{a}$ for the cities Cologne and Karlsruhe. It becomes obvious that the considered hazard in Karlsruhe is mainly ruled by $M_{w} 4.5$ and 5.0 earthquakes in a short distance of 10-20 km; though, minor influence on the hazard comes also from a $M_{w}$ range of up to 6.0-6.5 events up to distances of $80-110 \mathrm{~km}$. On the contrary, the contributions to the hazard of Cologne are more complex. It is governed by a broader range of magnitudes $M_{w}$ 4.5-6.0 and distances of 10-40 $\mathrm{km}$ and with minor impact on the hazard ranging up to about $M_{w} 6.5$ events up to $100-110 \mathrm{~km}$. Such deaggregations are made available for selected towns of Germany via our portal (www.gfz-potsdam.de/EqHaz_D2016).

\subsection{Seismic hazard maps}

Seismic hazard maps were calculated for the considered SRA, for PGA, for the mean SRA amplitudes at $T=0.1,0.15,0.2 \mathrm{~s}$, as described above, and for the macroseismic intensity - and all these for the three hazard levels used for the study as well as for the median, the mean and the 84th percentile. A selection of them is presented here, additional ones are compiled in the accompanying technical report (Grünthal et al. 2017) and are accessible via our web portal.

The central hazard maps of the project, where our study is related to, are those of the weighted arithmetic mean according to the end branches of the LT for meanSRA (0.1, $0.15,0.2 \mathrm{~s}$ ) which basically represents the level of the plateau of the UHS. Figure 24 shows such maps for $\mathrm{RP}=475 \mathrm{a}, \mathrm{RP}=975 \mathrm{a}$ and for $\mathrm{RP}=2475 \mathrm{a}$. The largest seismic load parameters occur for the area around the zone of the HZA (with the highest seismic activity in terms of seismic energy release), the LRG, the NW part of the MRZ, the middle and southern part of the URG, and the southernmost rim of the study area bordering to the seismically rather active Austrian Alps. Seismic loads along the VLZ are modest. Our preference in using the maps of the mean hazard values follows the arguments of McGuire et al. (2005) and Musson (2005). Moreover, mean hazard maps are provided for other modern building codes, as, e.g. for the 2015 National Building Code of Canada (Adams et al. 2015) or for the new Italian building code (Meletti, pers. comm. 2017). 


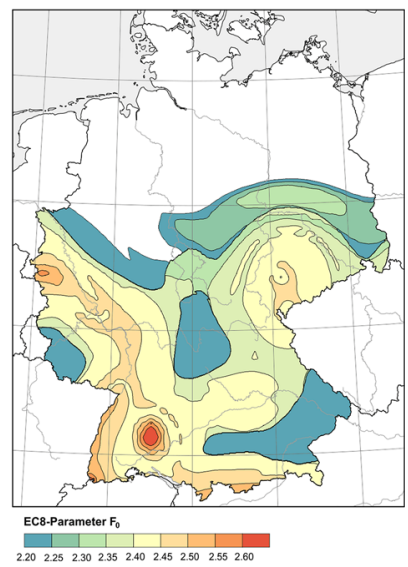

Fig. 22 Spatial variation of the effective amplification factor $F_{0}$ of spectral response acceleration for the hazard level of $\mathrm{RP}=475 \mathrm{a}$

Figure 25 displays the meanSRA maps for the 16th, 50th and the 84th percentile for $\mathrm{RP}=475 \mathrm{a}$. It is striking that the high load parameters for the HZA area do not show up in the 16th percentile map. This area remains inconspicuous here in comparison to the previously shown hazard maps. This means that the pendulum of uncertainties in the calculated hazard deflects here widely to lower seismic loads. The areal variation of uncertainties with its characteristics are illustrated in Fig. 26, where the meanSRA for $\mathrm{RP}=475 \mathrm{a}$ are shown for the following quotients of percentiles: $84 \mathrm{th} / 16 \mathrm{th}, 84 \mathrm{th} / 50 \mathrm{th}$ and 50 th/16th. The 84 th/16th quotient is generally in the range of 2.5-3.0 along the area of increased seismicity of the Rhine valley (locally 2.0-2.5 in the LRG). This quotient increases up to 5.0-5.5 towards the regions of lower seismic activity, but is, however, the largest with 6.5-7.0 just in the area of highest activity in the area of the HZA and is also remarkably high in another local area between the rivers Donau and Altmühl (also with 6.5-7.0). In contrary, the HZA is totally inconspicuous in the 84th/50th quotient map. On the other hand, the HZA area shows the by far largest quotients in the 50th/16th map. This specific behaviour is fully consistent with that, what we wanted to model and have indeed finally modelled. The explanation for this locally strong uncertainty and in particular towards much lower seismic loads has its reason in the fact that we cannot exclude that other parts of southern Germany could experience a behaviour similar to that of the HZA. Here, the seismicity started with the 1911 shock as a big bang-after lacking particularly increased activity there in the historical past before 1911. It still shows continuing activity. Our expectation of possible future increased activity also at other parts of the south German block is modelled with the two LASZs, which contributes to a general increase of loads in this respective larger region. These LASZs are in a very sharp contrast to the three SASZ and the zoneless approach, which mainly contributes to the mapped uncertainty behaviour.

Differences in the skewness of the hazard results were already mentioned in connection with Fig. 17, where the spread between median, mean and the 84th percentiles were presented between Aachen $\left(50.8^{\circ} \mathrm{N}, 6.1^{\circ} \mathrm{E}\right)$ and a site near Gera $\left(50.9^{\circ} \mathrm{N}, 12.2^{\circ} \mathrm{E}\right)$. This behaviour can be followed in detail with the 84th/50th quotient map (Fig. 26 middle part). 

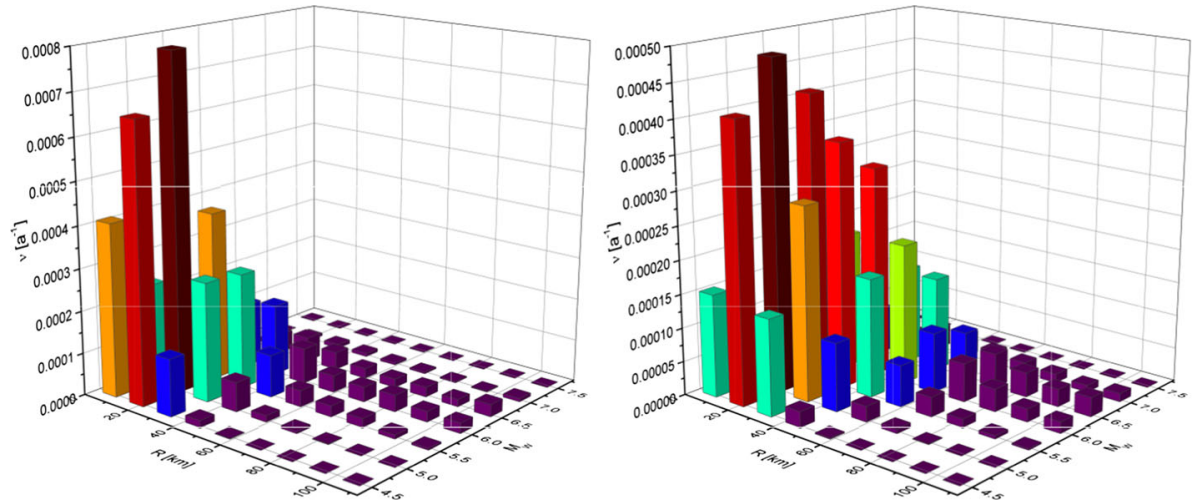

Fig. 23 Deaggregations for the centres of Karlsruhe (left) and Cologne (right) for PGA and RP = 475a as rates of magnitude-distance bins as they contribute to the respective hazard calculation

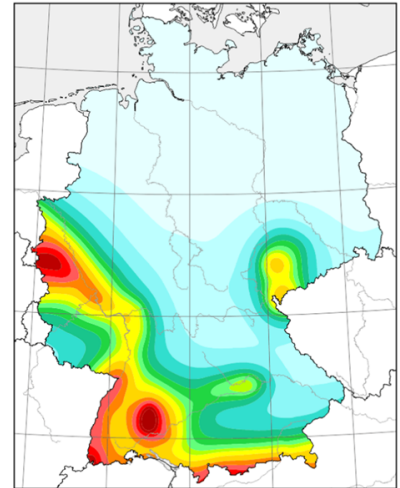

SRA $\left[\mathrm{m} / \mathrm{s}^{2}\right]$
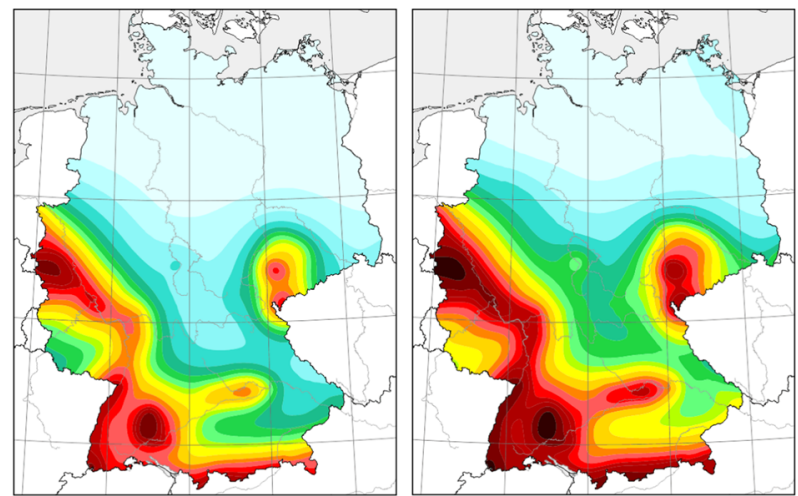

$\begin{array}{lllllllllllllllll}0.1 & 0.2 & 0.3 & 0.4 & 0.5 & 0.6 & 0.7 & 0.8 & 1.0 & 1.3 & 1.6 & 2.0 & 2.5 & 3.0 & 4.0 & 6.0 & 10.0\end{array}$

Fig. 24 The weighted arithmetic mean according to the end branches of the LT for meanSRA $(0.1,0.15$, $0.2 \mathrm{~s}$ ), which represent basically the level of the plateau of the UHS, for RP $=475 \mathrm{a}, \mathrm{RP}=975 \mathrm{a}$ and for $\mathrm{RP}=2475 \mathrm{a}$ (from left to right)

Aachen is located in an area with the almost lowest quotients, and the site near Gera in a local spot of almost highest ones.

\subsection{Intensity based seismic hazard map}

The earthquake input model for our PSHA was also used to calculate a hazard map in terms of macroseismic intensities, especially for the purpose of a plausibility check, since so few strong ground motion recordings exist for the target area that they can hardly be the basis for a testing of resulting hazard. The same is true with respect to a comprehensive and almost complete macroseismic database for entire Germany. These macroseismic data are solely sufficient to construct a map of maximum observed intensity of the roughly last 500 years. This means that testing of PSHA maps has currently clear limitations for our target region (cf. discussions in Beauval et al. (2008) or Mak et al. (2014)). Our new 

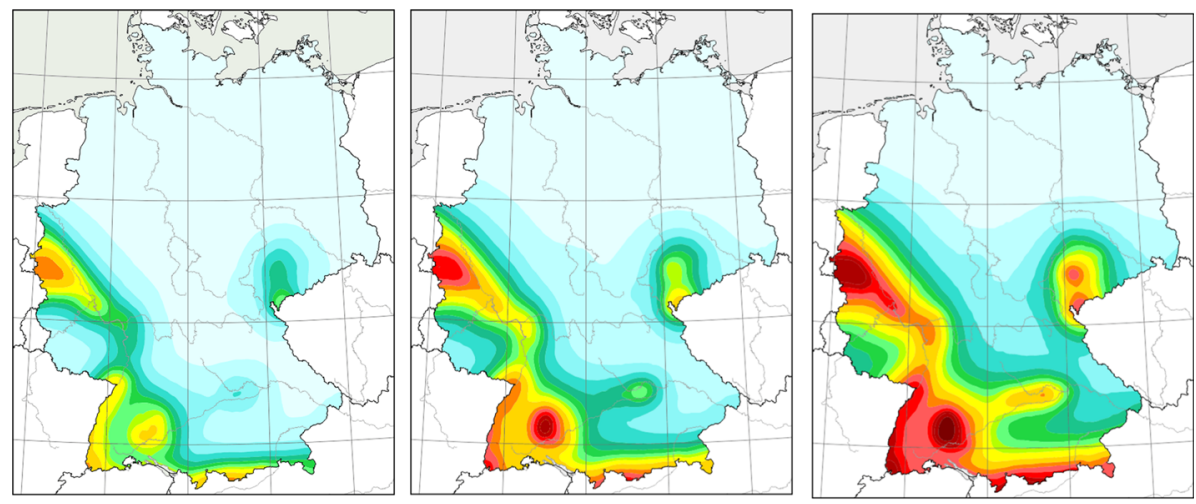

SRA $\left[\mathrm{m} / \mathrm{s}^{2}\right]$

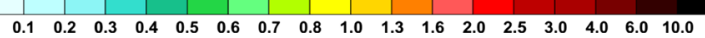

Fig. 25 Hazard maps of the meanSRA $(0.1,0.15,0.2 \mathrm{~s})$ for the 16 th, the 50 th and the 84 th percentile (from left to right) for $\mathrm{RP}=475 \mathrm{a}$
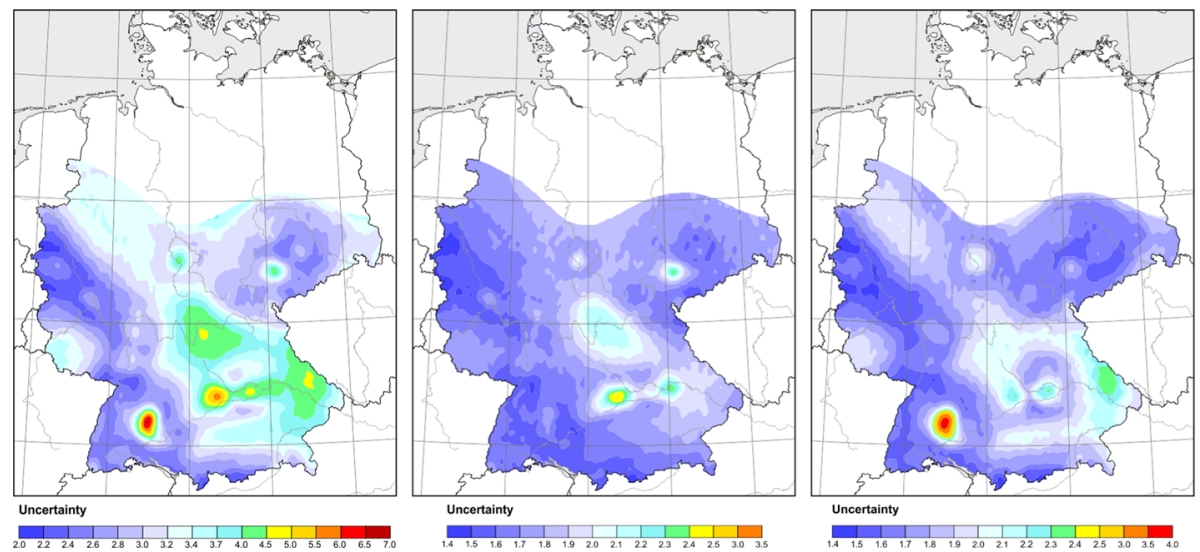

Fig. 26 Maps of meanSRA for $R P=475$ a for the following quotients of percentiles 84 th/16th, 84th/50th and 50th/16th (from left to right)

intensity based hazard map enables especially the comparison with our previous intensity hazard map (Grünthal et al. 1998a), which is still used as basis for the seismic zoning map of the national annex to the current building code.

The application of a magnitude calibrated intensity prediction equation (IPE) is the only modification in the earthquake model to calculate the intensity based map. We apply the intensity calibrated IPE by Stromeyer and Grünthal (2009) in combination with the master event relation between epicentral intensity $I_{0}$ and moment magnitude $M_{w}$ for Central Europe (Grünthal et al. 2009a) which results in

$$
I=1.5 M_{w}-0.45 \log (h)+0.15-2.95 \log \sqrt{\frac{R_{e p i}^{2}+h^{2}}{h^{2}}}-0.0025\left(\sqrt{R_{e p i}^{2}+h^{2}}-h\right)
$$


with an overall standard error of 0.7 intensity units. $R_{\text {epi }}$ is the epicentral distance. Limitations in the availability of data did not allow us to derive a magnitude calibrated IPE in one step. A stable parameter determination was only possible as performed in Stromeyer and Grünthal (2009), but not for the parameters of the source term. Therefore, the well constraint magnitude-intensity relation of Grünthal et al. (2009c) is used for this part of the IPE. The hazard calculation in terms of intensity was performed by integrating the normal distribution of the IPE from $-1 \sigma$ up to $+1 \sigma(-1 \leq \varepsilon \leq 1)$ (as, e.g. in Capera-Gomez et al. 2010 or in Bindi et al. 2013). The rationale for this is the consideration that IDP represent integer values based on a set of macroseismic diagnostics being characteristic for, e.g. one city and never for, e.g. one house (Grünthal et al. 1998b); i.e. they do not represent singular point records like strong ground motions, which require the need of a larger $\varepsilon$ when applying GMPEs. A certain intensity degree is reached when the range of observed diagnostics fit the definitions of a respective degree in the best way. In cases, where diagnostics even exceed descriptions of a given intensity, but are not clearly matching the descriptions of that next higher degree, the lower intensity value should be kept (Grünthal et al. 1998b). Also these features of the integer character of intensities distinguish them from point information of ground-motion data. The resulting mean hazard map in terms of intensity for $10 \%$ exceedance probability in 50 years is shown in Fig. 29.

\subsection{Comparisons with our previous PSHA and with the new Swiss earthquake hazard model}

Variations of seismic load parameters among different generations of PSHA for respective target regions are of significant relevance for the practice of earthquake engineering. We therefore compare our results with analogous code related ones in terms of the UHS and hazard maps for the DIN 19700 (Grünthal et al. 2009a) and the intensity based hazard map (Grünthal et al. 1998a), which form the basis for the seismic zoning map of the National Annex to the current building code DIN EN 1998-1/NA (2011).

The comparison of the UHS is shown here (Fig. 27) according to the example of Cologne. Since the DIN 19700 required the usage of rounded RPs, like 500a, we have calculated the respective UHS also for this RP. Both median UHS reveal practically the same amplitude; however, the spectral content is shifted according to our new approach towards shorter periods. This offset can be directly explained by the characteristics of the used GMPEs in both approaches. Due to the shift of the dominating spectral range, most SRA maps cannot be compared in a direct way with earlier ones.

The comparison of the new PGA maps with our previous ones is interesting. Figure 28 shows the median PGA for RP = 500a of the DIN 19700 in comparison with the median and the mean PGA according to our new earthquake model also for RP $=500 \mathrm{a}$. By the way, the median and the mean are definitely more similar in the frame of the DIN 19700 project in comparison to our new project. Both median maps are very resemblant in the areas of increased seismicity along the Rhine chain and in SW Germany. Only in the VLZ area with much lower seismicity (between $12^{\circ}$ and $13^{\circ} \mathrm{E}$ ) are the PGA values in the new median map smaller; here the mean map is more similar. The most striking difference concerns regions in larger distances from areas of increased seismicity, which is an effect of the far field of the GMPEs of both approaches. However, such regions of very low seismicity are not subject to antiseismic design provisions. Concerning the comparison with still earlier national and European maps from us, we refer to Grünthal et al. (2014) who describe the good agreement of the older maps with PGA of the DIN 19700. 
Fig. 27 Comparison of UHS for the DIN 19700 (Grünthal et al. 2009a) with the corresponding new one for the centre of the city of Cologne. Both for median values and $R P=500 \mathrm{a}$ which is used for the DIN 19700. The median RP $=475$ UHS from the new project is shown as dotted line well

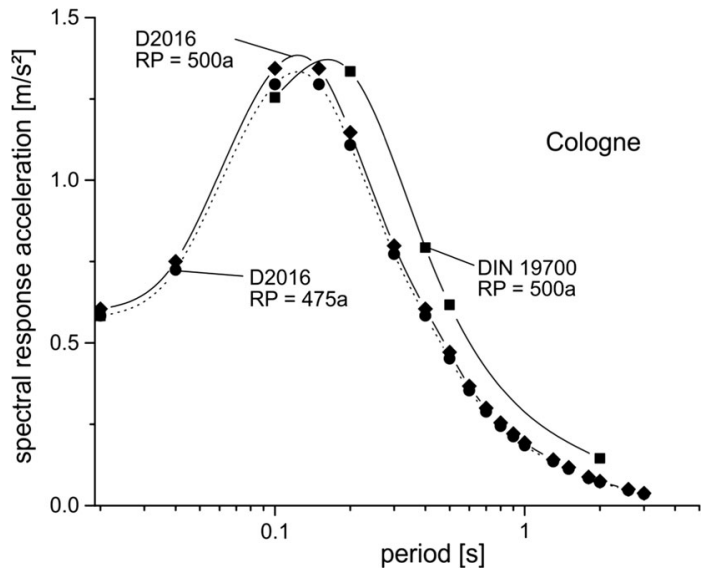

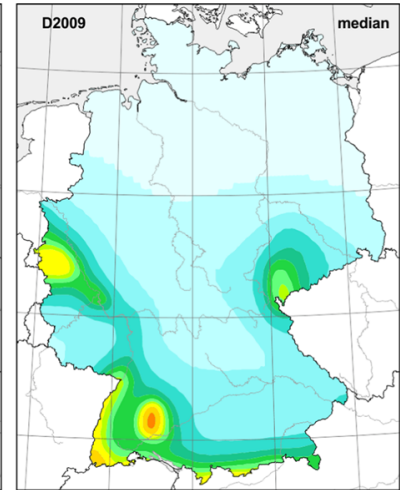

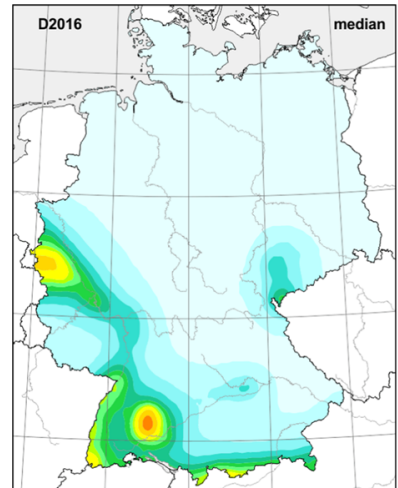

PGA $\left[\mathrm{m} / \mathrm{s}^{2}\right]$

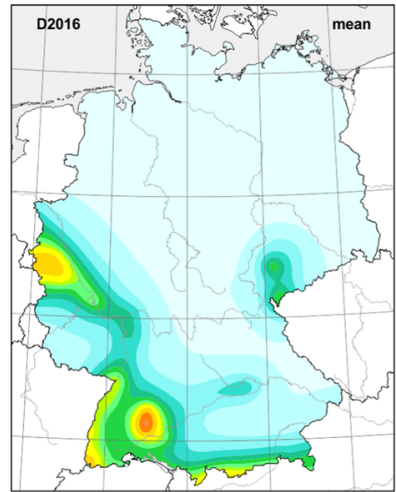

gensing

$\begin{array}{rrrrrrrrrrrrrrrrr}0.1 & 0.2 & 0.3 & 0.4 & 0.5 & 0.6 & 0.7 & 0.8 & 1.0 & 1.3 & 1.6 & 2.0 & 2.5 & 3.0 & 4.0 & 6.0\end{array}$

Fig. 28 Comparison of the median and the mean PGA for RP $=500$ a according to our new earthquake model (left and middle) with the median RP = 500a PGA for the DIN 19700 (Grünthal et al. 2009a) in the right

The mean intensity hazard map for $\mathrm{RP}=475 \mathrm{a}$ (Fig. 29) is based on the identical input model with respect to the results in terms of acceleration, with the exception of the GMPE. We use this map as plausibility check. Also interesting is the comparison with our earlier intensity based hazard map for Germany, Austria and Switzerland (Grünthal et al. 1998a), which is calculated using a purely intensity based approach (shown in Fig. 29 as well). Both maps are in general very similar. Peak intensities of the older map are more moderate now. Some areas of increased intensities, like in the northern part of the URG or in the area between the rivers Altmühl and Donau (west of Regensburg), have almost disappeared in the new map because of the many fake quakes that could be identified there (Grünthal 2004; Grünthal et al. 2009b).

Finally, we present the comparison of the median RP475 PGA maps according to our earthquake model with the corresponding new median PGA map for Switzerland (Wiemer et al. 2016) north and south of the common state border (Fig. 30). Both maps were calculated for $v_{S 30}=800 \mathrm{~m} / \mathrm{s}$. The figure with parts of the two national maps, presented 


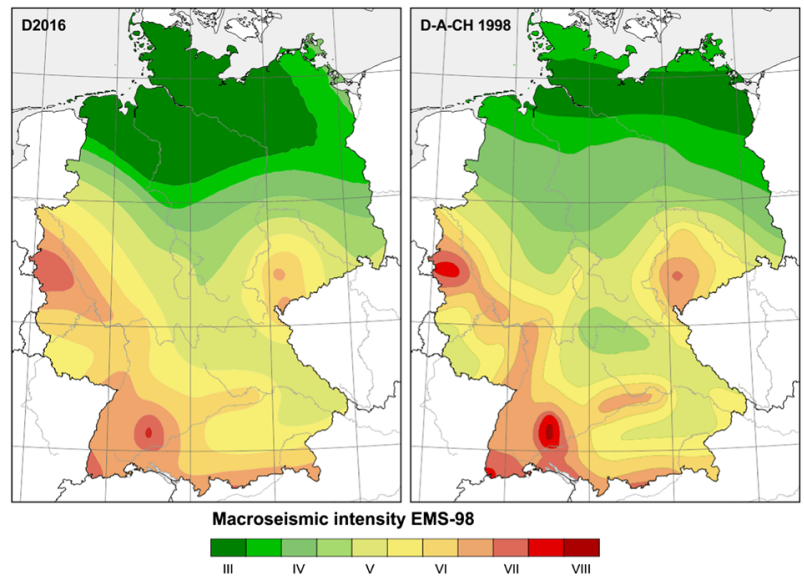

Fig. 29 Intensity based hazard map as mean values for $R P=475 a$ (left) calculated with our D2016 input model, except of the instrumental ground motion GMPEs. This map reveals macroseismic intensities which are very similar to those, which were observed during the about last 500 years. The comparable hazard map for the D-A-CH countries Germany, Austria and Switzerland (Grünthal et al. 1998a) is shown in the right

with a colour code in steps of hundredth of $g$, shows hardly any difference between both; although the two models were developed completely independently from each other. Concerning further comparisons we refer to the accompanying material (Grünthal et al. 2017).

\subsection{The interactive web portal}

The web portal http://gfz-potsdam.de/EqHaz_D2016 hosted at GFZ Potsdam provides access to the products of this national hazard project. Seismic hazard maps can be interactively viewed with respect to PGA, SRA at $T=0.02,1.0$ and $3.0 \mathrm{~s}$ as well as for mean SRA amplitudes at $T=0.1,0.15,0.2 \mathrm{~s}$. All results are presented as median, mean and 84th percentile maps for the hazard levels of exceedance probabilities of 10,5 and $2 \%$ within 50 years. The intensity based hazard map is available for mean values of the exceedance probability of $10 \%$ within 50 years.

The UHS are important for engineering applications and can interactively be selected by mouse click on the respective hazard map for any point within Germany or by entering a place name into the search control. In this case, the respective UHS is given for the centre of the corresponding settlement. The spectra are shown either as shape preserved splines or as fit to the EC8 elastic spectral shapes. All data of the UHS including the corresponding EC8 parameters are downloadable as CSV or JSON file.

\section{Summary, discussion and conclusions}

The derived earthquake model considers comprehensively the uncertainties as far as they are accessible, i.e. epistemic uncertainties in our LT and aleatory variabilities treated in the integration. We implemented 


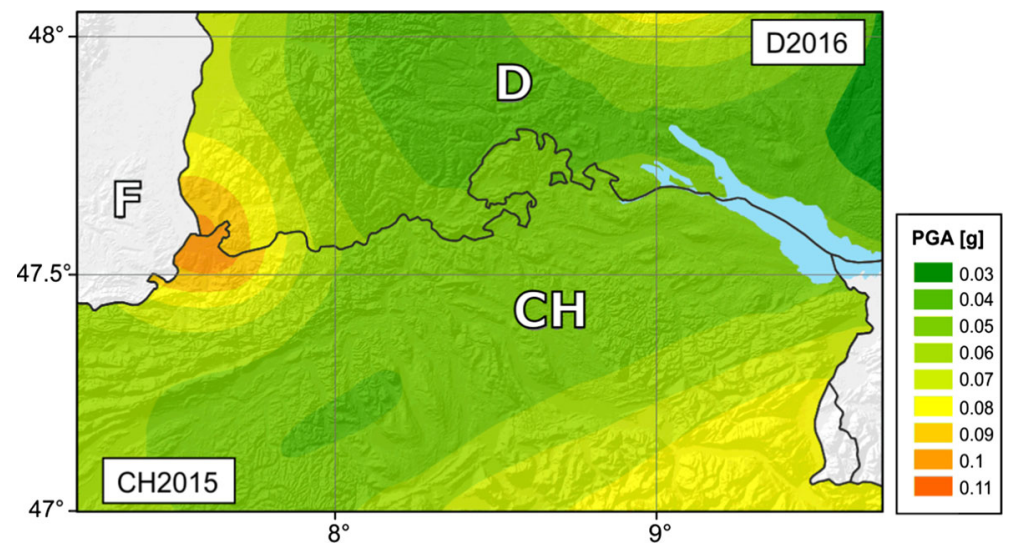

Fig. 30 Comparison of the median $\mathrm{RP}=475$ PGA maps according to the new German earthquake model D2016 with the corresponding new median PGA map for Switzerland (Wiemer et al. 2016) CH2015 north and south of the common state border. Both maps are for $\mathrm{v}_{\mathrm{S} 30}=800 \mathrm{~m} / \mathrm{s}$

(a) the application of a long-lasting harmonized historical earthquake database of the last millennium up to 2014;

(b) the extensive modelling of sources of future earthquakes as (1) large scale tectonic zones considering the prospective occurrence of significant seismicity in areas which have been quite in the historical past, (2) different small scale models considering seismotectonics, lineations of faults according to remote sensing satellite data, and crustal structure, and (3) zoneless approaches based on welldetermined data-driven kernels;

(c) composite finite fault models where sufficiently proved by data;

(d) adoption of superzones for the determination of parameters or distributions ( $b$ values, $M_{\max }, h$, tr, kernels) to guarantee a sufficient number of data points; e.g. more than 70 earthquakes per zone to derive rate parameters;

(e) considering paleoseismological findings for the modelling of maximum magnitudes with large ranges of uncertainties and a conservative upper bound truncation of their respective probability density functions;

(f) the consequent application of our new method to model uncertainties in the seismicity rates in a satisfactory way;

(g) the full involvement of relatively higher rates of larger magnitude earthquakes than predicted by the occurrence of modern smaller magnitude events in about one third of the seismic source zones with a relatively high weight;

(h) the use of the latest generation of a set of five GMPEs with an additional epistemic uncertainty concerning the variation in stress drop in the target area;

(i) the determination of weights in logic trees as a consensus of a larger group of experts;

(j) the integration over $\pm 3 \sigma$ of the aleatory variabilities of the used GMPEs;

(k) the integrating over probability density functions of focal depths and tectonic regimes determined within superzones;

(1) no allowance of any pruning of the logic tree for the hazard calculations;

(m) plausibility check of the model (except the part on GMPEs) by using the input model to calculate an intensity based hazard map and to compare it with previous respective calculations; 
(n) output response ground motions for mean values (as arithmetic mean of the outcome of all logic tree branches), median and percentiles for the period range of the UHS of $0.02 \mathrm{~s}$ up to $3.0 \mathrm{~s}$;

(o) fitting of the UHS additionally to the control parameters of the EC8 design spectral shape;

(p) provision of the hazard results on internet portals as well as the entire input model in a transparent way.

The comparison of our results in terms of UHS and seismic hazard maps with previous seismic hazard assessments shows a remarkable persistence, even though the approaches were performed independently and are indeed different. Figure 27 shows an example of one UHS according to our new results and the UHS for the same site according to Grünthal et al. (2009a). The largest amplitudes of both spectra are practically the same; however, there is a shift of the peak of spectrum towards lower periods, which is due to the fact that the site factors of recent GMPEs have changed and are better calibrated for rock conditions.

A similar agreement holds also for our earlier approaches on a national level (Grünthal et al. 2004, 2006) and for the comparison with our European hazard maps too (Grünthal and GSHAP Region 3 Working Group 1999; Grünthal et al. 2010; Chan and Grünthal 2010), where we can compare the PGA data. Of particular interest is the comparison of our new intensity based hazard map with the one of Grünthal et al. (1998a). The resemblances between both are also in this case remarkable (cf. Fig. 29). However, it is obvious that all these similarities in our approaches over the last almost 20 years are not a proof of the reliability of our new results. In this connection we have to stress that it was always a principle of our PSHA approaches to be independent from previous results; i.e. not to be influenced by any anchoring.

Concerning the comparison with results from new PSHA approaches in neighbouring countries, we could make use so far of the Swiss data (Wiemer et al. 2016), which indeed fit remarkably well along the common border (Fig. 30). These two converging, but fully independent approaches can be seen as a proof of concept and of the robustness of modern PSHA.

We would have wished to rigorously test our earthquake model. However, we have to face clear limitations of testing (Mak et al. 2014; Beauval et al. 2008) due to the lack of a sufficient number of strong ground motion records in Germany as well as sufficiently complete macroseismic data for the entire country.

Seismic hazard evaluations in low seismicity areas stay challenging. Because of the low tectonic loading rate, individual faults may stay dormant for a long time and then become active for a short period (e.g. Stein et al. 2017). Intraplate seismicity is also often characterized by clustered and episodic earthquakes and extended aftershock sequences (e.g. Calais et al. 2016). Exactly such features, which are treated in both papers, we had to tackle within our study. Furthermore, the expected maximum magnitudes of future earthquakes are fairly uncertain in low seismicity areas and future earthquakes may be larger than the historically observed ones, or new findings concerning paleoseismic earthquakes with larger magnitudes than assumed so far will come to light. Moreover, because of the lack of sufficient data, ground-motion models have been calibrated on data from other regions of the world and then may not be adequately adapted to source, propagation and rock conditions of our target area. Future efforts for improving the hazard model can benefit from the application of recently developed methods for evaluating the hazard sensitivity (Molkenthin et al. 2017). The availability of computational efficient sensitivity analysis 
techniques allows for focus to be placed on only on those input models whose variability is mostly controlling the key parameters of the overall hazard assessment, and to discuss the way we capture the CBR (Center, Body and Range) of technically defensible interpretations only on the logic tree branches that matter. It should be recognised, however, that despite the potential insights offered by analyses of this kind, they are difficult with such complete and complex logic tree.

Douglas et al. (2014b) encourage the publication of the uncertainties in hazard studies because this makes studies more transparent. Our model uncertainties have been captured with 4040 LT branches. The areal distribution of quotients of different percentiles have been shown and discussed in the previous section. The uncertainty index $(100 \times \log (85$ th/ 15th)), suggested by Douglas et al. (2014b), has also been computed. The obtained values of the uncertainty index (for PGA, RP $=475 \mathrm{a}$ ) range between 32 (Allgäuer Hochalpen; i.e. region at the border to Austria) and 81 (for the HZA). These values are larger than most of the values reported by Douglas et al. (2014b) for past national hazard studies but similar or even larger than those obtained in modern site-specific hazard analyses for equivalent tectonic context. This is an expected result as past regional studies have not quantified epistemic uncertainty in a comprehensive way and the uncertainty range of a regional study should be larger than the one obtained in a site-specific hazard analyses for equivalent tectonics (Pagani et al. 2016). This also confirms that the comprehensive effort we made to capture uncertainties has been reaching a technical and scientific level usually dedicated to site-specific studies.

It remains difficult to "be certain about uncertainty" (Knight 1921), however. While early PSHA studies came up solely with mean values without any quantification of uncertainties, the abilities in incorporating uncertainties have improved for the better uncertainties in the input models were understood and could become part of a PSHA. When comparing uncertainties in PSHA results, one has to be sensitive concerning limitations in the correct handling of uncertainties in the respective input sets of considered studies. Since we do not know the true hazard, we can hardly be confident what uncertainty range would be sufficient in the resulting hazard. We, at least, followed the goal to consider uncertainties in a comprehensive way inasmuch they are physically, geological-tectonically, mathematically and logically sound, balanced and justified.

Acknowledgements This analysis was partly funded by the Deutsches Institut für Bautechnik (DIBt). In this context, the work has greatly benefited from the discussions und suggestions by the members of the two review teams; i.e. the colleagues C. Butenweg, A. Fäcke, E. Fehling, H. Sadegh-Azar, F.-H. Schlüter, H. Schneider, T. Schmit, J. Schwarz, T. Spies, S. Stöhr. We would also like to express our thanks to our colleagues Oliver Heidbach and Graeme Weatherill, whose comments and insights are gratefully acknowledged. The authors appreciate the useful and constructive suggestions by Hilmar Bungum and one anonymous reviewer.

Open Access This article is distributed under the terms of the Creative Commons Attribution 4.0 International License (http://creativecommons.org/licenses/by/4.0/), which permits unrestricted use, distribution, and reproduction in any medium, provided you give appropriate credit to the original author(s) and the source, provide a link to the Creative Commons license, and indicate if changes were made. 


\section{Appendix: Data sources}

The EMEC catalogue is available under http://www.gfz-potsdam.de/emec/. Its update (2007-2014) is based on the following sources for the study area:

- British Geological Survey, http://earthquakes.bgs.ac.uk/earthquakes/dataSearch.html.

- Observatoire Royale du Belgique, Brussels, Belgium, http://seismologie.oma.be/index. php?

- Catalogo Parametrico dei Terremoti Italiani 2015, http://emidius.mi.ingv.it/CPTI15DBMI15/.

- FENCAT, Data file of earthquakes in northern Europe. Institute of Seismology, University of Helsinki, Helsinki, Finland.

- GEOFON Seismic Network. Deutsches GeoForschungsZentrum GFZ, http://geofon. gfz-potsdam.de/eqinfo/list.php?mode=mt.

- Hungarian Earthquake Bulletin, http://www.georisk.hu/Bulletin/bulletine.html.

- International Seismological Centre (ISC), http://www.isc.ac.uk/iscbulletin/.

- Royal Netherlands Meteorological Institute (KNMI), http://www.knmi.nl/kennis-endatacentrum/dataset/aardbevingscatalogus.

- Czech Regional Seismological Network, http://www.czechgeo.cz/en/gfu-catalog/.

- Monthly Bulletins of Earthquakes in Germany and Adjacent Areas, https://www.bgr. bund.de/DE/Themen/Erdbeben-Gefaehrdungsanalysen/Seismologie/Seismologie/ Erdbebenauswertung/Erdbebenkataloge/Kataloge_Bulletins/kataloge_bulletins_node. html.

- LDG, Data file of French earthquakes from 1962 and on. Laboratoire de Détection et de Géophysique, Bruyères-le-Châtel, France, http://www-dase.cea.fr/evenement/ syntheses_resultat.php? $\mathrm{n}=-1 \&$ type_bulletin=tele\&lang=fr.

- Regional Centroid Moment Tensors (RCMTS), http://mednet.rm.ingv.it/rcmt.php.

- Swiss Seismological Service, http://www.seismo.ethz.ch/en/home/.

- Earthquakes of Slovenia, http://www.arso.gov.si/potresi/poročila\%20in\% 20publikacije/.

- SisFrance, BRGM/EDF/IRSN, www.sisfrance.net.

- Seismologie-Verbund zur Erdbebenbeobachtung, Freistaat Sachsen, Thüringen und Sachsen-Anhalt. https://www.umwelt.sachsen.de/umwelt/geologie/9819.htm.

- Zentralanstalt für Meteorologie und Geophysik (ZAMG), https://www.zamg.ac.at/cms/ de/geophysik/erdbeben/erdbebenarchiv/jahresberichte.

\section{References}

Abrahamson NA, Bommer JJ (2005) Probability and uncertainty in seismic hazard analysis. Earthq Spectra 21(2):603-607

Adams J, Halchuk S, Allen TI, Rogers GC (2015) Canada's 5th generation seismic hazard model, as prepared for the 2015 National Building Code of Canada. In: The 11th Canadian conference on earthquake engineering, Victoria, BC. Paper no. 93775

Ahorner L, Rosenhauer W (1975) Probability distribution of earthquake accelerations with applications to sites in the Northern Rhine area, Central Europe. J Geophys 41:581-594

Ahorner L, Rosenhauer W (1978) Seismic risk evaluation for the Upper Rhine Graben and its vincinity. J Geophys 44:481-497 
Ahorner L, Rosenhauer W (1986) Regionale Erdbebengefährdung. In: Realistische Seismische Lastannahmen für Bauwerke, Kap. 9. Abschlussbericht an das Institut für Bautechnik Berlin, T 1829, König und Heunisch, Beratende Ingenieure, IRB Verlag Stuttgart

Akkar S, Sandıkkaya MA, Bommer JJ (2014) Empirical ground-motion models for point- and extendedsource crustal earthquake scenarios in Europe and the Middle East. Bull Earthq Eng 12(1):359-387

Algermissen ST, Perkins DM (1976) A probabilistic estimate of maximum acceleration in rock in the contiguous United States: U.S. Geological Survey open-file report 1976-416, 2 folded plates, scale $1: 7500000$

Ancheta TD, Darragh RB, Stewart JP, Seyhan E, Silva WJ, Chiou BS-J, Wooddell KE, Graves RW, Kottke AR, Boore DM, Kishida T, Donahue JL (2014) NGA-West2 database. Earthq Spectra 30(3):989-1005

Baltay A, Ide S, Prieto G, Beroza G (2011) Variability in earthquake stress drop and apparent stress. Geophys Res Lett 38(6):L06303. https://doi.org/10.1029/2011GL046698

Bankwitz P, Schneider G, Kämpf H, Bankwitz E (2003) Structural characteristics of epicentral areas in Central Europe: study case Cheb Basin (Czech Republic). J Geodyn 35:5-32

Barth A, Ritter JRR, Wenzel F (2015) Spatial variations of earthquake occurrence and coseismic deformation in the Upper Rhine Graben, Central Europe. Tectonophys 651-652:172-185

Bazzurro P, Cornel CA (1999) Disaggregation of seismic hazard. Bull Seism Soc Am 89(2):501-520

Beauval C, Scotti O, Bonilla F (2006) The role of seismicity models in probabilistic seismic hazard estimation: comparison of a zoning and a smoothing approach. Geophys J Int 165(2):584-595

Beauval C, Bard PY, Hainzl S, Guéguen P (2008) Can strong-motion observations be used to constrain probabilistic seismic-hazard estimates? Bull Seismol Soc Am 98(2):509-520

Beauval C, Tasan H, Laurendeau A, Delavaud E, Cotton F, Gueguen P, Kuehn N (2012) On the testing of ground-motion prediction equations against small-magnitude data. Bull Seismol Soc Am 102(5):1994-2007

Bindi D, Gómez Capera AA, Parolai S, Abdrakhmatov K, Stucchi M, Zschau J (2013) Location and magnitudes of earthquakes in Central Asia from seismic intensity data: model calibration and validation. Geophys J Int 192(2):710-724

Bindi D, Massa M, Luzi L, Ameri G, Pacor F, Puglia R, Augliera P (2014) Pan-European ground-motion prediction equations for the average horizontal component of PGA, PGV, and 5\%-damped PSA at spectral periods up to $3.0 \mathrm{~s}$ using the RESORCE dataset. Bull Earthq Eng 12(1):391-430

Bindi D, Cotton F, Kotha SR, Bosse C, Stromeyer D, Grünthal G (2017) Application-driven ground motion prediction equation for seismic hazard assessments in non-cratonic moderate-seismicity areas. J Seismol. https://doi.org/10.1007/s10950-017-9661-5

Bommer JJ, Scherbaum F (2008) The use and misuse of logic trees in probabilistic seismic hazard analysis. Earthq Spectra 24(4):997-1009

Bommer JJ, Abrahamson NA, Strasser FO, Pecker A, Bard P-Y, Bungum H, Cotton F, Fäh D, Sabetta F, Scherbaum F, Studer J (2004) The challenge of defining upper bounds on earthquake ground motions. Seismol Res Lett 75(1):82-95

Bommer JJ, Scherbaum F, Bungum H, Cotton F, Sabetta F, Abrahamson NA (2005) On the use of logic trees for ground-motion prediction equations in seismic-hazard analysis. Bull Seismol Soc Am 95(2):377-389

Bommer JJ, Coppersmith KJ, Coppersmith RT, Hanson KL, Mangongolo A, Neveling J, Rathje EM, Rodriguez-Marek A, Scherbaum F, Shelembe R, Stafford PJ, Strasser FO (2015) A SSHAC level 3 probabilistic seismic hazard analysis for a new-build nuclear site in South Africa. Earthq Spectra 31(2):661-698

Boore DM, Stewart JP, Seyhan E, Atkinson GM (2014) NGA-West2 equations for predicting PGA, PGV, and 5\% damped PSA for shallow crustal earthquakes. Earthq Spectra 30(3):1057-1085

Bora SS, Cotton F, Scherbaum F, Edwards B, Traversa P (2017) Stochastic source, path and site attenuation parameters and associated variabilities for shallow crustal European earthquakes. Bull Earthq Eng. https://doi.org/10.1007/s10518-017-0167-x

Bourgeois O, Ford M, Diraison M, Carlier Le, de Veslud C, Gerbault M, Pik R, Ruby N, Bonnet S (2007) Separation of rifting and lithospheric folding signatures in the NW-Alpine foreland. Int J Earth Sci (Geologische Rundschau) 96(6):1003-1031

Brandes C, Winsemann J (2013) Soft-sediment deformation structures in NW Germany caused by Late Pleistocene seismicity. Int J Earth Sci (Geol Rundsch) 102(8):2255-2274

Bräuer K, Kämpf H, Koch U, Strauch G (2011) Monthly monitoring of gas and isotope compositions in the free gas phase at degassing locations close to the Nový Kostal focal zone in the western Eger Rift, Czech Republic. Chem Geol 290:163-176

Burkhard M, Grünthal G (2009) Seismic source zone characterization for the seismic hazard assessment project PEGASOS by the Expert Group 2 (EG 1b). Swiss J Geosci 102(1):149-188 
Calais ET, Camelbeeck S, Stein ML, Craig TJ (2016) A new paradigm for large earthquakes in stable continental plate interiors. Geophys Res Lett 43(10):621-10637. https://doi.org/10.1002/ $2016 \mathrm{gl070815}$

Camelbeeck T, Vanneste K, Alexandre P, Verbeeck K, Petermans T, Rosset P, Everaerts M, Warnant R, Van Camp M (2007) Relevance of active faulting and seismicity studies to assessments of long-term earthquake activity and maximum magnitude in intraplate northwest Europe, between the Lower Rhine Embayment and the North Sea. In: Stein S, Mazotti S (eds) Continental intraplate earthquakes: science, hazard, and policy issues, GSA special papers 425. Geological Society of America. https://doi.org/10. $1130 / 2007.2425(14)$

Capera-Gomez AA, D’Amico V, Meletti C, Rovida A, Albarello D (2010) Seismic hazard in terms of macroseismic intensity in Italy: a critical analysis from the comparison of different computational procedures. Bull Seismol Soc Am 100(4):1614-1631

Carvalho A, Albarello D (2016) Application of SASHA to seismic hazard assessment for Portugal mainland. Bull Earthqu Eng 14(7):1827-1847

Cauzzi C, Faccioli E (2008) Broadband (0.05 to $20 \mathrm{~s}$ ) prediction of displacement response spectra based on worldwide digital records. J Seismol 12(4):453-475

Cauzzi C, Faccioli E, Vanini M, Bianchini A (2015) Updated predictive equations for broadband (0.01-10 s) horizontal response spectra and peak ground motions, based on a global dataset of digital acceleration records. Bull Earthq Eng 13(6):1587-1612

CEN (2004) Eurocode 8: Design of structures for earthquake resistance part 1: general rules, seismic actions and rules for buildings, European Norm. European Committee for Standardization, Brussels, April 2004

Chan C-H, Grünthal G (2010) Hybrid zoneless probabilistic seismic hazard assessment: test and first application to Europe and the Mediterranean. Final report of Network of Research Infrastructures for European Seismology NERIES, Subproject JRA2 "Real time hazard tools", Task A “The living EuroMed earthquake hazard". www.neries-eu.org/main.pfp/JRA2_D8.pdf

Chen Y, Weatherill G, Pagani M, Cotton F (2016) (2016) Insights into data-driven tectonic regionalisation in seismic hazard analysis. Japan Geoscience Union Meeting, Tokyo

Cloetingh S, Cornu T (2005) Surveys on environmental tectonics. Quart Sci Rev 24:235-240

Cloetingh S, Ziegler PA, Beekman F, Andriessen PAM, Matenco L, Bada G, Garcia-Castellanos D, Hardebol N, Dèzes P, Sokoutis D (2005) Lithospheric memory, state of stress and rheology: neotectonic control on Europe's intraplate continental topography. Quat Sci Rev 24:241-304

Coppersmith KJ (1994) Conclusions regarding maximum earthquake assessment. In: Johnston AC, Coppersmith KJ, Kanter LR, Cornell CA (eds) The earthquakes of stable continental regions, vol 1. Assessment of large earthquake potential. Electric Power Research Institute, Palo Alto, California, pp 6-1-6-24

Coppersmith KJ, Youngs RR, Sprecher C (2009) Methodology and main results of seismic source characterization for the PEGASOS Project, Switzerland. Swiss J Geosci 102:91-105

Cornell CA (1968) Engineering seismic risk analysis. Bull Seismol Soc Am 58(5):1583-1606

Cornell CA (1971) Probabilistic analysis of damage to structures under seismic loads. In: Howell DA, Haigh IP, Taylor C (eds) Dynamic waves in civil engineering. Wiley, New York, pp 473-488

Cornell CA (1994) Statistical analysis of maximum magnitudes. In: Johnston AC, Coppersmith KJ, Kanter LR, Cornell CA (eds) The earthquakes of stable continental regions, vol 1. Assessment of large earthquake potential. Electric Power Research Institute, Palo Alto, California, pp 5-1-5-27

Cornell CA, Vanmarcke EH (1969) The major influences on seismic risk. In: Chilean association on seismology and earthquake engineering. In: Proceedings of the fourth world conference on earthquake engineering, Santiago, Chile, vol 1, session A-1, pp 69-83

Cotton F, Scherbaum F, Bommer JJ, Bungum H (2006) Criteria for selecting and adjusting ground-motion models for specific target regions: application to Central Europe and rock sites. J Seismol 10(2):137-156

Cotton F, Pousse GF, Bonilla L, Scherbaum F (2008) On the discrepancy of recent European ground-motion observations and predictions from empirical models: analysis of KiK-net accelerometric data and point-sources stochastic simulations. Bull Seismol Soc Am 98(5):2244-2261

Cotton F, Archuleta R, Causse M (2013) What is sigma of the stress drop? Seismol Res Lett 84(1):42-48

D'Amico V, Albarello D, Sigbjörnsson R, Rupakhety R (2016) Seismic hazard for Iceland in terms of macroseismic intensity using a site approach. Bull Earthqu Eng 14(7):1797-1811

Decker K, Peresson H, Hinsch R (2005) Active tectonics and Quarternary basin formation along the Vienna basin Transform fault. Quart Sci Rev 24:305-320 
Delavaud E, Cotton F, Akkar S, Scherbaum F, Danciu L, Beauval C, Drouet S, Douglas J, Basili R, Sandikkaya MA, Segou M, Faccioli E, Theodoulidis N (2012) Toward a ground-motion logic tree for probabilistic seismic hazard assessment in Europe. J Seismol 16(3):451-473

Derras B, Bard PY, Cotton F (2014) Towards fully data driven ground-motion prediction models for Europe. Bull Earthq Eng 12(1):495-516

DIN EN 1998-1/NA:2011-01 (2011) National Annex-Nationally determined parameters-Eurocode 8: design of structures for earthquake resistance-part 1: general rules, seismic actions and rules for buildings. DIN Deutsches Institut für Normung e.V. Berlin

DIN 4149:2005-04 (2005) Bauten in deutschen Erdbebengebieten - Lastannahmen, Bemessung und Ausführung üblicher Hochbauten, April 2005

Douglas J, Akkar S, Ameri G, Bard P-Y, Bindi D, Bommer JJ, Bora SS, Cotton F, Derras B, Hermkes M, Kuehn NM, Luzi L, Massa M, Pacor F, Riggelsen C, Sandıkkaya MA, Scherbaum F, Stafford PJ, Traversa P (2014a) Comparisons among the five ground-motion models developed using RESORCE for the prediction of response spectral accelerations due to earthquakes in Europe and the Middle East. Bull Earthq Eng 12(1):341-358

Douglas J, Ulrich T, Bertil D, Rey J (2014b) Comparison of the ranges of uncertainty captured in different seismic hazard studies. Seismol Res Lett 85(5):977-985

Drouet S, Cotton F (2015) Regional stochastic GMPEs in low seismicity areas: scaling and aleatory variability analysis - application to the French Alps. Bull Seismol Soc Am 105(4):1883-1902

Edwards B, Fäh D (2013) A stochastic ground-motion model for Switzerland. Bull Seismol Soc Am 103(1):78-98

Edwards B, Cauzzi C, Danciu L, Fäh D (2016) Region-specific assessment, adjustment, and weighting of ground-motion prediction models: application to the 2015 Swiss seismic-hazard maps. Bull Seismol Soc Am 106(4):1840-1857

Esteva L (1969) Seismicity prediction: a Bayesian approach. In: Proceedings of the fourth world conference on earthquake engineering, Santiago de Chile, vol 1, A-1, pp 172-185

Esteva L (1970) Seismic risk and seismic design decisions. In: Hansen RJ (ed) Seismic design for nuclear power plants. MIT Press, Cambridge, pp 142-182

Ferry M, Meghraoui M, Delouis B, Giardini D (2005) Evidence for Holocene palaeoseismicity along the Basel-Reinach active normal fault (Switzerland); a seismic source for the 1356 earthquake in the Upper Rhine Graben. Geophys J Int 160(2):554-572

Frankel A (1995) Mapping seismic hazard in the Central and Eastern United States. Seismol Res Lett 66(4):8-21

Gaspar-Escribano JM, Rivas-Medina A, Parra H, Cabañas L, Benito B, Ruiz Barajas S, Martínez Solares JM (2015) Uncertainty assessment for the seismic hazard map of Spain. Eng Geol 199:62-73

Gautier DL (2003) Carboniferous-Rotliegend total petroleum system description and assessment results. USGS Bull. 2211, Reston Virginia

Geluk MC, Duin EJT, Dusar M, Rijkers MHB, van den Berg MW, van Rooijen P (1994) Stratigraphy and tectonics of the Roer Valley Graben. Geol Mijnb 73:129-141

Giardini D, Grünthal G, Shedlock KM, Zhang P (1999) The GSHAP global seismic hazard map. Ann Geofis 42(6): 1225-1230

Gregor N, Abrahamson NA, Atkinson GM, Boore DM, Bozorgnia Y, Campbell KW, Chiou BS-J, Idriss IM, Kamai R, Seyhan E, Silva W, Stewart JP, Youngs R (2014) Comparison of NGA-West2 GMPEs. Earthq Spectra 30(3):1179-1197

Grünthal G (2004) The history of historical earthquake research in Germany. Ann Geophys 47(2/3):631-643

Grünthal G (2005) Die Erdbebenzonenkarte als Bestandteil der neuen DIN 4149. In: Tagungsband der DGEB/DIN-Gemeinschaftstagung “Auslegung von Bauwerken gegen Erdbeben-die neue DIN 4149", Beuth Verlag, Berlin [u. a.], Leinfelden-Echterdingen/Germany, pp 3-24

Grünthal G (2008) Erdbebengefährdungskarten für die Bemessung von Stauanlagen nach DIN 19700. In: Erfahrungsaustausch Betrieb von Hochwasserrückhaltebecken in Baden-Württemberg. Berichtsband 14. Jahrestagung "Sicherheitsrelevante Einwirkungen auf Hochwasserrückhaltebecken-Extreme Betriebszustände", Stuttgart, 20. November 2007, WBW Fortbildungsgesellschaft für Gewässerentwicklung mbH, Karlsruhe, pp 25-29

Grünthal G (2014) Induced seismicity related to geothermal projects versus natural tectonic earthquakes and other types of induced seismic events in Central Europe. Geothermics 52:22-35

Grünthal G, Bosse C (1996) Probabilistische Karte der Erdbebengefährdung der Bundesrepublik Deutschland-Erdbebenzonierungskarte für das Nationale Anwendungsdokument zum Eurocode 8: Forschungsbericht. Scientific Technical Report 96/10, GeoForschungsZentrum Potsdam, Potsdam

Grünthal G, GSHAP Region 3 Working Group (1999) Seismic hazard assessment for central, north and northwest Europe: GSHAP Region 3. Ann Geofis 42(6):999-1011 
Grünthal G, Stromeyer D (1992) The recent crustal stress field in central Europe-trajectories and finiteelement modeling. J Geophys Res 97(B8):11805-11820

Grünthal G, Wahlström R (2001) Sensitivity of parameters for probabilistic seismic hazard analysis using a logic tree approach. J Earthq Eng 5(3):309-328

Grünthal G, Wahlström R (2012) The European-Mediterranean earthquake catalogue (EMEC) for the last millennium. J Seismol 16(3):535-570

Grünthal G, Bankwitz P, Bankwitz E, Bednárek J, Guterch B, Schenk V, Schenková Z, Zeman A (1985) Seismicity and geological features of the eastern part of the West European platform. Gerl Beitr Geophys 94(4-6):276-289

Grünthal G, Bosse C, Musson RMW, Gariel J-C, de Crook T, Verbeiren R, Camelbeeck T, Mayer-Rosa D, Lenhardt W (1996) Joint seismic hazard assessment for the central and western part of GSHAP-Region 3 (Central and Northwest Europe). In: Thorkelsson B (ed) Seismology in Europe, papers presented at the 25th general assembly of the European Seismological Commission (Reykjavik 1996), Icelandic Meteorological Office, Ministry for the Environment, University of Iceland, Reykjavik, pp 339-342

Grünthal G, Mayer-Rosa D, Lenhardt W (1998a) Abschätzung der Erdbebengefährdung für die D-A-CHStaaten—Deutschland, Österreich, Schweiz. Bautechnik 75(10):753-767

Grünthal G, Musson RMW, Schwarz J, Stucchi M (eds) (1998b) European Macroseismic Scale 1998 (EMS98). Cahiers du Centre Européen de Géodynamique et de Séismologie 15, Centre Européen de Géodynamique et de Séismologie, Luxembourg

Grünthal G, Wahlström R, Stromeyer D, Schelle H, Bosse C (2004) Neue Generation von Erdbebengefährdungseinschätzungen. In: Merz B, Apel $\mathrm{H}$ (eds) Risiken durch Naturgefahren in Deutschland: Abschlussbericht des BMBF-Verbundprojektes Deutsches Forschungsnetz Naturkatastrophen (DFNK), Scientific Technical Report 04/01, GeoForschungsZentrum Potsdam, Potsdam, pp $135-148$

Grünthal G, Thieken AH, Schwarz J, Radtke K, Smolka A, Merz B (2006) Comparative Risk Assessments for the City of Cologne-storms, floods, earthquakes. Nat Hazard 38(1-2):21-44

Grünthal G, Bosse C, Stromeyer D (2009a) Die neue Generation der probabilistischen seismischen Gefährdungseinschätzung der Bundesrepublik Deutschland: version 2007 mit Anwendung für die Erdbeben-Lastfälle der DIN 19700:2004-07 'Stauanlagen'. Scientific Technical Report STR 09/07, Deutsches GeoForschungsZentrum, Potsdam

Grünthal G, Wahlström R, Stromeyer D (2009b) The unified catalogue of earthquakes in central, northern, and northwestern Europe (CENEC) - updated and expanded to the last millennium. J Seismol 13(4):517-541

Grünthal G, Wahlström R, Stromeyer D (2009c) Harmonization check of $\mathrm{M}_{\mathrm{w}}$ within the central, northern, and northwestern European earthquake catalogue (CENEC). J Seismol 13(4):613-632

Grünthal G, Arvidsson R, Bosse C (2010) Earthquake model for the European-Mediterranean Region for the Purpose of GEM1. Scientific technical report 10/04, GFZ German Research Centre for Geosciences, Potsdam. http://dx.doi.org/10.2312/GFZ.b103-10043

Grünthal G, Bosse C, Stromeyer D (2014) Building Code Related Seismic Hazard Analyses of Germany and their Relation to SHARE. In: Butenweg C, Kaiser D (eds) Seismic Hazard Harmonization in Europe (SHARE): DGEB-Workshop, 27. May 2014, (DGEB-Publikation 16), Aachen: Deutsche Gesellschaft für Erdbebeningenieurwesen und Baudynamik (DGEB), pp 25-41

Grünthal G, Stromeyer D, Bosse C (2017) The data sets of the earthquake model for the probabilistic seismic hazard assessment of Germany, version 2016-report on supplementary material for the respective publication. Scientific Technical Report STR 17/05, GFZ German Research Centre for Geosciences, Potsdam. https://doi.org/10.2312/GFZ.b103-17056

Gutenberg B, Richter CF (1944) Frequency of earthquakes in California. Bull Seismol Soc Am 34(4): 185-188

Hakimhashemi A, Grünthal G (2012) A statistical method for estimating catalog completeness applicable to long-term nonstationary seismicity data. Bull Seismol Soc Am 102(6):2530-2546

Haller KM, Basili R (2011) Developing seismogenic source models based on geologic fault data. Seismol Res Lett 82(4):519-525

Harmsen S, Perkins D, Frankel A (1999) Deaggregation of probabilistic ground motions in the Central and Eastern United States. Bull Seismol Soc Am 89(1):1-13

Heidbach O, Custodio S, Kingdon A, Mariucci MT, Montone P, Müller B, Pierdominici S, Rajabi M, Reinecker J, Reiter K, Tingay M, Williams J, Ziegler M (2016) World stress map database release 2016. GFZ Data Serv. https://doi.org/10.5880/WSM.2016.001

IGN-UPM Working Group (2013) Actualización de Mapas de Peligrosidad Sísmica de España 2012. Editorial Centro Nacional de Información Geográfica, Madrid. ISBN 978-84-416-2685-0 
Illies JH (1972) The Rhine graben rift system - plate tectonics and transform faulting. Geophys Surv 1(1):27-60

Illies JH (1981) Mechanism of graben formation. Tectonophys 73(1-3):249-266

Illies JH (1982) Der Hohenzollerngraben und Intraplattenseismizität infolge Vergitterung lamellärer Scherung mit einer Riftstruktur. Oberrhein geol Abh 31:47-78

Jiménez M-J, Giardini D, Grünthal G (2003) The ESC-SESAME unified hazard model for the EuropeanMediterranean region. EMSC/CSEM Newsl 19:2-4

Johnston AC (1994) Seismotectonic interpretations and conclusions from the stable continental region seismicity database. In: Johnston AC, Coppersmith KJ, Kanter LR, Cornell CA (eds) The earthquakes of stable continental regions, vol 1. Assessment of large earthquake potential. Electric Power Research Institute, Palo Alto, California, pp 4-1-4-103

Kanter LR (1994) Tectonic interpretation of stable continental crust. In: The earthquakes of stable continental regions, vol 1. Assessment of large earthquake potential. Electric Power Research Institute (EPRI) TR-102261-V1, pp 2-1-2-98

Knight FH (1921) Risk, uncertainty, and profit. Hart, Schaffner \& Marx, Boston

Kotha SR, Bindi D, Cotton F (2016) Partially non-ergodic region specific GMPE for Europe and MiddleEast. Bull Earthq Eng 14(4):1245-1263

Kulkarni RB, Youngs RR, Coppersmith KJ (1984) Assessment of confidence intervals for results of seismic hazard analysis. In: Proceedings of the 8th world conference on earthquake engineering, San Francisco 1984, pp 263-270

Mak S, Clements RA, Schorlemmer D (2014) The statistical power of testing probabilistic seismic-hazard assessments. Seismol Res Lett 85(4):781-783

McGuire RK (1995) Probabilistic seismic hazard analysis and design earthquakes: closing the loop. Bull Seismol Soc Am 85(5):1275-1284

McGuire RK (2004). Seismic hazard and risk analysis, EERI monograph MNO-10. Earthquake Engineering Research Institute, Risk Engineering Inc., Boulder

McGuire RK, Cornell CA, Toro GR (2005) The case for using mean seismic hazard. Earthq Spectra 21(3):879-886

Meletti C, Visini F, D’Amico V, Rovida A (2016) Seismic hazard in Central Italy and the 2016 Amatrice earthquake. Ann Geophys 59:1-8. https://doi.org/10.4401/AG-7248

Miller AC, Rice TR (1983) Discrete approximation of probability distributions. Manag Sci 29(3):352-362. https://doi.org/10.1287/mnsc.29.3.352

Molina S, Lindholm CD, Bungum H (2001) Probabilistic seismic hazard analysis: zoning free versus zoning methodology. B Geofis Teor Appl 42(1-2):19-39

Molkenthin C, Scherbaum F, Griewank A, Leovey H, Kucherenko S, Cotton F (2017) Derivative-based global sensitivity analysis: upper bounding of sensitivities in seismic-hazard assessment using automatic differentiation. Bull Seismol Soc Am 107(2):984-1004

Musson RMW (2005) Against fractiles. Earthq Spectra 21(3):887-891

NAGRA (2004) Probabilistic seismic hazard analysis for swiss nuclear power plant sites (PEGASOS Project) prepared for Unterausschuss Kernenergie der Überlandwerke (UAK). Final report vol 1-6. To be obtained on request at swissnuclear by writing to info@swissnuclear.ch

Pagani M, Garcia J, Poggi V, Weatherhill G (2016) Probabilistic seismic hazard analysis issues and challenges from the GEM perspective. In: 5th IASPEI/IAEE international symposium: effects of surface geology on seismic motion, August 15-17, 2016

PEER (2015) NGA-east: median ground-motion models for the Central and Eastern North America Region. PEER report no. 2015/04, April 2015

Pohl D, Wetzel H-U, Grünthal G (2006) Tektonische Untersuchungen im Raum Vogtland-Leipzig mit Hilfe von Fernerkundung. Publ. d. Deutschen Gesellschaft f. Photogrammetrie, Fernerkundung u. Geoinformationen, Bd. 15:277-286

Ratschbacher L, Merle O, Davy P, Cobbold P (1991) Lateral extrusion in the eastern Alps, part: boundary conditions and experiments scaled for gravity. Tectonics 10(2):245-256

Reinecker J, Schneider G (2002) Zur Neotektonik der Zollernalb: Der Hohenzollerngraben und die AlbstadtErdbeben. Jber Mitt oberrhein geol Ver, N.F. 84:391-417

Reiter K, Heidbach O, Reinecker J, Müller B, Röckel T (2015) Spannungskarte Deutschland 2015. Erdöl Erdgas Kohle 11:437-442

Rietbrock A, Strasser F, Edwards B (2013) A stochastic earthquake ground-motion prediction model for the United Kingdom. Bull Seismol Soc Am 103(1):57-77

Risk Engineering Ltd. (1997) FRISK88Mc users manual, updated version 1.70

Rosenhauer W, Ahorner L (1994) Seismic hazard assessment for the Lower Rhine Embayment before and after the 1992 Roermond earthquake. Geol Mijnb 73:415-424 
Scherbaum F, Cotton F, Smit P (2004a) On the use of response spectral-reference data for the selection and ranking of ground-motion models for seismic-hazard analysis in regions of moderate seismicity: the case of rock motion. Bull Seismol Soc Am 94(6):2164-2185

Scherbaum F, Schmedes J, Cotton F (2004b) On the conversion of source-to-site distance measures for extended earthquake source models. Bull Seismol Soc Am 94(3):1053-1069

Schmid SM, Kissling E (2000) The arc of the western Alps in the light of geophysical data on deep crustal structure. Tectonics 19:62-85

Schmincke H-U (2010) Vulkanismus. Primus Verlag, Zurich

Scholz CA, Aviles CA, Wesnousky SG (1986) Scaling differences between large interplate and intraplate earthquakes. Bull Seismol Soc Am 76(1):65-70

Schwarz J, Kaufmann C, Abrahamczyk L (2017) Bauforschungsvorhaben im bauaufsichtlichen Bereich: Seismische Einwirkungen für die neue Generation von Erdbebenbaunormen: Gefährdungskonsistente und untergrundspezifische Spektren für die aktualisierte Erdbebenzonenkarte. Abschlussbericht zum Forschungsvorhaben 246 40175, Bauhaus-Universität Weimar, Earthquake Damage Analysis Center, Weimar, 84 pp, Anlagen, pp 85-221

Sesetyan K, Demircioglu MB, Duman TY, Çan T, Tekin S, Azak TE, Fercan ÖZ (2016) A probabilistic seismic hazard assessment for the Turkish territory-part I: the area source model. Bull Earthq Eng. https://doi.org/10.1007/s10518-016-0005-6

Sissingh W (2006) Syn-kinematic palaeogeographic evolution of the West European platform: correlation with Alpine plate collision and foreland deformation. Geol Mijnb 85(2):131-180

Stein S, Liu M, Camelbeeck T, Merino M, Landgraf A, Hintersberger E, Kübler S (2017) Challenges in assessing seismic hazard in intraplate Europe. In: Landgraf A, Kübler S, Hintersberger E, Stein S (eds) Seismicity, fault rupture and earthquake hazard in slowly deforming regions. Geological Society, London, Special Publication, vol 432, pp 13-28

Stock C, Smith EGC (2002) Adaptive kernel estimation and continuous probability representation of historical earthquake catalogs. Bull Seismol Soc Am 92(3):904-912

Stromeyer D, Grünthal G (2009) Attenuation relationship of macroseismic intensities in Central Europe. Bull Seismol Soc Am 99(2A):554-565

Stromeyer D, Grünthal G (2015) Capturing the uncertainty of seismic activity rates in probabilistic seismichazard assessments. Bull Seismol Soc Am 105(2A):580-589

Thybo H (1997) Geophysical characteristics of the Tornquist Fan area, northwest Trans-European Suture Zone: indication of late Carboniferous to early Permian dextral transtension. Geol Mag 134(05):597-606

Tyagunov S, Grünthal G, Wahlström R, Stempniewski L, Zschau J (2006) Seismic risk mapping for Germany. Nat Hazard Earth Sys 6(4):573-586

USNRC (2012) Practical implementation guidelines for SSHAC level 3 and 4 hazard studies. NUREG-2117, US Nuclear Regulatory Commission, Washington

Ustaszewski K, Pfiffner OA (2008) Neotectonic faulting, uplift and seismicity in the central and western Swiss Alps. In: Siegesmund S, Fügenschuh B, Froitzenheim N (eds) (2008) Tectonic aspects of the Alpine-Dinaride-Carpathian system. Geological Society, London, Special Publications, vol 298, pp 231-249

Ustaszewski K, Schmid SM (2007) Latest Pliocene to recent thick-skinned tectonics at the Upper Rhine Graben-Jura Mountains junction. Swiss J Geosci 100(2):293-312

Ustaszewski K, Schumacher ME, Schmid S, Nieuwland D (2005) Fault reactivation in brittle-viscous wrench systems-dynamically scaled analogue models and application to the Rhine-Bresse Transfer Zone. Quat Sci Rev 24:363-380

Vanneste K, Camelbeeck T, Verbeek K (2013) A model of composite seismic sources for the Lower Rhine Graben, Northwest Europe. Bull Seismol Soc Am 103(2A):984-1007

Vanneste K, Vleminckx B, Verbeeck K, Camelbeeck T (2014) Development of seismic hazard maps for Belgium. In: Butenweg C, Kaiser D (eds) Seismic hazard harmonization in Europe (SHARE), DGEBPublikation Nr. 16, Deutsche Gesellschaft für Erdbebeningenieurwesen und Baudynamik (DGEB), Aachen, pp 61-68

Vere-Jones D (1992) Statistical methods for the description of and display earthquake catalogues. In: Walden AT, Guttorp P (eds) Statistics in the environmental and earth sciences. London, pp 220-244

Wahlström R, Grünthal G (2000) Probabilistic seismic hazard assessment (horizontal PGA) for Sweden, Finland and Denmark using different logic tree approaches. Soil Dyn Earthq Eng 20(1-4):45-58

Wahlström R, Grünthal G (2001) Probabilistic seismic hazard assessment (horizontal PGA) for Fennoscandia using the logic tree approach for regionalization and nonregionalization models. Seismol Res Lett 72(1):33-45 
Weatherill GA, Crowley H, Danciu L (2013) Future directions for seismic input in European design codes in the context of the seismic hazard harmonisation in Europe (SHARE). In: Proceedings of the Vienna Congress on Recent Advances in Earthquake Engineering and Structural Dynamics (VEESD), pp 28-30 August 2013, paper no. 494

Weichert DH (1980) Estimation of the earthquake recurrence parameters for unequal observations periods for different magnitudes. Bull Seismol Soc Am 70(4):1337-1346

Wetzel HU, Franzke HJ (2001) Geologische interpretation eines ESR-1 Radarmosaiks von Deutschland. Deutsche Gesellschaft für Photogrammmetrie und Fernerkundung 10:503-510

Wetzel HU, Franzke HJ (2003) Lassen sich über die Fernerkundung weitere Kenntnisse zur seismogenen Zone Bodensee-Stuttgart ( $9^{\circ}$-Ost) gewinnen? Publikationen der Deutschen Gesellschaft für Photogrammetrie, Fernerkundung und Geoinformation, Band 12, 23. Wissenschaftlich-Technische Jahrestagung vom 9.-11.09. 2003 in Bochum, pp 339-348

Wiemer St, Danciu L, Edwards B, Marti M, Fäh D, Hiemer St, Wössner J, Cauzzi C, Kästli Ph, Kremer K (2016) Seismic hazard model 2015 for Switzerland (SUIhaz2015). Technical report, Swiss Seismological Service (SED) at ETH Zurich. https://doi.org/10.12686/a2

Woessner J, Danciu L, Giardini D, Crowley H, Cotton F, Grünthal G, Valensise G, Arvidsson R, Basili R, Demircioglu MN, Hiemer S, Meletti C, Musson RW, Rovida AN, Sesetyan K, Stucchi M, SHARE Consortium (2015) The 2013 European seismic hazard model: key components and results. Bull Earthq Eng 13(2):3553-3596

Woo G (1996) Kernel estimation methods for seismic hazard area source modeling. Bull Seismol Soc Am 86(2):353-362

Zechar JD, Jordan TH (2010) Simple smoothed seismicity earthquake forecasts for Italy. Ann Geophys 53(3):99-105

Ziegler PA (1994) Cenozoic rift system of Eastern and Central Europe: an overview. Geol Mijnb 73(2):99-127

Ziegler PA, Dèzes P (2006) Crustal evolution of Western and Central Europe. In: Gee DG, Stephenson RA (eds) European lithospheric dynamics. Geological Society, London, Memoirs, vol 32, pp 43-56

Ziegler PA, Dèzes P (2007) Cenozoic uplift of Variscan Massifs in the Alpine foreland: timing and controlling mechanisms. Glob Planet Change 58(1-4):237-269 